
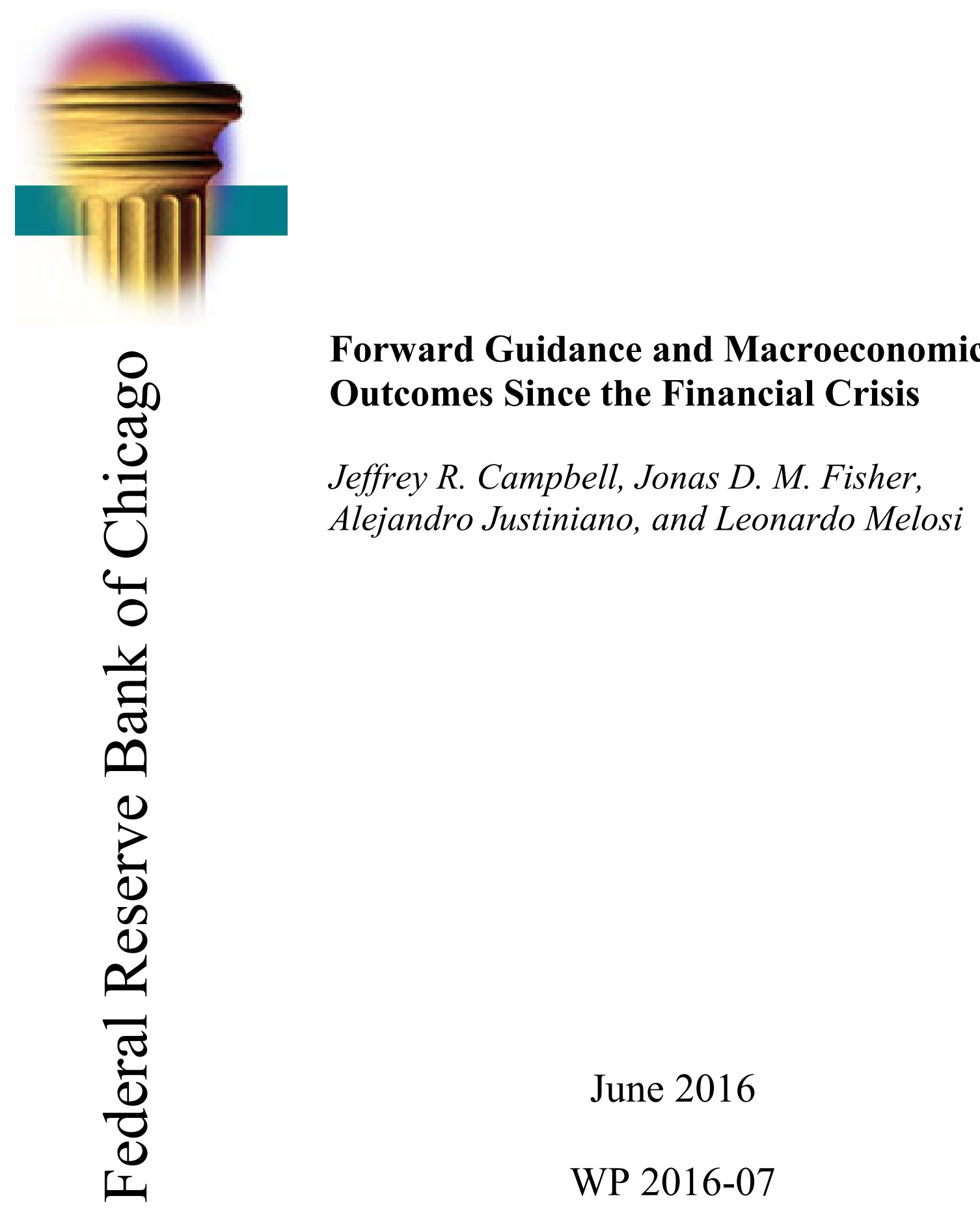


\title{
Forward Guidance and Macroeconomic Outcomes Since the Financial Crisis*
}

\author{
Jeffrey R. Campbell ${ }^{\dagger}$ \\ Alejandro Justiniano
}

\author{
Jonas D. M. Fisher \\ Leonardo Melosi
}

June 13, 2016

\begin{abstract}
This paper studies the effects of FOMC forward guidance. We begin by using high frequency identification and direct measures of FOMC private information to show that puzzling responses of private sector forecasts to movements in federal funds futures rates on FOMC announcement days can be attributed entirely to Delphic forward guidance. However a large fraction of futures rates' variability on announcement days remains unexplained, leaving open the possibility that the FOMC has successfully communicated Odyssean guidance. We then examine whether the FOMC used Odyssean guidance to improve macroeconomic outcomes since the financial crisis. To this end we use an estimated medium-scale New Keynesian model to perform a counterfactual experiment for the period 2009q1-2014q4, in which we assume the FOMC did not employ any Odyssean guidance and instead followed its reaction function from before the crisis as closely as possible while respecting the effective lower bound. We find that a purely rule-based policy would have delivered better outcomes in the years immediately following the crisis than FOMC forward guidance did in practice. However starting toward the end of 2011, after the Fed's introduction of "calendar-based" communications, the FOMC's Odyssean guidance appears to have boosted real activity and moved inflation closer to target. We show that our results do not reflect Del Negro, Giannoni, and Patterson (2015)'s forward guidance puzzle.
\end{abstract}

JEL Codes: E0.

Keywords: monetary policy, business cycles, Great Recession, counterfactual policy analysis

${ }^{*}$ We thank Gauti Eggertsson, Chris Gust and Narayana Kocherkota for their helpful discussions of this paper and Theodore Bogusz for extraordinarily helpful research assistance. Thanks also to Stefania D'Amico, Spencer Krane and Frank Smets for their very useful input. The views expressed herein the authors'. They do not necessarily represent those of the Federal Reserve Bank of Chicago, the Federal Reserve System, or its Board of Governors.

${ }^{\dagger}$ All authors Federal Reserve Bank of Chicago. In addition Campbell is affiliated with CentER, Tilburg University, and Justiniano is affiliated with the Paris School of Economics. E-mail addresses are: jcampbell@frbchi.org; jfisher@frbchi.org; ajustiniano@frbchi.org; lmelosi@frbchi.org. 


\section{Introduction}

Over the last thirty years the FOMC completely revised its communications policy, eventually making guidance about the future path of the funds rate a central component of those communications. Before 1994, the change in the fed funds rate was the only policy action taken on a meeting date. Indeed, the FOMC typically issued no communication at a meeting's conclusion, and market participants were left to infer any policy rate change from the trading activity of the System Open Market Account desk. Since its February 1994 meeting, the FOMC has typically made a post-meeting statement. Although these began as terse announcements of anticipated tightening and loosening in money markets, the FOMC soon routinely announced its policy rate decision and justification for it within the context of the committee's macroeconomic outlook. In May 1999, the committee added forwardlooking language to its statement that indicated whether the balance of risks to the achievement of its dual mandate was tilted towards undesirable inflation or output performance. As the FOMC followed the subsequent trend set by inflationtargeting central banks towards greater transparency regarding its policy goals and actions, its statement's forward-looking language expanded. Most notably, the FOMC repeatedly stated its expectation of maintaining low interest rates in the wake of the 2001 recession for a "considerable period." Once the removal of that accommodation was underway, the committee consistently forecasted that it would be removed "at a pace that is likely to be measured."

After the FOMC cut the federal funds rate to its effective lower bound (ELB) in December 2008, even more explicit forward guidance became one of the only tools available to it for providing monetary accommodation. ${ }^{1}$ In December 2008 the Committee began using language that the funds rate would remain exceptionally low for "some time." In March 2009 the FOMC replaced "some time" with "extended period." The FOMC introduced calendar-based forward guidance in August 2011, when the corresponding statement indicated that exceptionally low levels of the funds rate would remain in place "at least through mid-2013." The Evans rule, whereby the maintenance of low rates is tied to specific economic conditions, replaced

\footnotetext{
${ }^{1}$ Recently several foreign central banks have successfully lowered policy rates below zero. However throughout the period of our interest, the FOMC has acted as if the near zero ELB has been a binding constraint.
} 
the calendar-based language in the December 2012 statement. ${ }^{2}$ While the specificity of the Evans rule was dropped in March 2014, the statement has continued to highlight that any future policy tightening will be closely tied to tangible evidence about the state of the economy. ${ }^{3}$

To better understand FOMC communication policy, Campbell, Evans, Fisher, and Justiniano (2012) introduced the theoretical distinction between Delphic and Odyssean forward guidance. The former gets its name from the oracle of Delphi, who forecasted the future but promised nothing. Just so, central bankers routinely discuss macroeconomic fundamentals and outcomes objectively while forecasting their own likely responses to future developments. Moreover since the May 1999 meeting the policy statement routinely includes an assessment of current conditions as well as references to how the committee expects the economy to evolve in coming months. In contrast, Odyssean forward guidance consists of central bankers' statements that bind them to future courses of action. Just as Odysseus bound himself to his ship's mast so he could enjoy the Sirens' song without succumbing to the inevitable temptation to drown himself while swimming towards them, a central banker can improve welfare by publicly committing to a time-inconsistent plan that uses expectations of suboptimal future outcomes to improve current economic conditions. The forward guidance that implements the time-inconsistent Ramsey plans in Eggertsson and Woodford (2003) is Odyssean.

This paper aims to quantify the impact of Odyssean FOMC forward guidance on macroeconomic outcomes since the financial crisis that unwound from 2007 to 2009. Before the crisis, academic interest in forward guidance primarily arose from the aforementioned changes in its communication policy. The FOMC's use of more explicit forward guidance to provide monetary stimulus after the crisis gave the topic much greater policy relevance. So motivated, Campbell et al. (2012) extended the work of the previous empirical literature on forward guidance in two directions.

\footnotetext{
${ }^{2}$ The Evans rule is named after its main advocate President Charles Evans of the Federal Reserve Bank of Chicago.

${ }^{3}$ The other main tool of monetary policy since the financial crisis was "quantitative easing" (QE). While there is considerable debate over the importance of the various possible channels through which QE might affect real activity, it is widely viewed to at least in part involve influencing private sector expectations of future short term interest rates. See Evans, Fisher, Gourio, and Krane (2015) for references to the relevant literature. Krishnamurthy and Vissing-Jorgensen (2011) argued that signalling lower rates for longer is the main channel through which QE affects borrowing rate. So QE also can be viewed through the lens of forward guidance.
} 
First, they demonstrated that data from the post-crisis period continued to conform to the patterns documented by Gürkaynak, Sack, and Swanson (2005) in which yields on long-dated securities responded significantly to changes in federal funds rate futures on days with FOMC statements. That is, the financial crisis did not permanently damage the transmission mechanism from forward guidance shocks to asset prices. Second, they examined how private expectations of macroeconomic variables responded to forward guidance shocks in the pre-crisis period. They found strong evidence that an unexpected tightening of future rates lowered unemployment expectations.

Campbell et al. (2012) hypothesized that this event-study activity puzzle arises from Delphic forward guidance. If FOMC statements reveal information about near-term economic developments that would otherwise remain out of the public's hands, then the direct effects of the fundamentals so revealed (for example, lower unemployment and higher inflation from strong aggregate demand) will accompany the optimal policy response to those fundamentals (for example, an increase in expected future policy rates). That is, regressions of expectation revisions on changes in expected interest rates suffer from a simultaneity problem when FOMC statements contain Delphic forward guidance.

If the event-study activity puzzle reflects that FOMC communications are limited to be mostly Delphic then it casts doubt on the possibility that the FOMC has been able to communicate Odyssean guidance to improve macroeconomic outcomes since the financial crisis. Therefore we begin our analysis with an examination of the Delphic hypothesis using direct measures of FOMC private information based on now-public Greenbook forecasts. We find that the puzzling responses of private sector forecasts to FOMC announcements can be attributed entirely to Delphic forward guidance. However a large fraction of the variability in federal funds futures rates on days with FOMC announcements remains unexplained by our measure of FOMC private information. Therefore we conclude from this examination that the high frequency event-study approach to identification leaves open the possibility that the FOMC has communicated Odyssean guidance.

Hanson and Stein (2015) present other evidence that casts doubt on the New Keynesian (NK) mechanism by which forward guidance is transmitted to the broader economy. They found that changes in the stance of monetary policy substantially influence long-dated instantaneous real forward rates. They argue that this reflects 
variation in term premia that is absent from log-linearized NK models in which the expectations theory of the term structure holds good and real rates should not be affected much beyond the duration of price stickiness. These findings raise questions about the use of standard NK models for identifying the effects of Odyssean forward guidance. Therefore we reconsider the Hanson-Stein findings using our measures of forward guidance shocks and the FOMC private information revealed on announcement days. We argue that the effects of appropriately measured forward guidance shocks on long-dated real forward rates are actually quite small, enough so that they might be explained by Delphic guidance about the long run course of the economy communicated on announcement days. While further empirical scrutiny of this hypothesis is warranted, at this stage the evidence does not seem to disqualify using a NK framework to analyze the effects of forward guidance.

Our ultimate goal is to assess whether the FOMC improved economic performance since the financial crisis using Odyssean guidance. Below we review a nascent literature that examines the macroeconomic effects of forward guidance using VARs. This literature uses a variety of strategies to identify forward guidance shocks and finds that they have influenced real activity as does Odyssean forward guidance in standard NK models, at least qualitatively. Nevertheless VARs are inadequate for addressing our question. The literature pools pre- and post-crisis data to improve power, yet there is clear evidence that the nature of forward guidance changed substantially after the crisis. Consequently there is too little data to apply reduced form tools in the period of our interest.

Given the generally validating (or at least not invalidating) findings of the eventstudy and VAR literature for NK models with Odyssean guidance, we undertake our assessment with an enhanced version of the workhorse medium-scale model pioneered by Christiano, Eichenbaum, and Evans (2005) and Smets and Wouters (2007). The model's forward guidance in entirely Odyssean. It takes the form of unanticipated signals from the central bank about the future values of the interest rate rule's time-varying intercept, building on the insights of Laséen and Svensson (2011) and Campbell et al. (2012). Since our question is empirical, we estimate the forward guidance signals' stochastic structure. To do so we develop a new methodology that allows us to integrate the information obtained from high frequency identification of forward guidance on FOMC announcement days into an estimated model of quarterly macroeconomic fluctuations. Our approach identifies 
forward guidance using the term structure of overnight interest rate futures rates. As such we identify forward guidance as interpreted by market participants, which may or may not be as intended by the members of the FOMC.

In addition to introducing forward guidance to the monetary policy rule we make two changes to the preferences of the workhorse model. First, we include an additively separable stochastic preference for holding government bonds, as in Fisher (2015). This preference generates a spread between the policy rate and the rate of return on capital, because government bonds yield benefits over and above the transfer of consumption from one period to the next. As such it is possible to simultaneously match key long-run features of aggregate quantities and prices and to set the long-run real policy rate to a realistic value. Furthermore, the presence of this spread brings discounting to the linearized inter-temporal consumption Euler equation. As discussed by Campbell, Fisher, Justiniano, and Melosi (2016), Carlstrom, Fuerst, and Paustian (2015), Kiley (2014), and McKay, Nakamura, and Steinsson (2015) the absence of such discounting in standard NK models explains why the effects of Odyssean guidance can be implausibly large. With the discounting that arises from an empirically plausible spread, such large effects are mitigated in our model. ${ }^{4}$ The second change to the standard specification is to use Jaimovich and Rebelo (2009) preferences. In models with technology news shocks, these dampen the income-effect on labor supply and thereby enhance business cycle co-movement. We give them the opportunity to do the same for monetary news shocks.

Our model's estimation uses an unusually large number of data series: modelconsistent measures of GDP, consumption and investment based on chain aggregated NIPA data; a measure of hours worked adjusted for demographic trends; multiple indicators of wage and price inflation; a survey-based measure of long-run inflation expectations; and the current policy rate along with market-based measures of its expected future values from Eurodollar and OIS markets. The estimation itself is somewhat non-standard. We first calibrate parameters that the model has in common with the standard real business cycle framework to match long-run averages from the U.S. economy. This "first-moments-first" approach ensures that any success in replicating second moments does not come at the cost of counterfactual long-run predictions. We estimate the remaining parameters that govern pricing frictions,

\footnotetext{
${ }^{4}$ See Del Negro et al. (2015), Gabaix (2016) and McKay et al. (2015) for alternative approaches to introducing linearized Euler equation discounting.
} 
real rigidities and the model's shocks using relatively standard Bayesian methods. Because our estimation forces basic NIPA data and interest-rate futures data to coexist, we expect it to minimize any empirical "forward guidance puzzle" of the kind highlighted by Del Negro et al. (2015).

The sample period for our baseline estimation is 1993q1 to 2008q3. We demonstrate that over this period the model produces a credible business cycle history driven primarily by shocks to technology, the demand for government bonds, investment demand, and the representative household's discount rate. Furthermore, we verify that the model implies relatively modest effects effects of forward guidance, that is it does not display Del Negro et al. (2015)'s forward guidance puzzle. Hence, it appears to be a credible laboratory within which to conduct the analysis of monetary policy.

We use the estimated model to measure the effects of forward guidance from $2008 q 4$ to $2014 q 4$. Our measurement involves setting all the parameters to their baseline values except for those governing the forward guidance shocks. These we re-estimate using futures rates extending 10 quarters ahead instead of the 4 quarters used in the first sample period. For the evaluation of recent monetary policy, we compare the empirical outcomes with counterfactual outcomes from a version of the model without forward guidance. Our model is linear, and we use data on interest rate futures both to identify the forward guidance and to enforce the ELB on expected future interest rates. This presents a technical challenge: How do we remove the guidance while enforcing the ELB? Our solution is to replace the forward guidance shocks identified from the data with those chosen by a policy maker who wishes to minimize deviations from the baseline interest-rate rule subject to never violating the ELB and taking as given the non-monetary shocks identified with the re-estimated model. Our findings suggest that the purely rule-based policy would have delivered better outcomes in the years immediately following the crisis than FOMC forward guidance did in practice. However starting toward the end of 2011, after the Fed's introduction of "calendar-based" communications, the FOMC's Odyssean guidance appears to have boosted real activity and moved inflation closer to target. 5

\footnotetext{
${ }^{5}$ Engen, Laubach, and Reifschneider (2015) use a very different methodology based on the Board of Governors' FRB/US macro-econometric model to argue that improved macroeconomic outcomes from unconventional monetary policy were late to appear.
} 
The remainder of the paper begins with our analysis of FOMC private information using high frequency identification and a brief discussion of the VAR evidence on the effects of forward guidance. After this we describe the structural model, measurement and estimation of the model, properties of the estimated model, and our counterfactual policy analysis. The final section discusses aspects of forward guidance that are necessarily absent from a full information rational expectations framework like ours.

\section{Measures of Forward Guidance and Its Effects}

There is a large and growing literature that identifies the effects of forward guidance using event studies. Our review of this literature, below, affirms that it indeed solves many of identification problems associated with traditional VAR methods but nevertheless introduces other obstacles to identification. We follow our review with a new accounting framework that precisely delineates these difficulties. One of these difficulties arises from the potential presence of Delphic forward guidance in FOMC statements. We present new empirical work that measures the impact of these Delphic communications on expected future policy rates. This allows us to purge measured forward guidance of its Delphic component. When we do so we find that it explains the event-study activity puzzle but leaves in tact the previously measured effects on prices of short and medium duration assets. Our accounting framework identifies a second difficulty previously examined by Rigobon and Sack (2004): even on FOMC announcement days asset prices moves for reasons that have nothing to do with monetary policy. Any systematic covariances due to these dayto-day movements can contaminate event-study regression estimates. We show that this is indeed the case when employing Hanson and Stein (2015)'s preferred measure of the stance of monetary policy. When we redo their analysis with a measure that is empirically immune to this critique their finding of implausibly large effects of forward guidance on long-dated instantaneous forward rates go away. We conclude this section with a brief review of the VAR evidence on the macroeconomic effects of forward guidance. 


\subsection{Measurement with High-Frequency Data}

Both policy experience and modern macroeconomic theory emphasize the influence of the private-sector's expectations of future outcomes on current macroeconomic performance; so the FOMC's statments and other communications can be reasonably characterized as policy actions additional to any adjustments in the policy rate. However, the conditions under which such communications are effective remain unclear. Krugman (1998) and Eggertsson and Woodford (2003) implicitly assume that monetary policy makers can manipulate private sector expectations to be consistent with any rational expectations equilibrium. Unsurprisingly, this assumption makes proper communication policy very effective at improving macroeconomic outcomes. In contrast Bassetto (2016) models central bank communications as "cheap talk." When the central bank has private information about its own preferences, such cheap talk can communicate that to the public and thereby improve outcomes. However, these communications leave the equilibrium set unchanged if the public and policy maker are equally well informed. In this sense, central bank communications about future objectives and constraints are redundant policy instruments.

Although theory provides no certain identification of the efficacy of central bank communication, the high-frequency estimation strategy pioneered by Kuttner (2001) can be used to shed empirical light upon it. FOMC policy actions occur at discrete moments, usually during the U.S. business day. Financial market participants trade on these actions, and the resulting changes in asset prices can be used to identify their unexpected components. Kuttner (2001) measured the unexpected change in the current policy rate with changes in the price of the futures contract that settled based on the average fed funds rate in the month containing the FOMC meeting. Building on this work, Kohn and Sack (2004) measured the variance of asset price changes on days of FOMC meetings with and without accompanying post-meeting statements. After carefully controlling for the effects of any contemporaneous public announcements of macroeconomic news, they found that issuing a statement substantially increased the variance of fed funds futures contracts dated 3 months ahead as well as Eurodollar futures contracts dated 2 and 4 quarters ahead. (See their Table 3.) That is, central bank communications substantially change asset prices closely associated with policy rate changes in the near future. In this sense, 
FOMC communications demonstrably include forward guidance. ${ }^{6}$

Gürkaynak, Sack, and Swanson (2005) (hereafter GSS) continued this research agenda by examining the content of FOMC forward guidance in more detail and by characterizing its effects on Treasury yields. Specifically, GSS measured changes in fed funds futures and eurodollar futures contracts with one year or less to expiration over 30 minute windows centered on FOMC announcements. They then demonstrated that these changes have a simple two-factor structure in which the factors themselves account for nearly all of the sample variance. After an appropriate rotation, they label these the target and path factors. By assumption these are orthogonal; and only the target factor influences the current policy rate. Therefore, the path factor definitionally captures the effects of forward guidance on expected future policy rates. ${ }^{7}$ GSS furthermore showed that the path factor's largest realizations coincided with historically prominent cases of forward guidance. (See their Table 4.) Finally, they demonstrated that the path factor substantially influences the yields on two, five, and ten-year Treasury notes. In modern macroeconomic models, central bank forward guidance influences current economic performance only to the extent that it changes such bond rates, so this finding is necessary for us to continue entertaining the hypothesis that it can be an effective policy tool.

Campbell et al. (2012) extended the work of GSS in two directions. First, they demonstrated that data from the post-crisis period continued to conform to the patters documented by GSS. That is, the financial crisis did not permanently damage the transmission mechanism from forward guidance to asset prices. Second, they examined how private expectations of macroeconomic variables responded to forward guidance shocks in the pre-crisis period. They found strong evidence that an unexpected tightening of future rates lowered unemployment expectations and weaker evidence that it raised inflation expectations. (See their Table 3.)

The finding that private expectations' responses are the opposite of those we would expect from a simple NK model with shocks to expected future policy actions

\footnotetext{
${ }^{6}$ One might object that such asset price changes reflect only movements in term premiums rather than changes in underlying expectations of future interest rates. Indeed, Piazzesi and Swanson (2008) document substantial variation in these expected securities' expected excess holding returns. However, this variation occurs over business-cycle frequencies and so is not obviously relevant for the high-frequency changes measured by Kohn and Sack (2004).

${ }^{7}$ This statement is subject to the terms and conditions in Footnote 6.
} 
(i.e. forward guidance shocks) clearly indicates that something other than such a simple story is at work. Campbell et al. (2012) hypothesized that their results arise from Delphic forward guidance. If FOMC statements reveal information about near-term economic developments that would otherwise remain out of the public's hands, then the direct effects of the fundamentals so revealed (for example, lower unemployment and higher inflation from expected demand strength) will accompany the optimal policy response to those fundamentals (for example, an increase in expected future policy rates). That is, regressions of expectation revisions on changes in expected interest rates suffer from a simultaneity problem when FOMC statements contain Delphic forward guidance. Although this Delphic hypothesis is reasonable, it could also be wrong. Campbell et al. (2012) did not even commence with its empirical examination. Accordingly, we take up this challenge below by using direct measures of FOMC private information based on now-public Greenbook forecasts.

Additional scrutiny of asset price responses to FOMC forward guidance has also raised questions about the content and transmission of forward guidance. In the canonical log-linear New Keynesian model, the expectations theory of the term structure holds good; and changes in long-dated interest rates perfectly reflect concomitant changes in expected future spot interest rates. This applies to both real and nominal interest rates, but it is uncommon for monetary policy to influence expected real interest rates far beyond the duration of price stickiness. In contrast to this prediction Hanson and Stein (2015) found that changes in the stance of monetary policy substantially influence long-dated instantaneous forward rates. For FOMC meeting days, they regressed two-day changes in the ten-year ahead nominal instantaneous treasury yield, real TIPS yield, and implied inflation compensation (as measured by Gürkanynak, Sack, and Wright (2006, 2008) on the changes in the two-year zero-coupon nominal yield (also from Gürkanynak et al. (2006)), their preferred measure of the stance of monetary policy. They find no impact of the two-year nominal rate on forward inflation compensation, but the same rate has substantial effects on both the real and nominal forward rates.

Hanson and Stein dismiss out of hand the possibility that these estimated responses reflect changes in expected spot interest rates ten years ahead that are driven by monetary policy actions. We find this dismissal especially justified since long-dated inflation compensation does not respond to the two-year rate. 
They consider two alternative explanations for their findings. Perhaps FOMC communications contain Delphic forward guidance about changes in the longrun real rate of interest (which is obviously out of the committee's control). Alternatively, investors might "reach for yield" when short rates fall by shifting their portfolios into longer dated securities. This additional demand reduces their prices but not the expectations of outcomes ten-years hence. That is, the observed price changes reflect changes in term premia. Although Hanson and Stein cannot conclusively dismiss the Delphic explanation for their finding, they prefer the premium-based alternative for a variety of empirical reasons. Our measures of the private information the FOMC might reveal in forward guidance allow us to examine their Delphic hypothesis more directly.

\subsection{An Accounting Framework}

To enable a more precise discussion of the measurement of forward guidance and the estimation and interpretation of its effects, we present here a simple accounting framework for asset prices. The framework characterizes the prices of two fundamental assets, a zero-duration risk-free nominal security and a corresponding inflation-protected (hereafter "real") security. In addition to these two assets, households also trade futures contracts with all future expiration dates on these two securities.. Time is continuous, but there is a central bank that makes policy decisions at discrete moments (hereafter "meetings") that are one unit of time apart from each other. The current value of the nominal security is the central bank's policy rate, so this is fixed between the central bank's meetings.

The central bank follows a policy rule like that in Laséen and Svensson (2011) and Campbell et al. (2012). At meeting-instant $t^{\star}$, the policy rate $i_{t^{\star}}$ is set to

$$
i_{t^{\star}}=g_{t^{\star}}+\sum_{j=0}^{M} \xi_{t^{\star}-j}^{j}
$$

Here, $g_{t^{\star}} \equiv g\left(\Omega_{t^{\star}-\varepsilon}^{c}\right)$ is the systematic component of monetary policy, with $\Omega_{t^{\star}-\varepsilon}^{c}$ denoting the central bank's information set as of the moment $t^{\star}-\varepsilon$. The small time increment $\varepsilon$ represents an implementation delay, such as the time taken to transmit the central bank's policy rule choice to its trading desk. The remaining terms are the monetary policy shocks. The shock $\xi_{t^{\star}}^{0}$ is the current monetary policy shock, 
and it is uncorrelated with its own leads and lags. Furthermore, it is a surprise in the sense that even an observer with knowledge of both $g(\cdot)$ and $\Omega_{t-\varepsilon}^{c}$ cannot predict it. That is, $\xi_{t^{\star}}^{0} \notin \Omega_{t^{\star}-\varepsilon^{\prime}}^{c}$. The remaining terms are forward guidance shocks that the central bank revealed after past meetings. After the meeting at $t^{\star}-j$, the central bank revealed $\xi_{t^{\star}-j}^{j}$. At that moment, it became common knowledge that this should would be applied to the interest-rate rule $j$ meetings hence (that is, at $\left.t^{\star}\right)$. The central bank revealed shocks that influence $i_{t^{\star}}$ for the last $M$ meetings. The set of all public information at time $t$ is $\Omega_{t}^{p} \subset \Omega_{t}^{c}$. If $\bar{\Omega}_{t}^{p} \cap \Omega_{t}^{c}$ is not empty, then the central bank has private information.

At exactly $t^{\star}$, the central bank issues a statement to the public. This contains two components, which we label Delphic $\left(d_{t^{\star}}\right)$ and Odyssean $\left(o_{t^{\star}}\right)$. The Delphic component reveals some of the central bank's private information. If the central bank either chooses to reveal nothing or has nothing to reveal (when $\Omega_{t-\varepsilon}^{c}=\Omega_{t-\varepsilon}^{p}$ ), then $d_{t}$ equals the empty set, a trivial statement. Otherwise, we assume that $g_{t^{\star}} \in d_{t}$, so that the private sector can calculate $\xi_{t^{\star}}^{0}$ from $i_{t^{\star}}$ and $d_{t^{\star}}$. The Odyssean component equals a vector of forward guidance shocks, $o_{t^{\star}} \equiv\left(\xi_{t^{\star}}^{1}, \ldots, \xi_{t^{\star}}^{M}\right)$. Like the current policy shock, $o_{t^{\star}}$ is uncorrelated with its own leads and lags and those $\xi_{t^{\star}}^{0}$. However, it may be correlated with $\xi_{t^{\star}}^{0}$ itself. Furthermore, the elements of $o_{t^{\star}}$ may be correlated with each other. We also assume that and $o_{t^{\star}} \notin \Omega_{t^{\star}-\varepsilon}^{c}$. In this specific sense, $d_{t^{\star}}$ and $o_{t^{\star}}$ encompass Delphic and Odyssean forward guidance. ${ }^{8}$

At that same moment the central bank announces $i_{t^{\star}}, d_{t^{\star}}$, and $o_{t^{\star}}$; the media also communicates news $n_{t^{\star}}$ to the public. Without loss of generality, we assume that $n_{t^{\star}} \notin \Omega_{t^{\star}-\varepsilon}^{c} \cup\left\{i_{t^{\star}}, d_{t^{\star}}, o_{t^{\star}}\right\}$. That is, $n_{t^{\star}}$ is not merely a regurgitation of the central bank's policy action and statement. The public learns nothing else between $t^{\star}-\varepsilon$ and $t^{\star}$, so we have

$$
\Omega_{t^{\star}}^{p}=\Omega_{t^{\star}-\varepsilon}^{p} \cup\left\{i_{t^{\star}}\right\} \cup\left\{o_{t^{\star}}\right\} \cup\left\{d_{t^{\star}}\right\} \cup\left\{n_{t^{\star}}\right\}
$$

The real value of the nominal bond is subject to erosion (or enhancement) by inflation, which equals $\pi_{t} \in \Omega_{t}^{p}$ at instant $t$. This inflation and the returns to the

\footnotetext{
${ }^{8}$ Since $o_{t^{\star}}$ is revealed to the public, it obviously is in $\Omega_{t}^{c}$ for $t>t^{\star}$. Thus, the past values of these forward-guidance shocks appear on the right-hand side of (1) redundantly. This redundancy emphasizes that they are expected deviations from the systematic part of monetary policy.
} 
real and nominal bonds satisfy the Fisher equation,

$$
r_{t}=i_{t}-\pi_{t}
$$

always.

When two households execute a futures contract at instant $t$ which expires in $n$ periods, one of them agrees to exchange a zero-duration bond with a fixed yield, $f_{t}(n)$ (set at instant $t$ ) for the otherwise equivalent zero-duration bond with the interest rate prevailing at instant $t+n$. We use the superscripts $r$ and $i$ to distinguish the forward rates on real and nominal bonds from each other, and we define the $n$ period forward instantaneous inflation compensation with $f_{t}^{\pi}(n) \equiv f_{t}^{i}(n)-f_{t}^{r}(n)$. Following Piazzesi and Swanson (2008), we define the realized excess returns to the buyers of the $n$-period futures contracts and the realized excess inflation premium with

$$
x_{t}^{i}(n) \equiv f_{t}^{i}(n)-i_{t+n}, x_{t}^{r}(n) \equiv f_{t}^{r}(n)-r_{t+n}, \text { and } x_{t}^{\pi}(n) \equiv f_{t}^{\pi}(n)-\pi_{t+n} .
$$

Continuing, we define the $n$-period nominal, real, and inflation-compensation term premiums as the expectations of the corresponding excess returns given $\Omega_{t}^{p}$. That is

$$
\bar{x}_{t}^{i}(n) \equiv \mathbb{E}\left[x_{t}^{i}(n) \mid \Omega_{t}^{p}\right], \bar{x}_{t}^{r}(n) \equiv \mathbb{E}\left[x_{t}^{r}(n) \mid \Omega_{t}^{p}\right], \text { and } \bar{x}_{t}^{\pi}(n) \equiv \mathbb{E}\left[x_{t}^{\pi}(n) \mid \Omega_{t}^{p}\right]
$$

In general, we use the notation $\bar{z}_{t}(n)$ to denote the expectation of $z_{t+n}$ given $\Omega_{t}^{p}$. By construction $f_{t}^{z}(n)=\bar{z}_{t+n}+\bar{x}_{t}^{z}(n)$, for $z=i, r, \pi$.

Completing the framework requires us to describe the evolution of inflation and the determination of futures prices. We assume that $\pi_{t}$ evolves stochastically and that $\pi_{\tau} \in \Omega_{t}^{p}$ for all $\tau \leq t$. Otherwise, we leave inflation's stochastic process and the influence of monetary policy upon it unspecified. We make the weakest possible assumption regarding the futures prices: The rate of each contract consummated at $t$ is a function of $\Omega_{t}^{p}$ only. Henceforth, we leave this dependence implicit in our expressions. While this imposes very little structure, it is sufficient for our accounting purposes.

With the framework's specification complete, we can proceed to consider the measurement of monetary policy disturbances using high-frequency asset-price data. 
Consider first a stylized version of the Kuttner (2001) measurement strategy. ${ }^{9}$ Given the price of a futures' contract with floating rate $i_{t^{\star}} \equiv f_{t^{\star}}^{i}(0)$ written at $t^{\star}-\varepsilon$, this procedure proxies for $\xi_{t^{\star}}^{0}$ with

$$
\Delta_{\varepsilon} f_{t^{\star}}^{i}(0) \equiv f_{t^{\star}}^{i}(0)-f_{t^{\star}-\varepsilon}^{i}(\varepsilon)-\bar{x}_{t-\varepsilon}^{i}(\varepsilon)
$$

To determine the requirements for $\Delta_{\varepsilon} f_{t^{\star}}^{i}(0) \approx \xi_{t^{\star}}^{0}$, use the monetary policy rule and the term premium's definition to get

$$
\Delta_{\varepsilon} f_{t^{\star}}^{i}(0)-\xi_{t^{\star}}^{0}=g\left(\Omega_{t^{\star}-\varepsilon}^{c}\right)-\mathbb{E}\left[g\left(\Omega_{t^{\star}-\varepsilon}^{c}\right) \mid \Omega_{t-\varepsilon}^{p}\right]
$$

The estimation error's first component is the $\varepsilon$-period term premium; and we label the remaining terms' sum the contribution of central bank private information. So for this stylized version of the Kuttner procedure to yield reasonably accurate sequences of contemporaneous policy shocks, the term premium should vary little across meetings and the central bank should not base its current policy rate choices on any private information in its possession. The requirement on the term premium is consistent with the results of Piazzesi and Swanson (2008), which show that this premium's variance is concentrated at business-cycle frequencies. We test the assumption on private information below.

As noted above, GSS and Campbell et al. (2012) extended the Kuttner strategy to measure the surprise component of expected future policy rates with changes in nominal futures rates. For $j \in\{1,2, \ldots, M\}$, these changes can be written as

$$
\begin{aligned}
\Delta_{\varepsilon} f_{t^{\star}}^{i}(j) & \equiv f_{t^{\star}}^{i}(j)-f_{t^{\star}-\varepsilon}^{i}(j+\varepsilon) \\
& =\bar{i}_{t^{\star}}(j)-\bar{i}_{t^{\star}-\varepsilon}(j+\varepsilon)+\bar{x}_{t^{\star}}^{i}(j)-\bar{x}_{t^{\star}-\varepsilon}^{i}(j+\varepsilon) \\
& =\xi_{t^{\star}}^{j}+\bar{g}_{t^{\star}}(j)-\bar{g}_{t^{\star}-\varepsilon}(j+\varepsilon)+\bar{x}_{t^{\star}}^{i}(j)-\bar{x}_{t^{\star}-\varepsilon}^{i}(j+\varepsilon) \\
& =\xi_{t^{\star}}^{j}+\Delta_{\varepsilon} \bar{g}_{t^{\star}}(j)+\Delta_{\varepsilon} \bar{x}_{t^{\star}}^{i}(j) .
\end{aligned}
$$

Analogously to the current policy rate, the futures-based surprise measure sums the forward guidance shock, a revision to the expectation of the interest-rate rule's systematic component, and a policy-induced change in the term premium.

\footnotetext{
${ }^{9}$ Kuttner used futures contracts for which the floating rate was the average fed funds rate realized over the contract month; and so inference of the fed funds shock from the change in this contract's price requires careful accounting of the FOMC meeting's monthly timing. This work is obviously unnecessary in our more abstract environment.
} 
By definition, the shock $\xi_{t^{\star}}^{j}$ is one component of Odyssean forward guidance. The revision to the expectations of $g_{t^{\star}+j}$ embodies other Odyssean forward guidance (the revelation of $o_{t^{\star}}$ ), the current policy shock $\left(\xi_{t^{\star}}^{0}\right)$, Delphic forward guidance (the revelation of $d_{t^{\star}}$ ), and public news (the receipt of $n_{t^{\star}}$ ). Although the public receives these pieces of information simultaneously, it is helpful to imagine them being received sequentially in the order $n_{t^{\star}}, d_{t^{\star}}, \xi_{t^{\star}}^{0}, o_{t^{\star}}$. This allows us to write $\Delta_{\varepsilon} \bar{g}_{t^{\star}}(j)$ as the sum of four orthogonal components, each of which reflects one of these messages.

$$
\begin{aligned}
& \Delta_{\varepsilon} \bar{g}_{t^{\star}}(j)=\iota_{t^{\star}}^{o}(j)+\iota_{t^{\star}}^{\xi^{0}}(j)+\iota_{t^{\star}}^{d}(j)+\iota_{t^{\star}}^{n}(j) ; \text { with } \\
& \iota_{t^{\star}}^{n}(j) \equiv \mathbb{E}\left[g_{t^{\star}+j} \mid \Omega_{t^{\star}-\varepsilon}^{p} \cup\left\{n_{t^{\star}}\right\}\right]-\mathbb{E}\left[g_{t^{\star}+j} \mid \Omega_{t^{\star}-\varepsilon}^{p}\right] \\
& \iota_{t^{\star}}^{d}(j) \equiv \mathbb{E}\left[g_{t^{\star}+j} \mid \Omega_{t^{\star}-\varepsilon}^{p} \cup\left\{n_{t^{\star}}\right\} \cup\left\{d_{t^{\star}}\right\}\right]-\mathbb{E}\left[g_{t^{\star}+j} \mid \Omega_{t^{\star}-\varepsilon}^{p} \cup\left\{n_{t^{\star}}\right\}\right] \\
& \iota_{t^{\star}}^{\xi^{0}}(j) \equiv \mathbb{E}\left[g_{t^{\star}+j} \mid \Omega_{t^{\star}-\varepsilon}^{p} \cup\left\{n_{t^{\star}}\right\} \cup\left\{d_{t^{\star}}\right\} \cup\left\{\xi_{t^{\star}}^{0}\right\}\right]-\mathbb{E}\left[g_{t^{\star}+j} \mid \Omega_{t^{\star}-\varepsilon}^{p} \cup\left\{n_{t^{\star}}\right\} \cup\left\{d_{t^{\star}}\right\}\right] \text {, and } \\
& \iota_{t^{\star}}^{o}(j) \equiv \mathbb{E}\left[g_{t^{\star}+j} \mid \Omega_{t^{\star}-\varepsilon}^{p} \cup\left\{n_{t^{\star}}\right\} \cup\left\{d_{t^{\star}}\right\} \cup\left\{\xi_{t^{\star}}^{0}\right\} \cup\left\{o_{t^{\star}}\right\}\right] \\
& -\mathbb{E}\left[g_{t^{\star}+j} \mid \Omega_{t^{\star}-\varepsilon}^{p} \cup\left\{n_{t^{\star}}\right\} \cup\left\{d_{t^{\star}}\right\} \cup\left\{\xi_{t^{\star}}^{0}\right\}\right] \\
& =\mathbb{E}\left[g_{t^{\star}+j} \mid \Omega_{t^{\star}}^{p}\right]-\mathbb{E}\left[g_{t^{\star}+j} \mid \Omega_{t^{\star}-\varepsilon}^{p} \cup\left\{n_{t^{\star}}\right\} \cup\left\{d_{t^{\star}}\right\} \cup\left\{\xi_{t^{\star}}^{0}\right\}\right] .
\end{aligned}
$$

If we again appeal to Piazzesi and Swanson (2008) to justify ignoring the term premium's change, we can write the surprise change in the $j$-period ahead forward rate as

$$
\Delta_{\varepsilon} f_{t^{\star}}^{i}(j) \approx \xi_{t^{\star}}^{j}+\iota_{t^{\star}}^{o}(j)+\iota_{t^{\star}}^{\xi^{0}}(j)+\iota_{t^{\star}}^{d}(j)+\iota_{t^{\star}}^{n}(j)
$$

If the public and central bank were always equally well-informed and there were no Odyssean forward guidance; then the first, second, and fourth terms would identically equal zero. The change in the futures rate would equal a contribution from the propagation of the current policy shock through the economy and into the policy rule's value in $t^{\star}+j\left(\iota_{t^{\star}}^{\xi^{0}}(j)\right)$ and a term from the arrival of news from sources other than the central bank $\left(\iota_{t^{\star}}^{n}(j)\right)$. The inclusion of Delphic forward guidance introduces $\iota_{t^{\star}}^{d}(j)$. Finally, Odyssean forward guidance makes the first two terms non-zero. In this sense, (4) decomposes the surprise in the $j$-period ahead futures contract rate into four components: Odyssean forward guidance (the first two terms summed), Delphic forward guidance, the current policy shock's propagation, and the effects of coincident news. 
The characterization of the standard monetary shock measurement scheme is now in place, so we can proceed to consider the identification of their effects. For this, consider the change in the futures' contract rate for the nominal bond at some date $t^{\star}+h$, where $h>j$. This inequality ensures that $\xi_{t}^{0}$ only influences $i_{t^{\star}+h}$ indirectly through its effects on $\Omega_{t^{\star}+h^{\downarrow}-\varepsilon}^{c}$. (Here, $h^{\downarrow}$ is the greatest integer less than $h$.) Therefore, we can decompose the change in the forward rate into eight components.

$$
\begin{aligned}
\Delta_{\varepsilon} f_{t^{\star}}^{i}(h)= & \Delta_{\varepsilon} \bar{g}_{t^{\star}}^{i}(h)+\Delta_{\varepsilon} \bar{x}_{t^{\star}}^{i}(h) \\
= & \iota_{t^{\star}}^{o}(h)+\iota_{t^{\star}}^{\xi^{0}}(h)+\iota_{t^{\star}}^{d}(h)+\iota_{t^{\star}}^{n}(h) \\
& +\eta_{t^{\star}}^{o}(h)+\eta_{t^{\star}}^{\xi^{0}}(h)+\eta_{t^{\star}}^{d}(h)+\eta_{t^{\star}}^{n}(h)
\end{aligned}
$$

The $\iota(h)$ shocks are defined analogously to those for $j$, but with $g_{t+h} \equiv g_{t+h}$. (That is, the systematic component of monetary policy is fixed between meetings.) The $\eta(h)$ shocks give the analogous decomposition for the surprise change in the term premium. Hanson and Stein (2015) strongly suggest that these last shocks are not identically zero for large values of $h$.

We are now prepared to characterize the results of regressing $\Delta_{\varepsilon} f_{t^{\star}}^{i}(h)$ on $\Delta_{\varepsilon} f_{t^{\star}}^{i}(j)$. In population, this yields the coefficient

$$
\beta(h, j) \equiv \frac{\mathbb{E}\left[\Delta_{\varepsilon} f_{t^{\star}}^{i}(h) \Delta_{\varepsilon} f_{t^{\star}}^{i}(j)\right]}{\mathbb{E}\left[\Delta_{\varepsilon} f_{t^{\star}}^{i}(j)^{2}\right]} .
$$

These expectations are taken by averaging over an infinite sample of meetings. Using the decompositions in (4) and (5), we can express this coefficient as a weighted average of four regression coefficients.

$$
\begin{aligned}
\beta(h, j)= & \frac{\sigma^{2}\left(\xi_{t^{\star}}^{j}+\iota_{t^{\star}}^{o}(j)\right)}{\sigma^{2}\left(\Delta_{\varepsilon} f_{t^{\star}}^{i}(j)\right)} \beta^{o}(h, j)+\frac{\sigma^{2}\left(\iota_{t^{\star}}^{\xi^{0}}(j)\right)}{\sigma^{2}\left(\Delta_{\varepsilon} f_{t^{\star}}^{i}(j)\right)} \beta^{\xi^{0}}(h, j)+ \\
& +\frac{\sigma^{2}\left(\iota_{t^{\star}}^{d}(j)\right)}{\sigma^{2}\left(\Delta_{\varepsilon} f_{t^{\star}}^{i}(j)\right)} \beta^{d}(h, j)+\frac{\sigma^{2}\left(\iota_{t^{\star}}^{n}(j)\right)}{\sigma^{2}\left(\Delta_{\varepsilon} f_{t^{\star}}^{i}(j)\right)} \beta^{n}(h, j) .
\end{aligned}
$$


The weights in (6) sum to one, and the regression coefficients are defined with

$$
\begin{aligned}
\beta^{o}(h, j) & \equiv \frac{\mathbb{E}\left[\left(\xi_{t^{\star}}^{j}+\iota_{t^{\star}}^{o}(j)\right)\left(\iota_{t^{\star}}^{o}(h)+\eta_{t^{\star}}^{o}(h)\right)\right]}{\sigma^{2}\left(\xi_{t^{\star}}^{j}+\iota_{t^{\star}}^{o}(j)\right)}, \\
\beta^{\xi^{0}}(h, j) & \equiv \frac{\mathbb{E}\left[\iota_{t^{\star}}^{\xi^{0}}(j)\left(\iota_{t^{\star}}^{\xi^{0}}(h)+\eta_{t^{\star}}^{\xi^{0}}(h)\right)\right]}{\sigma^{2}\left(\iota_{t^{\star}}^{\xi^{0}}(j)\right)}, \\
\beta^{d}(h, j) & \equiv \frac{\mathbb{E}\left[\iota_{t^{\star}}^{d}(j)\left(\iota_{t^{\star}}^{d}(h)+\eta_{t^{\star}}^{d}(h)\right)\right]}{\sigma^{2}\left(\iota_{t^{\star}}^{d}(j)\right)}, \text { and } \\
\beta^{n}(h, j) & \equiv \frac{\mathbb{E}\left[\iota_{t^{\star}}^{n}(j)\left(\iota_{t^{\star}}^{n}(h)+\eta_{t^{\star}}^{n}(h)\right)\right]}{\sigma^{2}\left(\iota_{t^{\star}}^{n}(j)\right)} .
\end{aligned}
$$

These four regression coefficients are the "pure" measures of the effects of Odyssean forward guidance, the current policy rate, Delphic forward guidance, and public news on $f_{t^{\star}}^{i}(h)$. The identifiable regression coefficient weights these with variance contributions. Of course, analogous decompositions can be derived for the responses of $f_{t^{\star}}^{r}(h)$ and $f_{t^{\star}}^{\pi}(h)$.

Regardless of the asset under examination, the identified responses of asset prices to short-dated nominal interest-rate futures conflate the responses that directly map into simple models' impulse-response functions for future policy shocks with responses to Delphic forward guidance and news shocks. Therefore, the interpretation of this "cleanly" identified coefficient is far from straightforward. The Hanson and Stein (2015) results cited above strongly suggest that innovations to the expected systematic component of monetary policy are correlated with innovations to term premia. That is, the covariances of the $\iota(j)$ shocks with $\eta(h)$ shocks are not zero. Furthermore, when public news shocks influence expectations of future monetary policy $\left(\beta^{n}(h, j) \neq 0\right)$, high-frequency measurement does not by itself solve the classical simultaneous equations problem. Rigobon and Sack (2004) emphasize this obstacle and propose avoiding it by using estimates of asset price responses from days without FOMC policy actions to remove the influence of $\beta^{n}(h, j)$ from $\beta(h, j)$. Below, we undertake an effort to measure $\beta^{d}(h, j)$ based on measures of the information that could possibly be included within Delphic forward guidance. 
Table 1: Factor Structure of Short-Term FOMC Private Information

\begin{tabular}{lrrrrrr}
\hline \hline & \multicolumn{6}{c}{ Factors' Shares of Variance } \\
& CPI-Inflation & \multicolumn{2}{c}{ GDP Growth } & \multicolumn{2}{c}{ Unemployment } \\
& Short & Long & Short & Long & Short & Long \\
\hline Current quarter & 80 & 0 & 68 & 0 & 99 & 0 \\
Next quarter & 26 & 42 & 33 & 13 & 77 & 19 \\
Two quarters hence & 10 & 71 & 58 & 4 & 47 & 51 \\
Three quarters hence & 14 & 87 & 3 & 77 & 36 & 63 \\
Four quarters hence & 13 & 77 & 9 & 66 & 30 & 67 \\
\hline \hline
\end{tabular}

\subsection{The FOMC's Delphic Forward Guidance}

Unlike some inflation-targeting central banks abroad, the FOMC publishes no consensus forecasts of macroeconomic fundamentals and interest rates. Accordingly, the committee's post-meeting statements have historically lacked much quantitative content. Our approach to measuring Delphic forward guidance therefore does nothing with the statements themselves. Rather, we measure information that was available to FOMC participants but that was not in the public information set. Specifically, we take the forecasts for CPI inflation, GDP growth, and the unemployment rate contained in the committee's Greenbook and subtract the analogous consensus (that is, average) forecasts from the most recent Bluechip survey. ${ }^{10}$

The measured forecast differences cover the current quarter (the "nowcast") and the next four quarters. To keep our results interpretable, we reduce these 15 variables to 6 by conducting a factor analysis identical to that applied by GSS to the interest rate futures data. The factor analogous to the path factor, which by construction has no impact on the forecast of the current quarter's value, we call the "Long" factor. The other one is the "Short" factor. Table 1 reports the variance decompositions for these variables. With the exception of GDP growth one and two quarters into the future, these two factors account for the vast majority of observed

\footnotetext{
${ }^{10}$ The Bluechip survey collects forecasters' responses at the beginning of each calendar month, and the results are published on or about the 10th of the month. We match each Greenbook with the current month's Bluechip forecast if the Greenbook publication date was on or after the 10th. Otherwise, we use the previous month's Bluechip forecast. Of course, public information that was not available to Bluechip's private forecasters will be incorporated into the Greenbook forecasts. This biases our procedure against finding substantial effects of FOMC "private" information on innovations in interest rates and forecasts.
} 
variance.

Our next step uses these measures of FOMC private information to measure the information revealed in FOMC statements, as reflected in the concurrent changes in market expected interest rates. Table 2 reports the associated regression estimates and Wald tests for the exclusion of groups of regressors. Asymptotic standard errors are reported below each regression coefficient. For both coefficients' $t$-statistics and the Wald tests, we calculated critical values using 100,000 bootstrap replications that treat the meetings as identical. The significance stars that accompany the coefficient estimates and Wald test statistics come from these bootstrap calculations. Unsurprisingly, our reliance on bootstrapped critical values makes the results seem less "significant" than they otherwise would be. In that sense, our procedure is conservative. The regressions include twelve variables each, the six principle components from the current meeting as well as those from the previous meeting. These regressors might be relevant, because no theory requires the FOMC to reveal its information in a timely manner.

Table 2's first column reports the results from using changes in the current policy rate on the date of a FOMC meeting announcement as the dependent variable. The regression $R^{2}$ equals 0.13 , and none of the estimated coefficients are statistically-significant. More importantly, none of the Wald tests indicate that the included variables have explanatory power. ${ }^{11}$ Equation (3) identifies Delphic forward guidance as a possible complication for the identification scheme of Kuttner (2001), so this absence of evidence for short-run Delphic forward guidance influencing the current policy rate indicates that this is not a practical difficulty.

The second column reports results from using the four-quarter ahead futures contract rate as the dependent variable. Here, the $R^{2}$ is substantially higher, 0.23. Two of the GDP coefficients are statistically significant, those multiplying the Long factors from the current and past meetings. The former is positive, as we would expect if high expected GDP growth leads policy makers to signal tighter future policy. The latter coefficient is however negative. We do not find this too disturbing though, because the analogous coefficients on the two regressors which should have high correlations with the GDP long factor, the CPI and Unemployment ("U"). Long factors, have the expected signs. They have economically significant magnitudes, but

\footnotetext{
${ }^{11}$ Barakchian and Crowe (2013) also fail to find any substantial effect of FOMC private information on innovations to their measure of the current policy stance. See their Table 1.
} 
Table 2: FOMC Revelation of Private Information

\begin{tabular}{|c|c|c|}
\hline & Current Rate & Four Quarters Ahead \\
\hline \multirow[t]{2}{*}{ CPI Short Factor } & -0.40 & -1.25 \\
\hline & $(0.79)$ & $(0.99)$ \\
\hline \multirow[t]{2}{*}{ CPI Long Factor } & -1.62 & -4.99 \\
\hline & $(5.37)$ & $(6.72)$ \\
\hline \multirow[t]{2}{*}{ GDP Short Factor } & -1.38 & 4.00 \\
\hline & $(2.00)$ & $(2.50)$ \\
\hline \multirow[t]{2}{*}{ GDP Long Factor } & 3.72 & $9.16^{\star \star}$ \\
\hline & $(2.68)$ & $(3.36)$ \\
\hline \multirow[t]{2}{*}{ U Short Factor } & -8.93 & -11.13 \\
\hline & $(5.04)$ & $(6.31)$ \\
\hline \multirow[t]{2}{*}{ U Long Factor } & -6.08 & 4.69 \\
\hline & $(6.09)$ & $(7.64)$ \\
\hline \multirow[t]{2}{*}{ CPI Short Factor Lag } & 0.53 & 0.37 \\
\hline & $(0.77)$ & $(0.96)$ \\
\hline \multirow[t]{2}{*}{ CPI Long Factor Lag } & -0.73 & 3.48 \\
\hline & $(5.32)$ & $(6.66)$ \\
\hline \multirow[t]{2}{*}{ GDP Short Factor Lag } & 0.99 & 1.16 \\
\hline & $(1.86)$ & $(2.33)$ \\
\hline \multirow[t]{2}{*}{ GDP Long Factor Lag } & -2.17 & $-11.13^{\star \star \star}$ \\
\hline & $(2.91)$ & $(3.64)$ \\
\hline \multirow[t]{2}{*}{ U Short Factor Lag } & -0.17 & -1.65 \\
\hline & $(5.22)$ & $(6.54)$ \\
\hline \multirow[t]{2}{*}{ U Long Factor Lag } & 6.70 & -3.11 \\
\hline & $(6.02)$ & $(7.54)$ \\
\hline \multirow[t]{2}{*}{$R^{2}$} & 0.13 & 0.23 \\
\hline & \multicolumn{2}{|c|}{ Wald Tests } \\
\hline All Variables & 15.76 & $33.33^{\star \star}$ \\
\hline Current Variables & 8.52 & 11.08 \\
\hline Lagged Variables & 4.47 & $19.34^{\star \star \star}$ \\
\hline CPI Measures & 1.01 & 1.78 \\
\hline GDP Measures & 6.01 & $19.25^{\star \star \star}$ \\
\hline U Measures & 7.23 & 7.79 \\
\hline
\end{tabular}


they are measured imprecisely. The Wald test rejects the null hypothesis that all of the variables can be rejected at the five-percent level. So it does appear that Delphic forward guidance is associated with the statement. Perhaps more surprisingly, it appears that this guidance comes mostly from private information available in the previous meeting. The Wald test rejects the null that these variables can be excluded at the one percent level. On the other hand, the Wald test does not reject the null that the most recently obtained private information can be excluded. We interpret these results as indicating latency in the transmission of private information from the Federal Reserve's staff forecasters through FOMC participants and into the committee's statement. It seems that participants digest newly acquired information between meetings before incorporating it into statements.

The regression results in Table 2 provide one means of measuring short-run Delphic forward guidance: decompose the 4-quarter ahead futures rate into fitted values and residuals. The fitted values are our measure of short-run Delphic forward guidance. We emphasize "short-run" because the information used in its identification only covers the next several quarters. ${ }^{12}$ Although we doubt that other variables are available that substantially add to our measure of private FOMC information about the economy's near-term performance, there could be other information about longer-run outcomes. Even if those outcomes are outside of the FOMC's control (e.g. the long-run real interest rate), the FOMC's information about them might still be revealed in post-meeting statements and thereby influence asset prices. Since the regression's residuals can contain both longer-run Delphic forward guidance as well as Odyssean forward guidance, we refrain from applying any more structural interpretation to the regression's residuals.

Above, we discussed the possibility that Delphic forward guidance could be responsible for the counterintuitive effects of measured forward guidance on forecast revisions documented by Campbell et al. (2012). Table 3 provides evidence on that point. For the four forecasts of each variable available in our data, its first column reports estimated coefficients from bivariate regressions of the Bluechip survey's revision to that forecast (from the survey prior to the meeting to the one following it) on the four-quarter ahead futures rate itself. Each coefficient's asymptotic standard error is below it. The second column reports these regressions' $R^{2}$ measures. For the CPI forecasts, the regression coefficients and $R^{2}$ 's are all

\footnotetext{
${ }^{12}$ Our tables omit this qualifier only because of space constraints.
} 


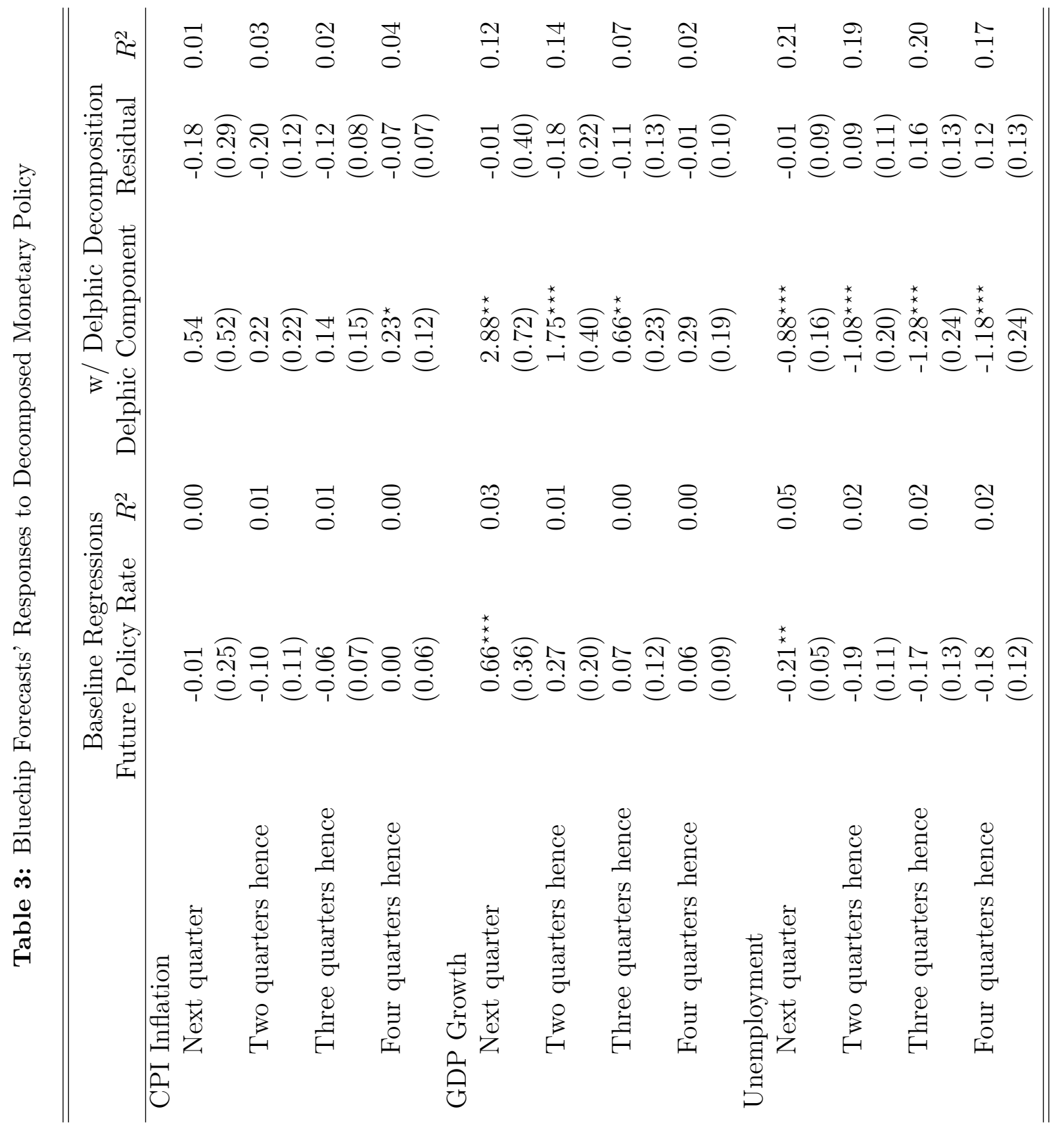


very close to zero. The coefficient for the forecast of next quarter's GDP growth forecast is positive and statistically significant at the one percent level. ${ }^{13}$ A naive reading of this would suggest that tightening monetary policy raises expected GDP growth. The coefficients for the remaining GDP forecasts are positive but not statistically significant. The forecast of next quarter's unemployment rate has a statistically significant (at the five percent level) and negative coefficient. The unemployment forecasts at other horizons have similar coefficients but they are measured less precisely. Again, a naive interpretation of this evidence would suggest that tightening monetary policy lowers the unemployment rate.

Table 2's remaining columns report the results from the analogous regressions that use the policy rate's decomposition into its short-run Delphic component and the associated residual. The CPI-forecast regressions have positive coefficients multiplying the forward rate's Delphic component, and negative coefficients multiplying the forward rate's residual. One of the coefficients multiplying the Delphic component is statistically-significant at the ten percent level, but otherwise inference from the simpler regression with only the forward rate itself remains unchanged. ${ }^{14}$ The results from the GDP and Unemployment forecast regressions differ substantially from this result. The GDP forecasts for one, two, and three quarters out all have statistically significant and large coefficients multiplying the forward rate's Delphic component. The coefficients multiplying the residual component are all negative but small and not statistically significant. The same pattern is true for the Unemployment forecasts. The forward rate's Delphic component has negative and statistically-significant (at the one percent level) coefficients, while the residual component has coefficients that are much closer to zero and (with one exception) positive. In light of these results, it should be no surprise that the $R^{2}$ measures from these regressions are much higher than those for the CPI-forecast regressions. Nevertheless, substantial variance in the forecast revisions remains.

Overall, the results of Table 3 validate the Delphic hypothesis as applied to

\footnotetext{
${ }^{13}$ Just as with the estimates in Table 2, we tabulated statistical significance of all coefficients in this table using 100,000 bootstrap replications.

${ }^{14}$ These regressions $R^{2} \mathrm{~s}$ are very low, which is perhaps unsurprising since much more information is revealed over the month than the FOMC's forward guidance. Improving inference by including other measurable relevant variables, such as differences between data releases and their consensus expectations, is on our research agenda.
} 
the revisions of Bluechip forecasts: the FOMC's statements reveal its private information (probably with a lag), and this influences expectations of short-run interest rates. The same information leads to substantial revisions of private forecasts, so we see forecasts of GDP growth and unemployment rising "in response to" increases in expected future policy rates. Of course, much remains to be uncovered; because the portion of the expected future policy rate that is unexplained by FOMC private information (about 80 percent of its variance) has no statisticallysignificant effect on short-term forecast revisions. We hope that better measurement of the FOMC's Delphic forward guidance that focuses more on medium-run and long-run economic outcomes combined with the inclusion of variables that are (theoretically) orthogonal to measured Delphic forward guidance but nevertheless relevant for private forecast revisions will yield a better understanding of how this residual's movements change expectations.

Our attempt to place the results of Hanson and Stein (2015) within the context of Delphic forward guidance is summarized in Table 4. Its first two columns report regressions analogous to those reported by those authors. The dependent variables are the instantaneous forward nominal rates, real rates, and inflation compensation rates at the two, five, and ten year horizons calculated by Gürkanynak et al. (2006, 2008). ${ }^{15}$ The independent variable is the same four-quarter ahead nominal futures rate examined in Tables 2 and 3. We comment further on the implications of this difference below. For now, note that our results are comparable to theirs. The future policy rate has large, positive, and statistically significant effects on both the nominal and real rates. These effects get smaller as the securities' horizons increase, but they do not disappear, even at a ten year horizon.

One important difference between our estimates and Hanson and Stein's is that these regressions' $R^{2}$ s are much lower than those they report for their baseline case. This can be entirely attributed to our use of a different monetary policy indicator. ${ }^{16}$ Hanson and Stein measured the stance of monetary policy with the nominal two-year zero-coupon yield from Gürkanynak et al. (2006). We were concerned that shocks to

\footnotetext{
${ }^{15}$ The estimation with the 2-year rates uses a sample that starts only in 2004, when sufficiently many previously-issued Tips had aged into this maturity to enable measurement of the yield curve at this very short horizon.

${ }^{16}$ Hanson and Stein (2015) considered the robustness of their results to using a policy indicator very similar to that we employ, the three-quarter ahead Eurodollar futures rate. Their estimated coefficients and $R^{2}$ s are correspondingly similar to those we report. Please see their Table 2 for more details.
} 


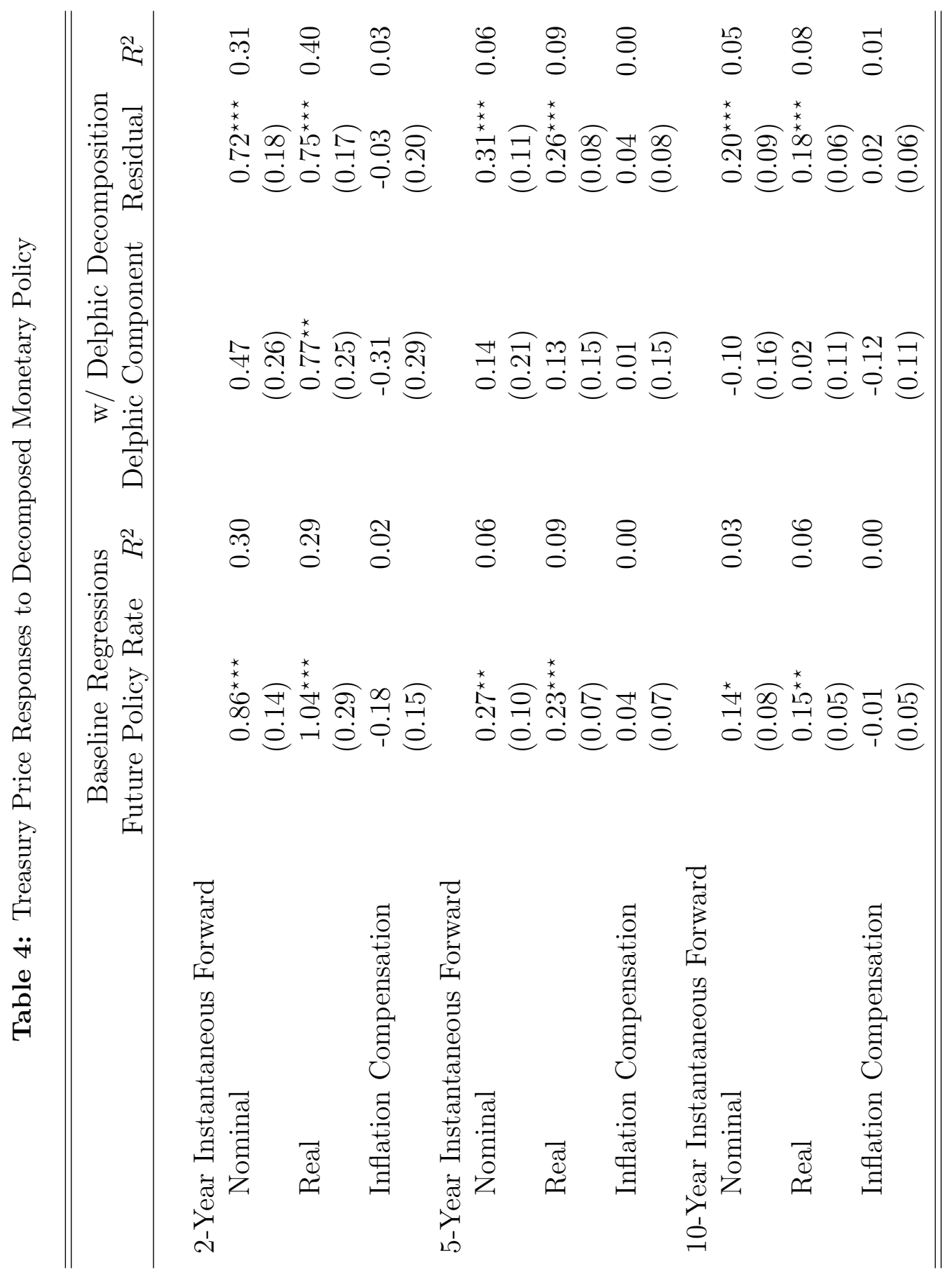


public news relevant for Treasury yield curves but not directly arising from monetary policy could be unduly contributing to the measured relationship between these asset prices. To examine this hypothesis, we estimated the regressions of Hanson and Stein using data from five days before each FOMC meeting. For recent meetings, this places the data within the "blackout period" during which staff and policymaker commentary on monetary policy developments is prohibited. Nevertheless, the coefficient estimates we obtain from those days are similar to those reported in Hanson and Stein (2015). ${ }^{17}$ In contrast, the estimates from the same days using changes in the forward rate we employ show no relationship between the two prices. In this specific sense, the forward rate that we employ is a "purer" measure of FOMC policy intentions than is the two-year zero coupon nominal treasury rate.

The remaining columns of Table 4 report the results from the analogous regressions that decompose the future policy rate into its short-run Delphic and residual components. Here, the results are very striking. As one might expect, the short-run Delphic component has a large and statistically-significant effect on the 2year instantaneous forward real rate. Unfortunately though, the sample is too short to precisely decompose that real effect into effects on the nominal rate and inflation compensation. However, the Delphic component has no measurable effects on any of the five-year or ten-year securities. In contrast, the residual component has large and statistically-significant (at the one-percent level) on the real and nominal forward rates at all three horizons. Just as in the original Hanson and Stein regressions, neither the Delphic component nor the residual has much of an effect on forward inflation compensation.

As we noted above, Hanson and Stein (2015) discussed two explanations for their findings, Delphic forward guidance (in their words, "the revelation of the Fed's private information about the future evolution of the economy." ${ }^{18}$ ) and changes in term premiums driven by yield-oriented investors. Although we cannot decisively eliminate the possibility of monetary policy impacting term premiums (nor do we wish to do so), we believe that the evidence in Table 4 favors an informationbased interpretation. The Delphic component of the four-quarter-ahead futures rate increases rates at the short end of the yield curve but not at the long end. It could be that the strong economic fundamentals that underly a Delphic increase in expected

\footnotetext{
${ }^{17}$ See Nakamura and Steinsson (2015) for a related critique of the Hanson-Stein results.

${ }^{18}$ See the third full paragraph of their page 430.
} 
policy rates increase demand for Treasuries that exactly offsets the flight of yieldoriented investors back to shorter-dated securities; but in that case we would expect the Delphic component to raise short interest rates much more than does the residual component. There is no evidence that this is the case. In an information-based story, the Delphic component only matters for short-dated securities simply because it is short-run information. The effects of the residual component on long rates can then be understood as the revelation of information about long-run outcomes. The standard deviation of this residual component is approximately 10 basis points. If we take these over eight meetings, this results in an annual standard deviation of revisions to the long-run real rate of $0.18 \sqrt{8 \times 10^{2}} \approx 5$ basis points per year. This is hardly so large that it would be the dominant factor in long-run rates. Nevertheless, further empirical scrutiny of such an information-based hypothesis is warranted.

\subsection{Evidence from VARs}

The reduced form empirical evidence discussed above has the advantage that it relies on relatively weak identifying assumptions, but this approach currently has little to say about the impact of Odyssean forward guidance shocks on macroeconomic outcomes. However there is a nascent literature that addresses this issue by making stronger assumptions. This literature builds on the traditional approach to identifying monetary policy shocks using VARs pioneered by Bernanke and Blinder (1992) and reviewed by Christiano, Eichenbaum, and Evans (1999). The traditional approach measures monetary policy shocks with changes in a policy indicator, typically the federal funds rate, that are orthogonal to a particular information set defined by a subset of the variables included in the VAR. Unlike high frequency identification, then, this literature takes a stand on the nature of the monetary policy rule and in particular the information used by the Fed in making its policy choices.

The traditional approach ignores forward guidance because it implicitly assumes for $\xi_{t-j}^{j}=0$ for $j>0$ in the policy rule defined in (1). Ramey (2016) discusses the challenges to identifying monetary policy shocks when this assumption is violated and Campbell et al. (2012) find that a substantial fraction of the residual variation in an estimated policy rule is forecastable. So this assumption is not innocuous. The

new monetary VAR literature allows that $\xi_{t-j}^{j} \neq 0$ and makes a variety of assumptions 
to extract this information from different specifications of the policy rule.

Gertler and Karadi (2015) extract this information by using changes in four quarter ahead fed funds futures on FOMC days as instruments for the policy residuals with the one year treasury yield as the policy indicator. Like most of the new literature they focus on a sample that includes observations from both before and after the funds rate attained its lower bound. Following a positive instrumented forward guidance shock real activity and prices fall. These findings are qualitatively consistent with the predictions of NK models. However Gertler and Karadi (2015) also find that the response of long term interest rate cannot be explained by the expected path of short rates (as predicted by their VAR), which is the principle channel through which forward guidance operates in NK models. Bundick and Smith (2015) also use high frequency data to identify forward guidance shocks in a VAR, and they also find that real activity contracts after a positive forward guidance shock. Their results are particularly noteworthy since their sample only covers the period at the ELB.

D'Amico and King (2016) use a sign restriction methodology to extract forward guidance shocks. They include survey expectations in VARs that include the 3month T-bill rate as the policy indicator. Forward guidance shocks are identified as innovations in expected T-bill rates that drive them oppositely to survey expectations of output and prices. This identification strategy is attractive because it isolates shocks in which Odyssean dominates Delphic guidance. D'Amico and King (2016) also find that realized output and consumer prices decline in response to positive forward guidance shocks.

Finally, Ben Zeev, Gunn, and Khan (2015) extract forward guidance from policy rule residuals using Barsky and Sims (2011)'s method of identifying news shocks. They first construct policy residuals as the difference between the federal funds rate and a pre-specified policy rule. Forward guidance shocks are then identified from a VAR as the linear combination of reduced form residuals that are orthogonal to the policy residuals and maximize the contribution to the policy residual's forecast error variance over a finite horizon. They find that after a positive forward guidance shock the federal funds rate does indeed rise gradually and is accompanied by declines in output and prices.

This literature is in its early stages and is subject to many of the perceived shortcomings of the traditional approach reviewed by Ramey (2016). Nevertheless 
the similarity in the findings across distinct identification strategies is striking. Taken at face value they generally support the view that forward guidance influences output and prices much as predicted by standard NK models, at least qualitatively. However there are limits to what can be accomplished with reduced form analysis.

Our ultimate goal is to quantify the impact of forward guidance on macroeconomic outcomes since the financial crisis. In principle an estimated VAR can be used to address this question, for example by simulating it under the assumption of no forward guidance shocks. However, conducting such an exercise does not guarantee that the lower bound on nominal rates will be respected. Furthermore the nature of forward guidance clearly changed during the ELB period so there is a very short sample available for estimation. Therefore, we address our question within the context of a fully-specified structural model. While such an approach inevitably requires even stronger assumptions than employed in the VAR literature, it does make it possible to consider a richer array of forward guidance and to impose the lower bound constraint when we consider our counterfactual exercise. The generally validating (or not invalidating) event-study and VAR findings we have described above motivate us to do this within a NK setting.

\section{The Model}

We employ an enhanced version of the canonical medium-scale NK model pioneered by Christiano et al. (2005) and Smets and Wouters (2007). Our model incorporates many of the refinements that have been introduced since these seminal papers were written. In addition we model forward guidance building on Laséen and Svensson (2011) and Campbell et al. (2012), introduce a preference for government bonds as suggested by Fisher (2015), and employ Jaimovich and Rebelo (2009) (hereafter JR) preferences over consumption and work. Since much of the model's specification is familiar we emphasize the novel aspects of our framework together with a complete description of the underlying structural shocks, which is essential to understand the experiments discussed below. For a complete characterization of the model see the online appendix. 


\section{$3.1 \quad$ Households}

The economy consists of a large number of identical, infinitely lived households with preferences described by the lifetime utility function

$$
E_{0} \sum_{t=0}^{\infty} \beta^{t} \varepsilon_{t}^{b}\left[U\left(V_{t}\right)+\varepsilon_{t}^{s} L\left(\frac{B_{t+1}}{P_{t} R_{t}}\right)\right]
$$

The period utility function $\mathrm{U}$ is specified as

$$
U(V)=\frac{V^{1-\gamma_{C}}-1}{1-\gamma_{C}}
$$

with $\gamma_{C}>0$. The argument of $U$ is given by

$$
V_{t}=C_{t}-\varrho \bar{C}_{t-1}-X_{t} H_{t}^{1+\gamma_{H}}
$$

where $C_{t}$ denotes the household's date $t$ consumption purchased in the final goods market at nominal price $P_{t}, \bar{C}_{t}$ denotes aggregate per capita consumption (which is equal to $C_{t}$ in equilibrium), $H_{t}$ denotes hours worked, and $X_{t}$ evolves as

$$
X_{t}=\left(C_{t}-\varrho \bar{C}_{t-1}\right)^{\mu} X_{t-1}^{1-\mu} .
$$

These are the preferences introduced in JR except that we have modified them to include external habit formation in consumption. ${ }^{19}$ These preferences include the parameter $\mu \in(0,1)$ which controls the wealth elasticity of labor supply while preserving compatibility with balanced growth. The parameter $\varrho>0$ determines the degree of habit formation and $\gamma_{H}$ controls the Frisch elasticity of labor supply in the special case in which $\varrho=\mu=0$. As $\mu \rightarrow 0$ and in the absence of habit formation these preferences reduce to the specification considered by Greenwood et al. (1988). In this special case labor supply depends only on the current real wage faced by households and is independent of the marginal utility of wealth. So as $\mu$ and $\varrho$ get smaller, anticipated changes in income have smaller effects on current labor supply. Conversely as $\mu$ gets larger the wealth elasticity gets larger and in the polar case when $\mu=1$ preferences reduce to the standard preferences proposed by King,

\footnotetext{
${ }^{19}$ Schmitt-Grohé and Uribe (2012) study a real business cycle model with the same preferences except their formulation involves internal habit.
} 
Plosser, and Rebelo (1988).

JR introduced their preferences because of their implications for the propagation of news about future production possibilities. With standard preferences news about improved production possibilities in the future raises current wealth thereby increasing current consumption and lowering labor supply. They found that allowing for flexibility in the short run effects of wealth on labor supply it was possible to generate business cycle co-movement in response to news about future production possibilities. We similarly include these preferences because of our focus on news about future settings of monetary policy, that is forward guidance. In NK models news about future settings of monetary policy influence current activity in part through wealth effects.

The household's subjective discount factor is decomposed into the non-stochastic component $\beta \in(0,1)$ and the exogenous discount factor shock $\varepsilon_{t}^{b}$. This shock has been shown by Justiniano et al. (2010) and others to be an important driver of consumption fluctuations. In addition it is often used, for example by Eggertsson and Woodford (2003), to motivate why monetary policy might become constrained by the ELB and so it is particularly relevant for our analysis. We assume $\varepsilon_{t}^{b}$ evolves according to

$$
\ln \varepsilon_{t}^{b}=\rho_{b} \ln \varepsilon_{t-1}^{b}+\eta_{t}^{b}, \eta_{t}^{b} \sim N\left(0, \sigma_{b}^{2}\right),
$$

The second novel feature of preferences is the inclusion of the increasing and concave period utility function $L$. The argument of $L, B_{t+1} /\left(P_{t} R_{t}\right)$, represents the real quantity of one-period government bonds purchased by the household at date $t$. It comprises of the nominal quantity of those assets, $B_{t+1}$, their return from date $t$ to date $t+1, R_{t}$, and the nominal price of consumption, $P_{t}$. Including $L$ introduces a demand for risk-free government bonds that is absent from existing empirical NK models. Krishnamurthy and Vissing-Jorgensen (2011) used such preferences to study the market for government securities.

Including this model feature allows the interest rate controlled by the central bank, $R_{t}$, to deviate from the return to installed capital. NK models typically maintain the assumption that these two rates of return coincide. Since the level of the federal funds rate is usually included as an observable in estimation, the assumption of equality potentially influences the values of parameters and the 
business cycle decompositions derived from those parameters. We show below that a spread between private and government rates of return introduces discounting into the household's linearized inter-temporal Euler equation for consumption which is otherwise absent.

A second reason for introducing "liquidity preferences" is that, as demonstrated by Fisher (2015), these preferences provide a simple micro-foundation for the ad hoc shock to the household's consumption Euler equation introduced by Smets and Wouters (2007). This shock plays a crucial role in empirical NK models because it is one of the few sources of co-movement between consumption and investment and therefore in estimated models often appears as a major source of cyclical fluctuations. In our context this shock is the preference shifter $\varepsilon_{t}^{s}$ in 7 . We assume it evolves according to

$$
\ln \varepsilon_{t}^{s}=\rho_{s} \ln \varepsilon_{t-1}^{s}+\eta_{t}^{s}, \eta_{t}^{s} \sim N\left(0, \sigma_{s}^{2}\right)
$$

Since it directly impacts the utility of "safe and liquid" government bonds we refer to $\varepsilon_{t}^{s}$ as the liquidity preference shock.

Households own the installed capital stock $K_{t}$. This is assumed to evolve over time according to

$$
K_{t}=\left[1-\delta\left(U_{t}\right)\right] K_{t-1}+\varepsilon_{t}^{i}\left[1-S\left(\frac{I_{t}}{q_{t} I_{t-1}}\right)\right] I_{t}
$$

where $I_{t}$ denotes gross investment and $S$ and its argument correspond to the kind of investment adjustment costs introduced by Christiano et al. (2005). We assume that $S$ evaluated along the non-stochastic growth path satisfies $S=S^{\prime}=0$ and $S^{\prime \prime}>0$. The term $q_{t}$, defined below, corresponds to the growth rate of investment's stochastic trend in equilibrium. The technology for transforming investment goods into installed capital is subject to the shock $\varepsilon_{t}^{i}$. We assume this investment-demand shock evolves according to

$$
\ln \varepsilon_{t}^{i}=\rho_{i} \ln \varepsilon_{t-1}^{i}+\eta_{t}^{i}, \eta_{t}^{i} \sim N\left(0, \sigma_{i}^{2}\right)
$$

The owners of installed capital can control the intensity with which it is utilized. Let $U_{t}$ measure capacity utilization in period $t$. Then the effective amount of capital services supplied to firms in period $t$ is $U_{t} K_{t}$. We assume that increasing the intensity 
of capacity utilization entails a cost in the form of faster depreciation, given by $\delta\left(U_{t}\right)$. We assume the functional form

$$
\delta\left(U_{t}\right)=\delta_{0}+\delta_{1}\left(U_{t}-1\right)+\frac{\delta_{2}}{2}\left(U_{t}-1\right)^{2}
$$

with $\delta_{0}, \delta_{1}, \delta_{2}>0$. The parameter $\delta_{2}$ determines the sensitivity of capacity utilization to variation in the rental rate of capital; the parameter $\delta_{1}$ governs the steady state utilization rate, which we normalize to unity; and the parameter $\delta_{0}$ corresponds to the rate of depreciation along the non-stochastic growth path or steady state.

\subsection{Goods Markets}

Households own all goods producers. Perfectly competitive firms produce the composite final good $Y_{t}$ that sells for price $P_{t}$. They produce the final good using differentiated intermediate inputs purchased from a unit mass of monopolistically competitive firms, with technology

$$
Y_{t}=\left(\int_{0}^{1} Y_{i t}^{\frac{1}{1+\lambda_{t}^{p}}} d i\right)^{1+\lambda_{t}^{p}}
$$

and $Y_{i t}$ denotes the quantity of inputs purchased from intermediate good producer $i$. Each intermediate good producer sells its product at a mark-up over marginal cost shocked by $\lambda_{t}^{p}$, which evolves according to

$$
\ln \lambda_{t}^{p}=\left(1-\rho_{p}\right) \ln \lambda_{\star}^{p}+\rho_{p} \ln \lambda_{t-1}^{p}-\theta_{p} \eta_{t-1}^{p}+\eta_{t}^{p}, \eta_{t}^{p} \sim N\left(0, \sigma_{p}\right)
$$

The parameter $\lambda_{\star}^{p}$ denotes the mark-up in the steady state. We refer to $\lambda_{t}^{p}$ as the price mark-up shock.

Intermediate goods producer $i$ produces $Y_{i t}$ using the technology:

$$
Y_{i t}=\left(K_{i t}^{e}\right)^{\alpha}\left[A_{t}^{Y} H_{i t}^{d}\right]^{1-\alpha}-A_{t} \Phi
$$

where $H_{i t}^{d}$ is composite labor input bought at wage $W_{t}$ in a competitive market from the labor compositors described below, $K_{i t}^{e}=U_{i t} K_{i t}$ is effective capital rented from households and $\Phi$ is the fixed costs of production, paid in final goods (the value of $\Phi$ is chosen so that aggregate monopoly profits of intermediate goods producers are 
zero in steady state.) The term $A_{t}^{Y}$ is the level of the neutral technology. This is a non-stationary process which evolves as

$$
\nu_{t}=\left(1-\rho_{\nu}\right) \nu_{\star}+\rho_{v} \nu_{t-1}+\eta_{t}^{\nu}, \eta_{t}^{\nu} \sim N\left(0, \sigma_{\nu}^{2}\right)
$$

where $\nu_{t} \equiv \ln \left(A_{t}^{Y} / A_{t-1}^{Y}\right)$. We refer to $\nu_{t}$ as the neutral technology shock. The term $A_{t}$ in (8) is the stochastic trend of equilibrium consumption and output measured

in consumption units given by $A_{t}=A_{t}^{Y}\left(A_{t}^{I}\right)^{\alpha /(1-\alpha)}$, where $A_{t}^{I}$ is the level of the investment-specific technology described below. We use $z_{t}$ to denote the log growth rate of $A_{t}: z_{t}=\nu_{t}+\alpha \omega_{t} /(1-\alpha)$.

The intermediate goods producers maximize profits according to a Calvo pricing scheme. Each firm is subject to an exogenous probability of having the opportunity to adjust its price, $\zeta_{p} \in(0,1)$. Absent this opportunity firms index the previously set price using the exogenous formula $\pi_{t-1}^{\iota_{p}} \pi_{*}^{1-\iota_{p}}$, where $\pi_{*}$ is the the central bank's inflation target (corresponding to steady state inflation), and $\iota_{p} \in[0,1]$.

Perfectly competitive firms supply investment goods to households at price $P_{t}^{I}$ in consumption units using a linear technology that transforms final goods into investment at rate $A_{t}^{I}$. The investment-specific technology $A_{t}^{I}$ is a non-stationary process which evolves as

$$
\omega_{t}=\left(1-\rho_{\omega}\right) \omega_{*}+\rho_{\omega} \omega_{t-1}+\eta_{t}^{\omega}, \eta_{t}^{\omega} \sim N\left(0, \sigma_{\omega}^{2}\right)
$$

where $\omega_{t} \equiv \log \left(A_{t}^{I} / A_{t-1}^{I}\right)$. The parameter $\omega_{\star}$ is the mean growth rate of the investment-specific technology. We refer to $\omega_{t}$ as the investment-specific technology shock. In equilibrium investment has a stochastic trend with log growth rate equal to $\nu_{t}+\omega_{t} /(1-\alpha)$.

\subsection{Labor Markets}

We adopt Smets and Wouters (2007)'s strategy for introducing sticky wages into an environment that includes preferences that are non-separable in consumption and labor. Households' rent their homogenous labor in a perfectly competitive market to a unit mass of household-owned labor guilds at wage $W_{t}^{h}$. Each labor guild is endowed with a technology that allows it to differentiate the households' labor. They rent this differentiated labor to the labor compositors, also owned by households, as 
monopolistic competitors. The labor compositors re-package the differentiated labor into the homogenous factor input $H_{t}^{s}$ supplied to intermediate goods producers. The labor re-packaging technology is given by

$$
H_{t}^{s}=\left(\int_{0}^{1} H_{i t}^{\frac{1}{1+\lambda_{t}^{w}}} d i\right)^{1+\lambda_{t}^{w}}
$$

where $H_{i t}$ is the differentiated labor of guild $i$ and $\lambda_{t}^{w}$ drives the guilds' mark-up over their marginal cost, $W_{t}^{h}$. We assume the wage mark-up shock $\lambda_{t}^{w}$ follows an exogenous process similar to $\lambda_{t}^{p}$ :

$$
\ln \lambda_{t}^{w}=\left(1-\rho_{w}\right) \ln \lambda_{*}^{w}+\rho_{w} \ln \lambda_{t-1}^{w}-\theta_{w} \epsilon_{t-1}^{w}+\eta_{t}^{w}, \eta_{t}^{w} \sim N\left(0, \sigma_{w}^{2}\right)
$$

The labor guilds maximize profits according to a Calvo wage-setting scheme. Each guild is subject to an exogenous probability of having the opportunity to adjust its wage, $\zeta_{w} \in(0,1)$. Absent this opportunity a guild indexes their previously

set wage using the exogenous formula $\left(\pi_{t-1} z_{t-1}\right)^{\iota_{w}}\left(\pi_{\star} z_{\star}\right)^{1-\iota_{w}}$, where $\iota_{w} \in[0,1]$ and $z_{t}=\nu_{t}+\alpha \omega_{t} /(1-\alpha)$ is the log growth rate of the stochastic trend $A_{t}$.

\subsection{Central Bank and Government}

The central bank sets the nominal interest rate on one-period government bonds, $R_{t}$, using a parametric specification of the monetary policy rule stated above in equation (1). Specifically,

$$
\ln R_{t}=\rho_{R} \ln R_{t-1}+\left(1-\rho_{R}\right) \ln R_{t}^{n}+\sum_{j=0}^{M} \xi_{t-j}^{j}
$$

The parameter $\rho_{R} \in[0,1]$ governs the degree of interest rate smoothing and $R^{n}$ is the notional target interest rate, that is the rate the central bank would choose in the absence of interest rate smoothing. Recall that the first of these disturbances, $\xi_{t}^{0}$, is the usual contemporaneous monetary policy disturbance while the remaining shocks are forward guidance shocks, because they are revealed to the public before they are applied to the policy rule. Agents see $\xi_{t}^{j}$ in quarter $t$, and it applies to the rule $j$ quarters hence. This approach to modeling forward guidance was introduced by Laséen and Svensson (2011) and studied previously by Campbell et al. (2012), 
Del Negro et al. (2015) and Ben Zeev et al. (2015). Gather all monetary policy shocks into the vector $\varepsilon_{t}^{1}$,

$$
\varepsilon_{t}^{1} \equiv\left(\xi_{t}^{0}, \xi_{t}^{1}, \ldots, \xi_{t}^{M}\right)^{\prime}
$$

Each realization of $\varepsilon_{t}^{1}$ influences the expected path of interest rates. We wish to map expectation revisions, which are uncorrelated over time by construction, into realizations of $\varepsilon_{t}^{1}$; so we assume that $\varepsilon_{t}^{1}$ is also uncorrelated over time.

The notional rate $R^{n}$ is set according to

$$
\ln R_{t}^{n}=\ln r_{*}+\ln \pi_{t}^{*}+\frac{\psi_{1}}{4} E_{t} \sum_{j=-2}^{1}\left(\ln \pi_{t+j}-\ln \pi_{t}^{*}\right)+\frac{\psi_{2}}{4} E_{t} \sum_{j=-2}^{1}\left(\ln Y_{t+j}-\ln y^{*}-\ln A_{t+j}\right)
$$

The constant $r_{*}$ corresponds to the steady state real interest rate and $\pi_{t}^{*}$ is an exogenous inflation drift that could be interpreted as the central bank's intermediate target for inflation. The drift term is included to address inflation's low-frequency movements during our sample. ${ }^{20}$ We call it the inflation drift shock and it evolves as

$$
\ln \pi_{t}^{*}=\left(1-\rho_{\pi}\right) \pi_{*}+\rho_{\pi} \ln \pi_{t-1}^{*}++\eta_{t}^{\pi}, \eta_{t}^{\pi} \sim N\left(0, \sigma_{\pi}^{2}\right)
$$

where $\pi_{*}$ is steady state inflation. The last two terms in (11) correspond to the inflation and output gaps which drive the central bank's response to the economy's shocks with the parameters $\psi_{1}, \psi_{2} \geq 0$ determining the elasticity of the response to these gaps. The inflation gap is a four-quarter moving average of the difference between twice and once lagged, current, and expected one-period-ahead log inflation and the contemporaneous value of the drift term. The output gap is a fourquarter moving average of the difference between twice and once lagged, current, and expected one-period-ahead log aggregate output and its stochastic trend. The constant $y_{*}$ denotes steady state output in the model. Its inclusion in (11) guarantees that the gaps are closed and the steady state nominal interest rate on government bonds is $R_{*}=r_{*} \pi_{*}$.

Notice that our specification of the monetary policy rule and the assumption of rational expectations imply that forward guidance in the model is all Odyssean.

\footnotetext{
${ }^{20}$ See Smets and Wouters (2003) for an early example of a NK model with an inflation drift term in the monetary policy rule.
} 
When forming expectations at any given date agents take the current and past forward guidance to be binding commitments to deviate from the policy rule. This guidance does not reveal information about the economy that is not already known to agents other than these commitments to deviate from the rule. Our empirical findings in Section 2 clearly indicate that FOMC communications contain Delphic guidance. This evidence is based on high frequency identification and perhaps at the quarterly frequency Delphic guidance is not essential for understanding quarterly fluctuations. Recent work, discussed in the conclusion, suggests this may not be the case. In any event, we view our formulation as a necessary first step in assessing the quantitative impact of the FOMC's extensive use of forward guidance since the crisis.

The government issues bonds $B_{t+1}$ and collects lump sum taxes $T_{t}$ to pay for government spending $G_{t}=A_{t} g_{t}$ in the final goods market. Therefore its one-period budget constraint is

$$
G_{t}+B_{t}=T_{t}+\frac{B_{t+1}}{R_{t}}
$$

We assume the government balances its budget every period, so government bonds are in zero net supply, $B_{t}=0$, in equilibrium. ${ }^{21}$ The government spending shock $g_{t}$ evolves as

$$
\ln g_{t}=\left(1-\rho_{g}\right) \ln s_{*}^{g}+\rho_{g} \ln g_{t-1}+\eta_{t}^{g}, \eta_{t}^{g} \sim N\left(0, \sigma_{g}^{2}\right),
$$

where $s_{*}^{g}$ is a parameter equal to government's share of output in steady state.

\subsection{Equilibrium}

Equilibrium is defined in the usual way. Agents optimize as described above and prices adjust to clear all markets except those for intermediate goods and composite labor. The constancy of the capital-labor ratio across intermediate good producers, Calvo pricing and wage setting, and our functional form assumptions for aggregating differentiated intermediate goods and labor, eliminates any heterogeneity from the

\footnotetext{
${ }^{21}$ With the introduction of liquidity preferences it is natural to extend the model to include a positive supply of government bonds. Doing so would be a step toward an environment where QE could be studied alongside forward guidance. We leave this avenue of inquiry to future work.
} 
log linearized equilibrium. At its core this is a real business cycle model and the first order conditions and resource constraints of the real side of the economy are the same. In addition to these equations the equilibrium is characterized by the wage and price Phillips curves derived from the Calvo price and wage setting schemes and the monetary policy rule.

In equilibrium households are always on their labor supply schedules and so they are willing to work at the going wage $W_{t}^{h}$. Guilds charge a mark-up over $W_{t}^{h}$ but must deliver the differentiated labor demanded by the intermediate goods firms no matter the wage they have set. This demand is derived from the fact that intermediate good firms are contracted to deliver their goods to the final good firms no matter the price they have set. The wedges between revenues and costs for guilds and intermediate good firms, reflecting the absence of price adjustment to guarantee market clearing, are made up with positive or negative dividends to the household. Otherwise profits are zero.

We study the solution to the log linearized equilibrium conditions of the detrended economy and apply econometric techniques that rely on linearity to estimate a subset of the parameters and to conduct our counterfactual experiment. One may question how such an approach can be squared with the ELB. Without forward guidance shocks it is possible that at some dates the model's forecast would have the ELB violated in the future even if it were not contemporaneously. For example, the forecasted evolution of the output and inflation gaps might dictate a negative nominal policy rate. We use data on expected future funds rates, which of course do not violate the ELB, in our list of observables when we estimate our model. The forward guidance shocks give our model the flexibility to fit these data and thereby respect the ELB.

One equilibrium condition is worth emphasizing at this stage because it illustrates some important differences between our model and standard NK models. Consider the log-linearized intertemporal Euler equation:

$$
\hat{\lambda}_{t}=\theta_{s}\left(\hat{R}_{t}+E_{t}\left[\left(\hat{\lambda}_{t+1}-\hat{\pi}_{t+1}-\gamma_{C} \hat{z}_{t+1}\right]\right)+\hat{\varepsilon}_{t}^{s}+\left(1-\theta_{s}\right) \hat{\varepsilon}_{t}^{b}\right.
$$

where $\theta_{s} \equiv R_{\star} / R_{*}^{P}$ is the ratio of the gross rate of return on government bonds to private bonds (which correspond to the return to capital) in the steady state, $\lambda_{t}$ is the shadow value of consumption (the detrended Lagrange multiplier on the 
household's budget constraint), $\pi_{t}$ is the gross rate of inflation in the consumption price, and "hats" denote log deviations from steady state. With a positive steady state spread $R_{*}^{P}>R_{\star}$ and $\theta_{s}<1$. In this case both liquidity $\hat{\varepsilon}_{t}^{s}$ and $\hat{\varepsilon}_{t}^{b}$ appear in the Euler equation whereas in Smets and Wouters (2007) only $\hat{\varepsilon}_{t}^{s}$ appears. ${ }^{22}$

When $\theta_{s}<1$ discounting is introduced into the linearized consumption Euler equation that is otherwise not present. McKay et al. (2015) and Del Negro et al. (2015) argue that the absence of such discounting explains the large effects of forward guidance that have been emphasized in the literature. For convenience set the shocks to zero and assume that from some finite date onward inflation and the policy rate equal their steady state values. Then the linearized Euler equation can be solved forward to obtain

$$
\hat{\lambda}_{t}=\sum_{j=0}^{\infty}\left(\theta_{s}\right)^{j+1}\left(\hat{R}_{t+j}-\hat{\pi}_{t+j}\right) .
$$

In standard NK models the spread equals zero, $\theta_{s}=1$, and the sum of the deviations from steady state of the real return on government bonds pins down consumption's shadow value. This has the perverse implication that ceteris paribus a credible commitment to change the policy rate tomorrow has the same impact as a commitment to do the same change 10 years out. With a spread, $\theta_{s}<1$, the direct effects of expected future real rates on the shadow value of consumption decline with the horizon of the rate increase, with the rate of decline increasing in the size of the spread. Similar discounting is obtained by Del Negro et al. (2015) (perpetual youth), Gabaix (2016) (bounded rationality), and McKay et al. (2015) (incomplete markets). Del Negro et al. (2015) and McKay et al. (2015) find smaller effects of forward guidance with discounting.

\section{Measurement and Estimation}

The model's estimation follows a somewhat nonstandard approach. We first calibrate parameters that the model has in common with standard real business cycle models to match long-run averages from the U.S. economy calculated using data over

\footnotetext{
${ }^{22}$ Equation (12) only holds for $\theta_{s}<1$ since it is based on rescaling the variance of the liquidity preference shock by $\left(R_{*}^{P}-R_{*}\right) / R_{*}^{P}$. When $\theta_{s}=1$ both shocks drop from the Euler equation but it is otherwise unchanged.
} 
the entire post-WWII period. This "first-moments-first" approach ensures that any success in replicating second moments does not come at the cost of counterfactual long-run predictions. The remainder of the estimation relies on relatively standard Bayesian methods and focuses on the 1993q1-2008q3 period. ${ }^{23}$ This section briefly discusses our data and then presents our hybrid calibration-Bayesian estimation strategy with particular emphasis on how we identify the forward guidance signals. ${ }^{24}$

\subsection{Data}

Our Bayesian estimation uses 18 quarterly time series variables for the 1993q12008q3 sample, including measures of output, consumption, investment, hours worked, the real price of investment, the real price of government consumption plus net exports, wage and consumer price inflation, average inflation expected over the next ten years, the federal funds rate (our measure of the rate of return on government bonds in the model) and four quarters of federal funds rate futures rates. Our calibration uses data measuring the capital stock, capital's share of aggregate income and nominal expenditure shares. Finally, we use changes in federal funds rate futures on FOMC days to center the priors in our estimation of forward guidance. This section describes how all of these variables enter into our analysis.

Our measurement of macroeconomic variables derives from three simple principles which set our analysis apart from most modern business cycle studies. First, we want to perform inference with a measure of labor input that best addresses demographic and other low frequency developments in the labor market. Second we want our measures of real quantities and prices to be consistent with the chainweighting procedures used in the NIPA. Third, because it is implausible that any one measure of wages or prices is an adequate proxy for wages and prices in the model, we want to use multiple indicators all of these objects in our estimation.

\subsubsection{Hours}

Empirical studies of medium-scale NK models typically measure labor input with hours per capita constructed from directly from estimates of hours worked from the BEA and the civilian population over the age of 16 obtained from the BLS. Such

\footnotetext{
${ }^{23}$ While the federal funds futures market operated before 1993q1 it was relatively illiquid.

${ }^{24}$ The discussion leaves out many important details. See the online appendix for these details.
} 
measures do not correspond well with business cycle models because of underlying low frequency variation. As a consequence the results obtained in these studies are difficult to interpret. In our context, measures of the output gap are directly affected by the measure of hours. This in turn affects the estimate of the coefficient on the output gap in the policy rule and consequently impacts our identification of forward guidance shocks. Clearly the measurement of hours is crucial to our analysis.

We use a simple procedure for overcoming this discrepancy between model and data. ${ }^{25}$ Assume that hours per worker outside and inside the private business sector are the same. Then it is straightforward to show that hours per capita for the economy as a whole, $H^{p c}$, can be measured as three variables multiplied together: hours per worker in the private business sector, the employment rate and the labor force participation rate. Measures of these objects are available from the BLS' Establishment Survey (ES) and Current Population Survey (CPS). Therefore we define $H^{p c}$ to be

$$
H^{p c} \equiv \frac{H^{E S}}{E^{E S}} \frac{E^{C P S}}{L F^{C P S}} \frac{L F^{C P S}}{P^{C P S}}
$$

where $H^{E S}$ and $E^{E S}$ denote hours and employment in the private business sector from the ES; and $E^{C P S}, L F^{C P S}$ and $P^{C P S}$ denote total civilian employment, the labor force and civilian population over the age of 16 obtained from the CPS. ${ }^{26}$ Applying the log operator we obtain a simple additive decomposition of log per capita hours.

Figure 1 displays log per capita hours calculated using the right hand side of equation (14) over the period 1968q1 to 2015q1. One indication that this measure is problematic is that as of $2015 q 1$ it is near the trough of the 1982 recession. While the labor market in 2015q1 arguably had some way to go to reach full employment, it seems unlikely that conditions early last year were representative of the trough of a major recession.

\footnotetext{
${ }^{25}$ See Francis and Ramey (2009), Galí (2005) and Ramey (2012) for related discussions of nonstationarity in per capita hours worked.

${ }^{26}$ It is standard in the literature to measure hours per capita using a measure of hours from the ES and a measure of population obtained from the CPS. A similar decomposition of this measure of per capita hours reveals that it embeds the discrepancy in measures of employment in the two surveys. There is substantial variation in the survey discrepancy (see Aaronson, Rissman, and Sullivan (2004)) which further complicates the interpretation of results based on standard measures of per capita hours. We avoid this issue because the numerator and denominator in each ratio from which we build our per capita hours series are always obtained from the same survey.
} 
Figure 1: Total economy-wide log per capita hours worked

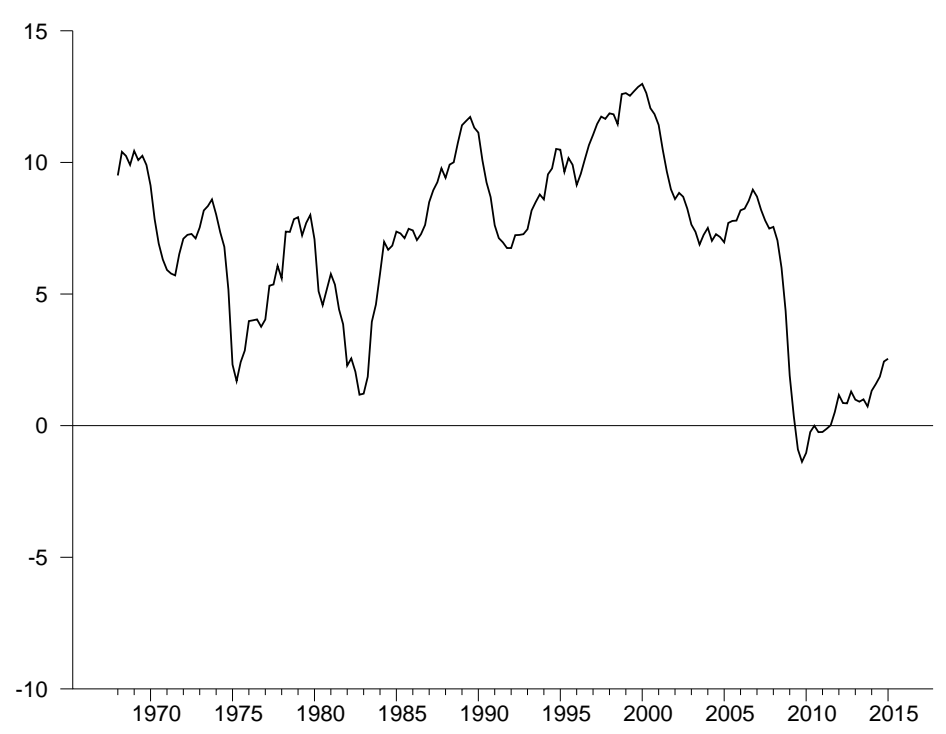

A clearer picture of the labor market is obtained by considering the three constituent parts of log hours per capita displayed in Figure 2. This figure shows that per capita hours confounds low frequency movements in all three of its components. These movements can be attributed to a variety of demographic and social developments as well as changes in the underlying structure of the economy related to technological change and, perhaps, the growing role of international trade.

Figure 2 strongly suggests that conventional measures of per capita hours are problematic; it is hard to argue that all variation in them is due to factors driving the business cycle. We are then presented with two main alternatives to consider. Either we incorporate the underlying trends into our models or we remove the trends prior to analysis. Developing structural models of the trends is an extremely challenging task and goes far beyond the scope of a business cycle study. Therefore we take the latter approach.

To do so we take advantage of work done at the Federal Reserve Board to address evolving demographic effects as well as other secular changes in the labor market described in Aaronson, Cajner, Fallick, Galbis-Reig, Smith, and Wascher (2014), Fleischman and Roberts (2011), and Roberts (2014). The Board estimates variables that can be used to de-trend all three components of per capita hours. ${ }^{27}$ We do not

\footnotetext{
${ }^{27}$ These variables are obtained from http://www.federalreserve.gov/econresdata/frbus/ data_only_package.zip.
} 
Figure 2: The three components of per capita hours worked

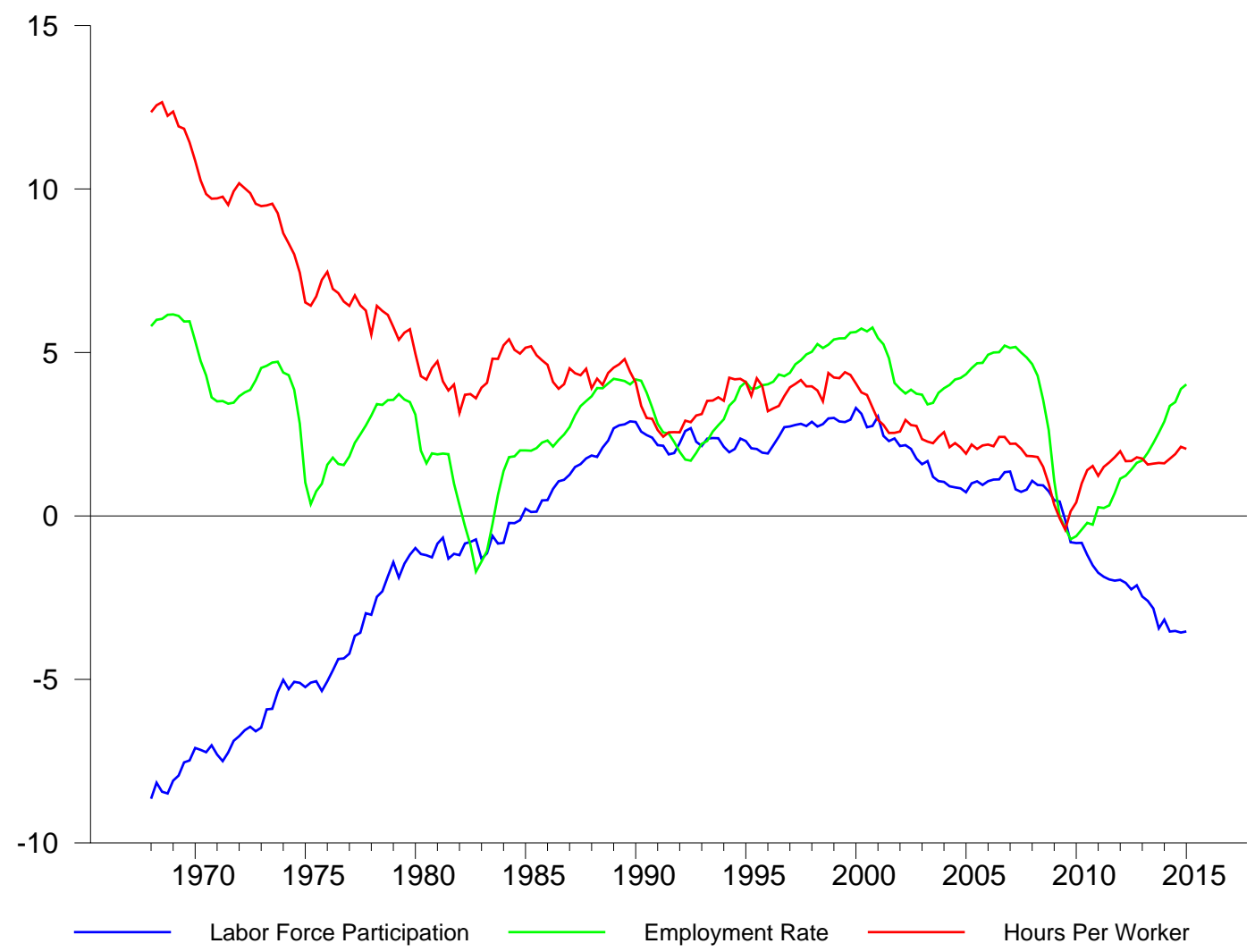

incorporate the estimation of these trends into our analysis. Instead we take them as given to construct an observable for per capita hours which is then used in the estimation of our model. Figure 3 displays the three components of per capita hours along with their trends and de-trended per capita hours which is derived as the sum of the differences between each component and its trend. We use this latter variable as our observable for per capita hours, $H^{\text {obs }}$.

\subsubsection{Aggregate quantities and prices}

Our measure of capital needs to be economy-wide to be consistent with our measure of hours. Therefore our measure of capital is the net stock of fixed assets and consumer durables from the BEA which includes private non-residential and residential capital, government capital and the stock of consumer durables. Investment is measured consistently with this measure of the capital stock $\left(I_{t}^{o b s}\right)$. 
Figure 3: Detrending per capita hours
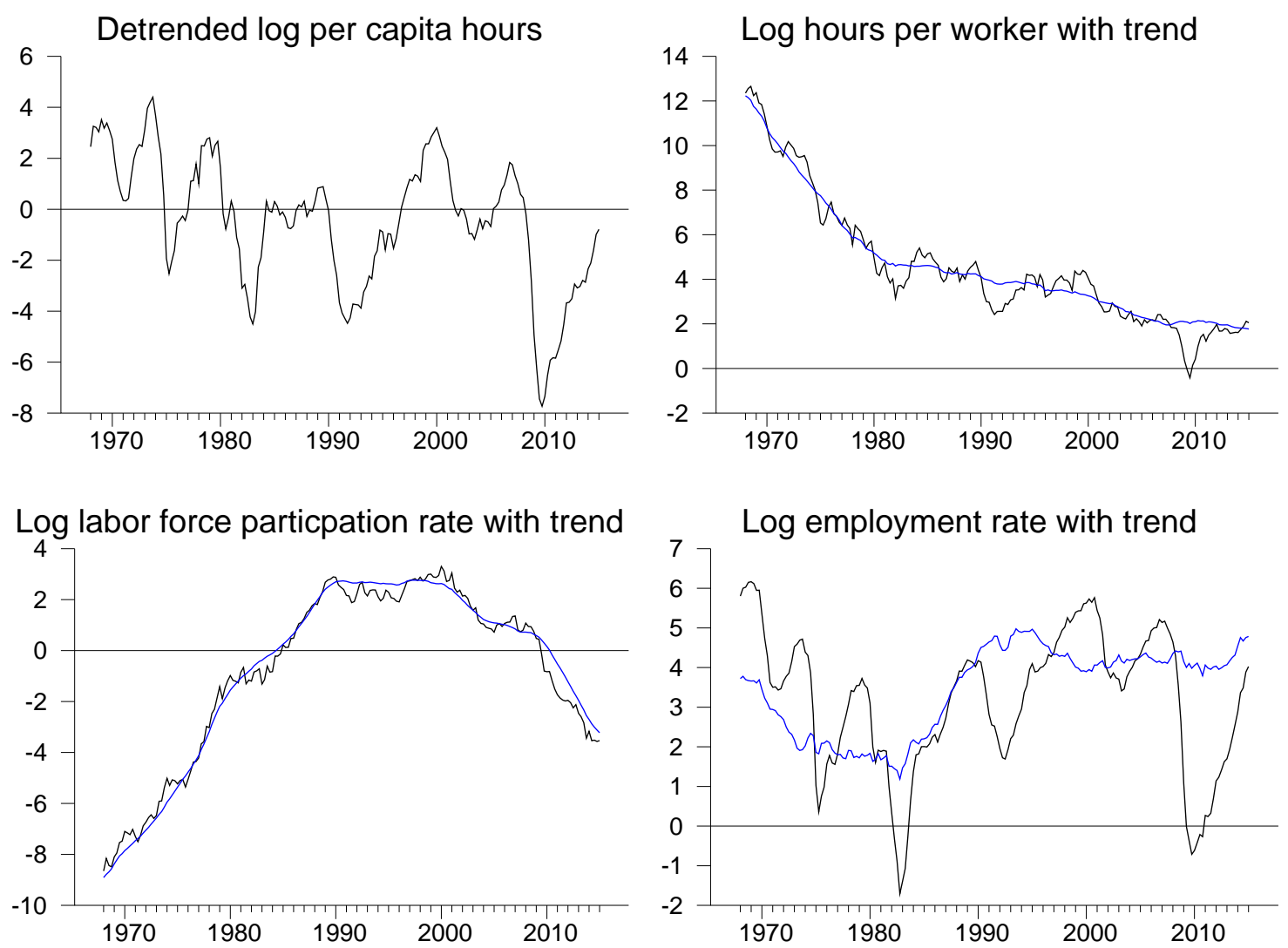

Similarly the measure of capital income we use to calculate capital's income share augments the NIPA measure to include the service flows from government capital and the stock consumer durables. Our concept of capital is also inconsistent with the NIPA measure of real GDP which includes the service flows from the stock of residential capital but excludes the service flows from the stocks of consumer durables and government capital. Therefore the measure of GDP we use in estimation augments the NIPA measure to include these two service flows. Our measure of consumption $\left(C_{t}^{o b s}\right)$ includes the NIPA measure of consumption of nondurables and services plus the service flow from the stock of consumer durables. We measure the inverse of the real investment price as the ratio of the price deflators corresponding to our measures of consumption and investment (inflation in this variable is denoted $\pi^{i, o b s}$. 
In our model consumption, investment and government spending are homogenous final goods when measured in consumption units. Real GDP as measured in the NIPA is a chain-weighted aggregate of these goods measured in their own units. If the model excluded government spending then we could calculate the growth rate of real GDP in the model using consumption and investment in their own units and inflation in the real investment price. With government consumption in the model as well, calculating real GDP growth in the model requires having on hand the real price of government consumption plus net exports. We now explain this.

The BEA measures real GDP growth using the Fisher ideal index. In our context the formula is

$$
\frac{Q_{t}^{o b s}}{Q_{t-1}^{o b s}}=\left(\frac{\sum P_{j, t-1}^{o b s} Y_{j, t}^{o b s}}{\sum P_{j, t-1}^{o b s} Y_{j, t-1}^{o b s}}\right)^{1 / 2}\left(\frac{\sum P_{j, t}^{o b s} Y_{j, t}^{o b s}}{\sum P_{j, t}^{o b s} Y_{j, t-1}^{o b s}}\right)^{1 / 2}
$$

where the superscript 'obs' denotes observable according to our measurement strategy. The summations are over $j=c, i, g$. $P_{j}$ denotes nominal deflator for $j$ and $Y_{j}$ denotes real expenditures on $j$. We can rewrite the two terms in the formula and make the translation to model variables and observable relative prices to arrive at:

$$
\frac{Q_{t}}{Q_{t-1}}=z_{t}\left(\frac{c_{t}+e^{-\omega_{t}} i_{t}+g_{t} / \pi_{t}^{g, o b s}}{c_{t-1}+i_{t-1}+g_{t-1}}\right)^{1 / 2}\left(\frac{c_{t}+i_{t}+g_{t}}{c_{t-1}+e^{\omega_{t}} i_{t-1}+\pi_{t}^{g, o b s} g_{t}}\right)^{1 / 2}
$$

where $c_{t}=C_{t} / A_{t}$ and $i_{t}=I_{t} / A_{t}^{I}$. We identify $Q_{t} / Q_{t-1}$ with our empirical measure of real GDP growth. ${ }^{28}$ In deriving this formula we have used the fact that we identify the investment shock with the inverse of inflation in the real price of investment, as the model's linear investment technology suggests. The variable $\pi_{t}^{g, o b s}$ denotes inflation in the real price of government consumption plus net exports.

Our model includes all the variables in (15) except for $\pi_{t}^{g, o b s}$. To be consistent with our measurement of GDP, consumption and investment we measure $\pi_{t}^{g, o b s}$ using the price deflator corresponding to the real quantity of government consumption (including the service flow from government capital) plus net exports, divided by the deflator corresponding to our measure of consumption. To measure GDP in the model we estimate an auxiliary regression for $\pi_{t}^{g, o b s}$ modeled as an $\operatorname{AR}(2)$

\footnotetext{
${ }^{28}$ Edge, Kiley, and Laforte (2010) also measure model output using chain-weighting.
} 
independent of and not feeding into the structural equations of the model. That is, this variable is only used in measurement. It affects equilibrium outcomes through the identification of shocks, but not directly through agents' decisions. ${ }^{29}$

\subsubsection{Wage and Price Inflation}

In most empirical studies of medium-scale NK models, variables are measured with a single empirical counterpart. We measure wage and price inflation in our model with multiple empirical analogues. ${ }^{30}$ Specifically, in the measurement equations each observable is expressed as a linear function of its model counterpart, plus a constant to reflect discrepancies in sample averages across different wage and price inflation measures, plus idiosyncratic measurement error. In the case of price inflation we include an additional variable in the measurement equations, discussed below. Our price measures are core CPI, core PCE and market-based PCE. For wages we use average hourly earnings of production and non-supervisory workers for total private industry from the payroll survey and the BEA's employment cost index for total compensation of all civilian workers.

We include an additional variable in the measurement equations for price inflation because the price of consumption goods in the model is conceptually different from the CPI and PCE measures we use in estimation. Model consumption is non-durable yet the CPI and PCE price indices include prices of durable consumption goods. We address this incongruity by augmenting the measurement equations for price inflation to include linear functions of the consumer durable nominal price inflation as measured by the BEA $\left(\pi_{t}^{d, o b s}\right)$. The weights on model inflation and consumer durable inflation in the measurement equations are estimated. Consumer durable inflation is included in our measurement similar to how we include government plus net exports real price inflation to measure real GDP growth. It is modeled as an $\mathrm{AR}(2)$ independent of and not feeding into the structural equations of the model. Just as in the GDP case this inflation rate does affect equilibrium outcomes through the identification of shocks but not directly

\footnotetext{
${ }^{29}$ To include this inflation rate as an exogenous shock would only have meaning if government consumption was endogenously determined, which it is not in our model. Apart from representing a major departure from standard medium-scale NK models, we think the presence of net exports in our empirical measure of $G_{t}$ justifies treating government spending in the model as exogenous.

${ }^{30}$ See also Boivin and Giannoni (2006), Galí, Smets, and Wouters (2012) and Justiniano et al. (2013). We obtain our wage and price inflation indicators from Haver Analytics.
} 
through agents' decisions.

Including multiple wage and price series has several advantages. First, as made clear by Justiniano et al. (2013), doing so in principle reduces the role of markup shocks in explaining cyclical fluctuations. In most empirical NK models these shocks play an outsized role in explaining labor market dynamics, yet they are difficult to interpret. ${ }^{31}$ Second, inflation that enters the monetary policy rule is identified using three inflation series that are major inputs into actual monetary policy-making. This contrasts with the many studies that measure inflation instead using the GDP deflator, which is seldom referenced as a key input in policy formation. Third, as discussed by Barsky, Justiniano, and Melosi (2014) and Justiniano et al. (2013) it tends to reduce the trade-off between inflation and output stabilization which is a key factor driving whether or not the ZLB is binding in New Keynesian models.

\subsubsection{Monetary policy variables}

We measure expectations of CPI inflation over the next ten years with the Survey of Professional Forecasters' measure, $\pi_{t}^{40, o b s}$. This variable helps us identify the inflation drift $\pi_{t}^{*}$ in (11). The remaining variables we use to identify monetary policy are the (quarterly average) federal funds rate $\left(R_{t}^{o b s}\right)$ and (end of quarter instantaneous) federal funds futures rates 1 to 4 quarters ahead (first sample) and 1 to 10 quarters ahead (second sample) based on Eurodollar and overnight interest rate swap data $\left(R_{t}^{j, o b s}\right) .{ }^{32}$ These data inform the forward guidance signals. In our identification of these signals we use both the quarterly measures of future rates and the change in the futures rates in a day-long window around policy announcements. The changes on FOMC announcement days are used to inform the priors in our factor representation of forward guidance, described below. The quarterly data are used in the actual estimation of the model.

\footnotetext{
${ }^{31}$ This forms a major component of Chari, Kehoe, and McGrattan (2009)'s critique of NK models.

${ }^{32}$ The funds rate paths implied by these contracts include a 1 basis point per month adjustment for term premiums through 2011q2. We do not apply any adjustments after this date when it appears that term premiums disappeared or perhaps turned negative. The unadjusted data yield very similar results.
} 


\subsection{Calibration}

We calibrate $\alpha, s_{\star}^{g}, s_{\star}^{i}$ (investment's steady state share of final goods), $\delta_{0}, \pi_{*}^{g}$ (the "steady state" value of inflation in the real government spending price), $\omega_{\star}, z_{\star}$, and $\theta_{s}$ by matching the same number of targets calculated with our data to the model's steady state. Our targets include average values of capital's share of income, government and investment shares of nominal output, the capital-to-output ratio, real per-capita GDP growth, inflation in the real investment good price, inflation in the real government plus net exports price, and the federal funds rate. Using steady state conditions $\delta_{1}$ can be expressed as a function of the capital-to-output ratio, $z_{*}$ and $\omega_{*}$. In turn the real return on capital can be expressed as a function of $\delta_{0}, \delta_{1}$ and $\omega_{*}$. Assuming a steady state inflation rate, $\pi_{*}=2$, we obtain the nominal return on capital, $R_{*}^{P}$. The parameter $\theta_{s}$ is then calibrated to the ratio of the $1993 \mathrm{q} 1-2007 \mathrm{q} 3$ average gross federal funds rate to $R_{*}^{P}$ thereby ensuring the model is consistent with the large deviation of money market interest rates and rates of return on physical capital. In steady state $\beta$ can be expressed as a function of $\delta_{0}, \delta_{1}, \omega_{\star}, z_{*}$ and a given value of $\gamma_{C}$. We estimate $\gamma_{C}$ along with the rest of the model's parameters using Bayesian methods and this yields a value for $\beta$. The calibrated parameter values and proximate targets are in Table 5.

Table 5: Calibrated Parameters

\begin{tabular}{lll}
\hline \hline Parameter & Targets & Value \\
\hline$\alpha$ & Capital's share of income & 0.4 \\
$s_{*}^{g}$ & Government + Net Exports' share of nominal GDP & 0.15 \\
$s_{*}^{i}$ & Investment's share of nominal GDP & 0.26 \\
$\delta_{0}$ & Capital:output ratio & 0.016 \\
$\pi_{*}^{g}$ & Government+net exports real price inflation & 1.0025 \\
$\omega_{*}$ & Investment real price inflation & 1.0037 \\
$z_{*}$ & Per capita real GDP growth & 1.0049 \\
$\theta_{s}$ & Nominal federal funds rate & 0.9867 \\
$\delta_{1}$ & Steady state function of capital:output ratio, $z_{*}$ and $\omega_{*}$ & 0.016 \\
$\beta$ & Steady state function of $\delta_{0}, \delta_{1}, \omega_{*}, z_{*}$ and $\gamma_{C}$ & 0.9862 \\
\hline \hline
\end{tabular}




\subsection{Bayesian Estimation}

We use Bayesian methods to estimate all the parameters except those fixed by the calibration described above (and a few others such as steady-state mark-ups) using the sample period 1993q1-2008q3, where the break-point is the last quarter before the federal funds rate attained is effective lower bound. For the second sample, 2008q4-2014q4, we hold fixed every calibrated parameter as well as the other parameter values we estimate using the first sample, except for those associated with the forward guidance signals and the variance of the inflation drift. We re-estimate the inflation drift's variance because the standard deviation of long run expected inflation in the second sample is many times smaller than it is in the first. ${ }^{33}$ To implement these methods we formulate the system of log linearized equilibrium conditions in state-space form with the equilibrium implied by the parameter values characterized by the state equation and the mapping from model variables to the data summarized by the measurement equation.

The measurement equations are as follows:

$$
\begin{aligned}
\Delta \ln Q_{t}^{o b s} & =f\left(\hat{c}_{t}, \hat{c}_{t-1}, \hat{i}_{t}, \hat{i}_{t-1}, \hat{g}_{t}, \hat{\omega}_{t}, \hat{\pi}_{t}^{g, o b s}\right) \\
\Delta \ln C_{t}^{o b s} & =z_{*}+\Delta \hat{c}_{t}+\hat{z}_{t} \\
\Delta \ln I_{t}^{o b s} & =z_{*}+\omega_{\star}+\Delta \hat{\imath}_{t}+\hat{z}_{t}+\hat{\omega}_{t} \\
\log H_{t}^{o b s} & =\hat{H}_{t} \\
\pi_{t}^{i, o b s} & =\omega_{*}+\hat{\omega}_{t}+\varepsilon_{t}^{i} \\
R_{t}^{o b s} & =R_{*}+\hat{R}_{t} \\
R_{t}^{j, o b s} & =R_{*}+E_{t} \hat{R}_{t+j}, j=1,2,3,4 \\
\pi_{t}^{40, o b s} & =\pi_{*}+\pi_{\star}^{40}+\frac{1}{40} \sum_{i=1}^{40} E_{t} \hat{\pi}_{t+i}+\varepsilon_{t}^{40, \pi} \\
\pi_{t}^{j, o b s} & =\pi_{*}+\pi_{*}^{j}+\beta^{\pi, j} \hat{\pi}_{t}+\gamma^{\pi, j} \pi_{t}^{d, o b s}+\varepsilon_{t}^{j, p}, \text { with } \beta^{\pi, 1}=1, j=1,2,3 \\
\Delta \ln w_{t}^{j, o b s} & =z_{*}+w_{*}^{j}+\beta^{w, j}\left(\hat{w}_{t}-\hat{w}_{t-1}+\hat{z}_{t}\right)+\varepsilon_{t}^{j, w}, \text { with } \beta^{w, 1}=1, j=1,2 \\
\pi_{t}^{d, o b s} & =\pi_{*}^{d}+\beta_{1,1} \pi_{t-1}^{d, o b s}+\beta_{1,2} \pi_{t-2}^{d, o b s}+\varepsilon_{t}^{d} \\
\pi_{t}^{g, o b s} & =\pi_{*}^{g}+\beta_{2,1} \pi_{t-1}^{g, o b s}+\beta_{2,2} \pi_{t-2}^{g, o b s}+\varepsilon_{t}^{g}
\end{aligned}
$$

The first equation is the log linearized version of (15) with the right hand side of that equation summarized by the linear function $f$. These measurement equations

\footnotetext{
${ }^{33}$ Throughout we calibrate the persistence of the inflation drift to $\rho_{\pi}=.99$.
} 
introduce some additional notation: $\pi_{t}^{j, o b s}$ correspond to the three inflation indicators discussed above; $w_{t}^{j, o b s}$ are the real counterparts to the nominal wage indicators discussed above, where these variables are measured by deflating the nominal wages

by core PCE; $\varepsilon_{t}^{i}, \varepsilon_{t}^{40, \pi}, \varepsilon_{t}^{j, p}$ and $\varepsilon_{t}^{j, w}$ denote classical measurement errors; $\varepsilon_{t}^{d}$ and $\varepsilon_{t}^{g}$ denote regression residuals; $\pi_{*}^{j}$ are constants that account for the average differences between the observable measures of inflation and inflation expectations and the model's steady state inflation; $\beta^{\pi, j}$ and $\gamma^{\pi, j}$ denote the factor loadings relating observable inflation to model inflation and observed consumer durable inflation; and $\beta i, j$ denote regression coefficients .

Notice that our estimation respects the lower bound on the policy rate. This is because we measure expected future rates in the model, the $E_{t} \hat{R}_{t+j}$, using the corresponding empirical futures rates, the $R_{t}^{j, o b s}$. Because our estimation forces basic NIPA data and interest-rate futures data to coexist, we expect the estimation to minimize any forward guidance puzzle.

\subsection{Estimation of Forward Guidance}

Our Bayesian estimation is similar to many other studies except that we introduce new methods to identify the forward guidance signals. These methods involve using changes in federal funds futures rates in one-day windows surrounding FOMC announcements, following the reduced form empirical literature, to centre a prior on our structural representation of the policy signals. Since we use data on expected future federal funds rates to identify the policy signals our methodology identifies forward guidance as interpreted by market participants. Consequently we have no way of identifying the FOMC's true intentions. However our approach has the advantage of ensuring that despite our model being linear our estimation of it enforces the effective lower bound.

To explain our methodology it is helpful to introduce some notation. Using $s_{t}$ to denote the model's state vector and $y_{t}$ to denote the vector of observables (the left hand side variables in the equations listed above) the log linearized solution of our model can be represented in state-space form with the following state and measurement equations:

$$
\begin{aligned}
& s_{t}=\Gamma_{0} s_{t-1}+\Gamma_{1} \varepsilon_{t}^{1}+\Gamma_{2} \varepsilon_{t}^{2} \\
& y_{t}=A+B s_{t}+C u_{t},
\end{aligned}
$$


where we have reordered the equations so the first $k+1$ rows of $s_{t}$ contain the quarterly averages of the current policy rate and the expectations of the policy rate in quarter $t+1, \ldots, t+k$. In the first (second) sample estimation $k$ equals four (ten) and these expectations are given by $E_{t} \hat{R}_{t+j}, j=1,2, \ldots, k$. We gather the current policy shocks and the $k$ signals revealed at period $t$ about the policy implemented in the next $k$ quarters into $\varepsilon_{t}^{1}$ (see also equation 10). Accordingly, the matrix $\Gamma_{1}$ has $k+1$ columns. The remaining structural (non-policy) shocks are contained in $\varepsilon_{t}^{2}$. Values of the economic model's structural parameters determine the matrices $\Gamma_{0}, \Gamma_{1}, \Gamma_{2}, A, B$ and $C$ and variance- covariance matrix of the shock processes.

To bridge forward guidance in the structural model with the event-study literature discussed in Section 2.1, we rely on the high frequency analysis of GSS. These authors document that the (intra-) daily changes in the current and expected federal funds rate, $\Delta_{\varepsilon} s_{t}^{(0: k)}$ with $\Delta_{\varepsilon}$ the first difference operator only for announcement dates, are well described by a two factor model

$$
\begin{aligned}
\Delta_{\varepsilon} s_{t}^{(0: k)} & =\Lambda f_{t}+u_{t} \\
E\left(\Delta_{\varepsilon} s_{t}^{(0: k)}\left[\Delta_{\varepsilon} s_{t}^{(0: k)}\right]^{\prime}\right) & =\Lambda \Omega \Lambda^{\prime}+\Sigma
\end{aligned}
$$

where $f_{t}$ are the two factors, $u_{t}$ the idiosyncratic errors, while the matrix $\Lambda$ contains the factor loadings and is of dimension $(k+1) \times 2$. Notice that the variance-covariance matrix of the data is then parsimoniously given as a function the loadings together with $\Omega$ and $\Sigma$, the variance-covariance matrices of factors and idiosyncratic errors, respectively.

The high frequency identification of forward guidance rests on the premise that signals about the future path of interest rates are communicated by the FOMC on announcement days with very little other news about the economy. While the evidence presented in Section 2.3 suggests the FOMC reveals private information about the state of the economy on announcement days, this Delphic guidance accounts for only a fifth of the variation in futures rates on announcement days, leaving room for the possibility that Odyssean guidance explains most of it. If our structural model were observed daily as well, and only Odyssean guidance were revealed on announcement days, the non-policy shocks $\left(\varepsilon_{t}^{2}\right)$ are zero and the state of the economy, $s_{t-1}$ is unchanged, such that from equation (16) the structural model 
for those days would imply

$$
\Delta_{\varepsilon} s_{t}^{(0: k)}=\Gamma_{1} \varepsilon_{t}^{1}
$$

Hence, embedding the GSS factor structure within our structural model would establish a clear mapping between the structural policy shocks $\varepsilon_{t}^{1}$ and the reducedform high frequency factors and idiosyncratic errors. To see this invert the above and plug it into (18) to obtain

$$
\varepsilon_{t}^{1}=\left[\Gamma_{1}^{-1} \Lambda\right] f_{t}+\Gamma_{1}^{-1} u_{t}
$$

and

$$
E\left(\varepsilon_{t}^{1} \varepsilon_{t}^{1 \prime}\right)=\Gamma_{1}^{-1} \Lambda \Omega \Lambda^{\prime} \Gamma_{1}^{\prime}+\Gamma_{1}^{-1} \Sigma\left(\Gamma_{1}\right)^{\prime}
$$

Put differently, with a daily structural model augmented to include a GSS factor structure we could use the reduced form estimates of the factor loadings and covariances directly to inform their model-based counterparts. Combined with our structural parameters, which pin down $\Gamma_{1}$, this would inform the transmission of forward guidance signals.

However, the structural model is cast at a quarterly frequency. Therefore, from one quarter to another non-policy shocks are realized as well, and most likely influence the expected path of policy through their impact on the expected path of the inflation and output gaps. It is also likely that additional forward guidance signals are communicated outside of announcement days. Consequently we do not expect equation (19) to hold exactly. Yet the nature of the high frequency identification suggests that estimates of $\Lambda, \Omega$ and $\Sigma$ using high frequency data should still be very informative about their model counterparts (even in the presence of Delphic guidance on announcement days.)

These considerations motivate our strategy for estimating the forward guidance signals. Specifically, in the first sample we estimate GSS's "target" and "path" factor model using changes in futures rates on announcement days and then use the resulting factor loadings to center a prior on $\Lambda, \Omega$ and $\Sigma$, which we now take to denote parameters of our business cycle model. We then estimate $\Lambda, \Omega$ and $\Sigma$ along with the model's other non-calibrated parameters. For the second sample we center 
the prior using a two factor model based on the sample period $2009 q 1-2014 q 4$. We use a different normalization of the factors for the ELB period since the funds rate target is essentially constant. ${ }^{34}$ The online appendix describes our high frequency estimation in detail.

Note that this strategy differs from the one implemented by Campbell et al. (2012). In that paper the factor structure is put directly on the forward guidance signals $\varepsilon_{t}^{1}$. Here the factor structure is put instead on the reduced form signals $\Gamma_{1} \varepsilon_{t}^{1}$. The current approach has two key advantages. First, we are able to tie our estimation more closely to the reduced form empirical literature. Second, an impulse to forward guidance is much easier to interpret. For example, an idiosyncratic reduced form signal about the funds rate $h$-quarters ahead does not engender an endogenous policy reaction immediately in the opposite direction to counteract the ensuing increases in the output and inflation gaps, as occurs with the analogous structural signal (see for example Del Negro et al. (2015) and Ben Zeev et al. (2015)). Instead it unleashes a vector of structural signals that ensures that in equilibrium only the expected policy rate $h$-quarters ahead changes with expected policy rates for $j$-quarters ahead, $j<h$, unchanged.

\subsection{Parameter estimates}

The resulting values of the model's key parameters (modes of the posterior distributions) are displayed in Table 6. Many of the parameter estimates are similar to those found in the literature, including small price and wage Phillips curve slopes, the parameters governing the model's real rigidities, and the magnitudes of the policy reaction function coefficients. Notice that the inferred value of the JR wealth effect parameter $\mu$ is .1 , much lower than the value of 1 that corresponds to the standard preference specification. Evidently the best fit of the data requires that the short run wealth effects on labor supply be much smaller than is typically assumed.

\footnotetext{
${ }^{34}$ Two factors account for $99.5 \%$ of the variance in the FOMC-day changes in futures rates over the second sample period and slightly less in the first sample.
} 
Table 6: Key Inferred Parameter Values

\begin{tabular}{llc}
\hline \hline Parameter & Description & Value \\
\hline$\delta_{2}$ & Utilization sensitivity to capital's rental rate & .026 \\
$\gamma_{C}$ & Coefficient of relative risk aversion & 0.92 \\
$\kappa_{p}$ & Price Phillips curve slope & .004 \\
$\kappa_{w}$ & Wage Phillips curve slope & .003 \\
$\mu$ & Wealth effect in preferences & .10 \\
$\iota_{p}$ & Lagged inflation's coefficient in price Phillips curve & .23 \\
$\iota_{p}$ & Lagged inflation's coefficient in wage Phillips curve & .80 \\
$\varrho$ & Habit coefficient & .80 \\
$\gamma_{H}$ & Labor supply elasticity & .57 \\
$S^{\prime \prime}(1)$ & Investment adjustment costs & 5.03 \\
$\psi_{1}$ & Taylor inflation gap elasticity & 1.76 \\
$\psi_{2}$ & Taylor output gap elasticity & .43 \\
$\rho_{R}$ & Interest rate smoothing & .78 \\
$\rho_{b}$ & Discount rate shock serial correlation & .81 \\
$\rho_{g}$ & Government spending shock serial correlation & .90 \\
$\rho_{s}$ & Liquidity preference shock serial correlation & .86 \\
$\rho_{i}$ & Investment demand shock serial correlation & .70 \\
$\rho_{\omega}$ & Investment technology growth serial correlation & .35 \\
$\rho_{\nu}$ & Neutral technology growth serial correlation & .60 \\
\hline \hline
\end{tabular}

\section{The estimated model}

This section describes our estimated model. Our objective is to establish its plausibility as a tool for performing counterfactual policy experiments. To accomplish this we study the estimated model's implications for the sources of business cycle fluctuations; the dynamics of the inflation and output gaps; and the shocks underlying the 2001 recession and the Great Recession.

\subsection{Source of business cycle variation}

The sources of business cycle variation in key aggregate variables for the sample 1993q1-2007q3 are shown in Table 7. Technology shocks (neutral and investmentspecific) play a prominent role in explaining fluctuations in all the real variables. Liquidity preference shocks are the prime driver of hours and discount factor shocks play a similar role for consumption. The markup shocks are included in the "All 
other" category. They are essentially irrelevant for real activity. However price markup shocks account for more than $50 \%$ of inflation fluctuations. Finally, forward guidance shocks explain just $16 \%$ of the business cycle variation in the funds rate. This suggests our estimated model does not display an empirical forward guidance puzzle.

Table 7: Percent of Variation at Business Cycle Frequencies by Shock

\begin{tabular}{lcccccc}
\hline \hline & \multicolumn{5}{c}{ Shocks } \\
\cline { 2 - 7 } Variable & Technology & $\begin{array}{c}\text { Liquidity } \\
\text { preference }\end{array}$ & $\begin{array}{c}\text { Investment } \\
\text { demand }\end{array}$ & $\begin{array}{c}\text { Discount } \\
\text { rate }\end{array}$ & $\begin{array}{c}\text { Policy } \\
\text { other }\end{array}$ \\
\hline GDP & .65 & .15 & .10 & .02 & .02 & .06 \\
Consumption & .24 & .24 & .01 & .45 & .04 & .02 \\
Investment & .54 & .07 & .23 & .09 & .01 & .06 \\
Hours & .37 & .47 & .02 & .00 & .07 & .09 \\
Inflation & .14 & .03 & .15 & .10 & .00 & .58 \\
Fed. funds rate & .11 & .41 & .15 & .07 & .16 & .10 \\
\hline \hline
\end{tabular}

Note: The technology shock category includes neutral and investment-specific shocks.

Most variation in the model is explained by the four shocks to the discount factor, investment-demand, liquidity preference, and neutral technology. To get a better sense of why this is so consider Figures 4 and 5. Figures 4 displays responses of GDP, consumption, investment and hours to one standard deviation impulses to these shocks. The units of the responses are percentage point deviations from steady state at an annual rate. The figure demonstrates that business cycle co-movement is induced by the technology and liquidity preference shocks only. These shocks induce relatively large responses of all the variables. The responses to the liquidity preference shock indicate that periods of unexpected high demand for government bonds coincide with contractions in real activity. The discount factor shock induces large movements in consumption and investment in opposite directions with very little impact on GDP and hours. The investment demand shock has little impact on consumption and hours, somewhat large effects on GDP and very large effects on investment.

Figure 5 shows how inflation and the funds rate respond to the four main shocks (the funds rate is measured in percentage points so a response of .01 corresponds to 1 basis point.) The small responses of inflation reflects the small value of the 
Figure 4: Impulse responses of activity variables to main business cycle shocks
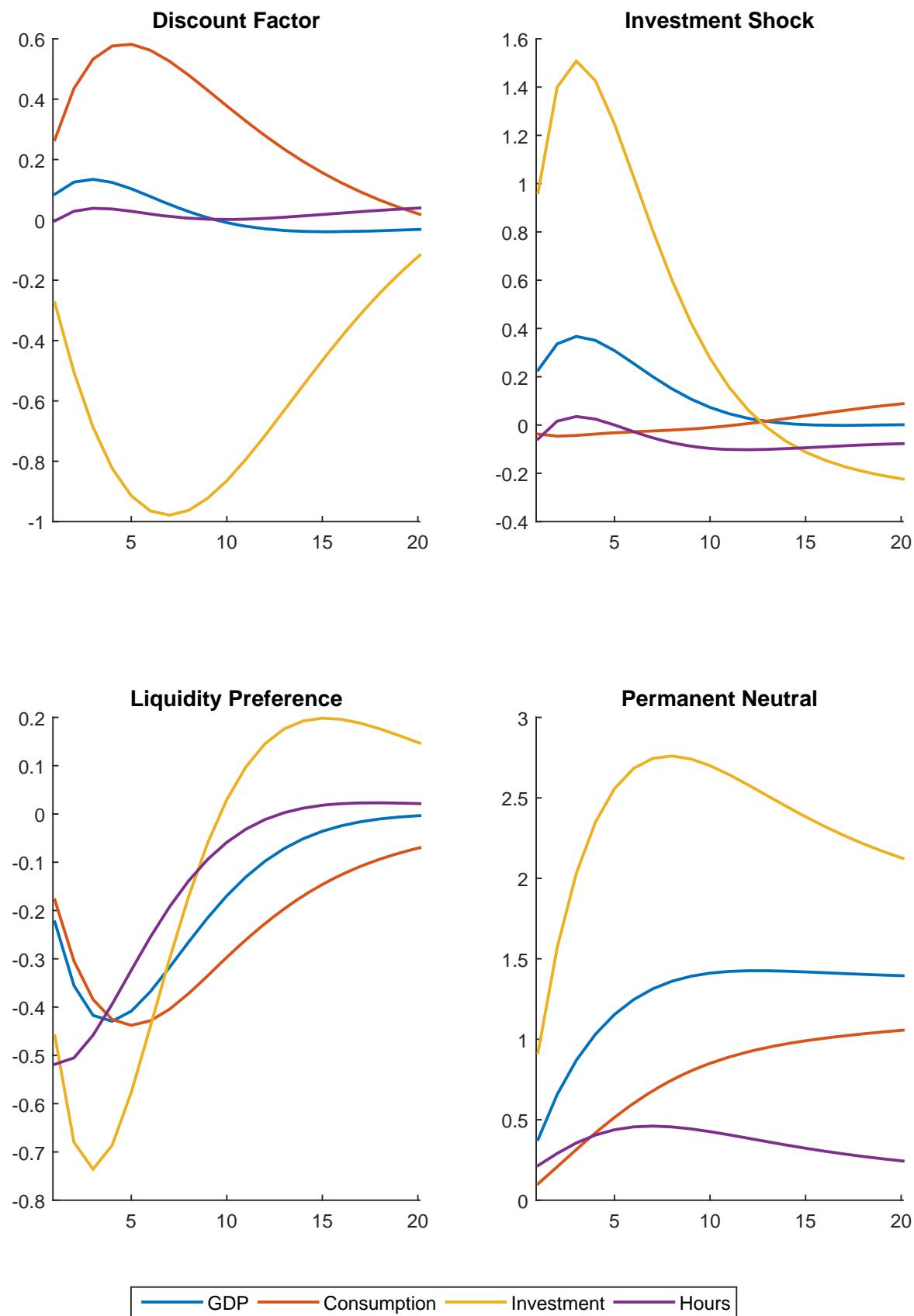

price-Phillips curve slope. Notice that the funds rate falls in the aftermath of a positive technology shock. This mainly reflects the fact that the output's short run response is smaller than its long run one due to the model's real rigidities so that the output gap turns negative initially. The liquidity preference shock induces the 
Figure 5: Responses of nominal variables to main business cycle shocks
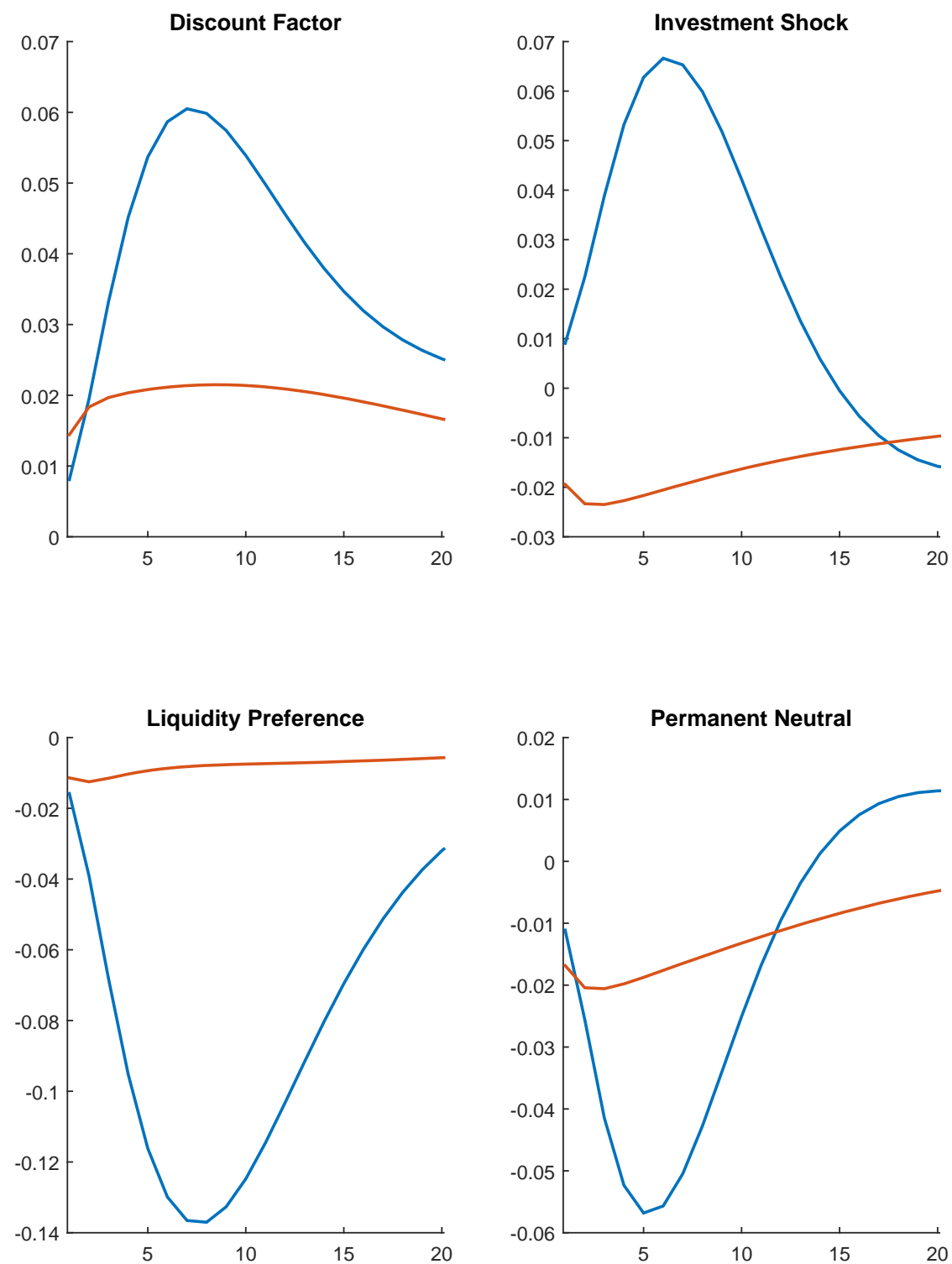

Fed Funds Rate $\longrightarrow$ Model Inflation

largest movements in the funds rate. The funds rate drops to accommodate an increase in the demand for government bonds.

Figure 6 shows how GDP, inflation and the funds rate respond to one standard deviation innovations to each of the two forward guidance factors and too idiosyncratic shocks to the 1q-ahead and 4q-ahead federal funds futures rates. In the first sample we normalize the factors as in GSS: the "path" factor does not 
Figure 6: Responses to forward guidance shocks
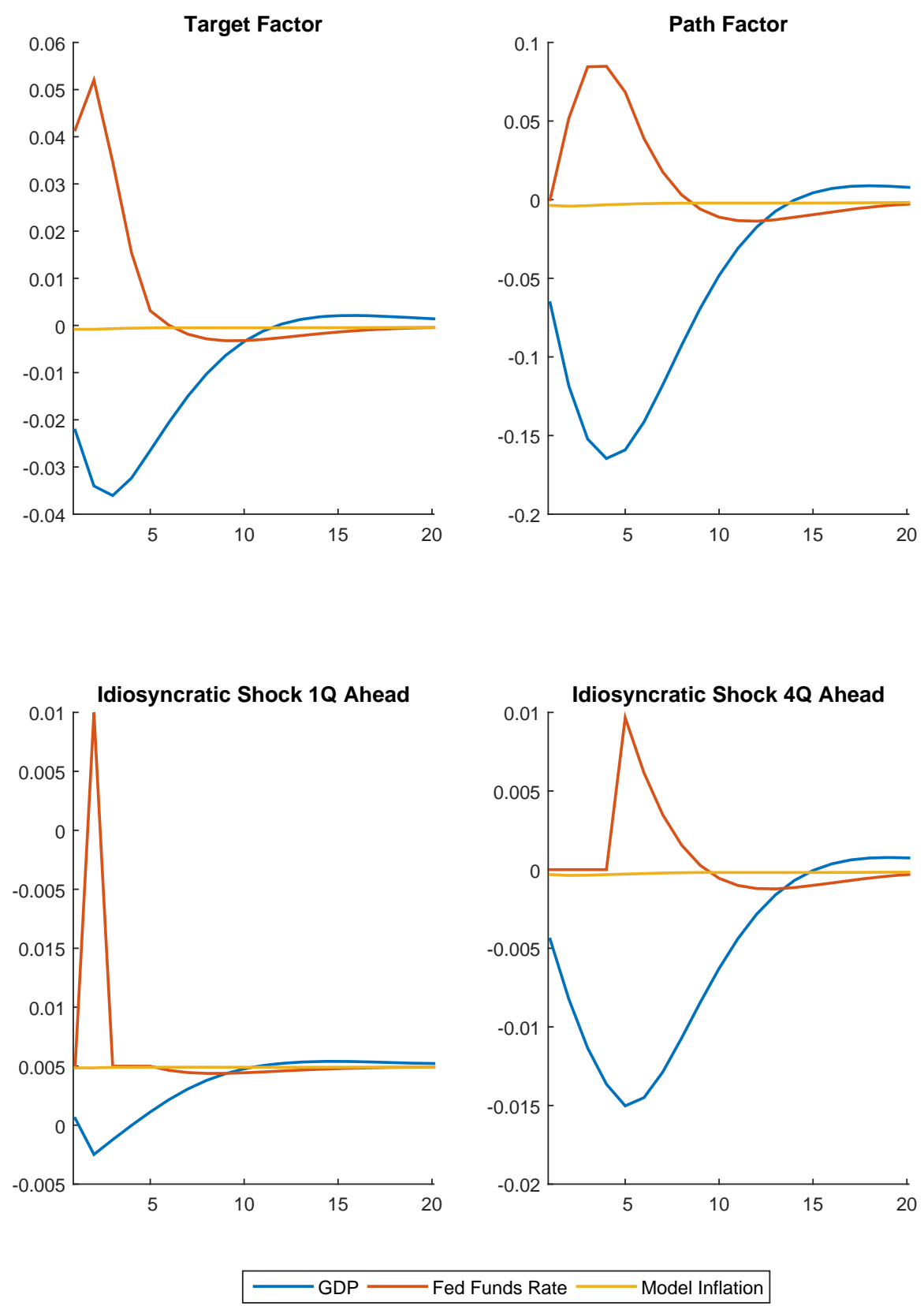

impact the current funds rate while the "target" factor does. The nature of these shocks is to unleash a sequence of forward guidance signals such that the equilibrium path of the funds rate is as stipulated by the factor structure. At the conclusion of the guidance the endogenous component of the rule is the sole driver of policy. The figure demonstrates that when the funds rate is expected to be above the 
level stipulated by the policy rule output and inflation decline although inflation's response is very small due to the relative flat price-Phillips curve.

The responses to the idiosyncratic forward guidance shocks displayed in Figure 6 are particularly informative. The idiosyncratic shocks correspond to a binding commitment by the central bank to not change rates for $k-1>0$ quarters, then increase the policy rate in quarter $k$, after which rates follow the rule. Like the shocks to the factors the idiosyncratic shocks unleash a sequence of signals that yield the funds rate paths in the plots as equilibrium outcomes. The 4q-ahead idiosyncratic shock is roughly the same size as the 1q-ahead shock, but it is also delayed by 4 quarters. As expected this delay leads to a larger response of GDP compared to the 1q-ahead shock, but the response is very small reflecting the small size of the shock.

\subsection{The dynamics of the inflation and output gaps}

Figure 7 shows core PCE inflation (orange) and the path of core PCE inflation implied by the model's inflation drift shock alone (blue). By constraining the drift to be close to a random walk the model is able to account for the low frequency trend in inflation. The difference in the two variables closely corresponds to the model's inflation gap. This was negative in the early part of the sample and positive later on. These dynamics to some extent rationalize the path of the fed funds rate over this period. Note that the drift shock is pinned down by the long run inflation survey expectations and the relatively high level of the blue line early on reflects the lag in expectations relative to realized inflation.

Figure 7: Contribution of Inflation Drift Shocks to PCE Core inflation

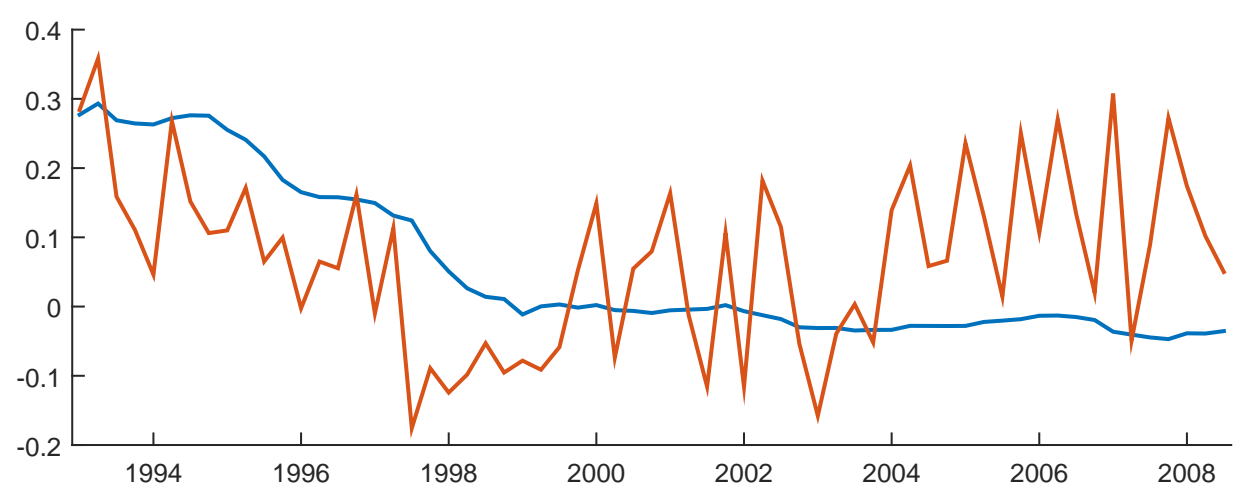

Note: Blue $=$ drift, Orange $=$ core PCE. Quarterly rates relative to steady state. 
Figure 8: Model and CBO output gaps with hours, 1993q1-2008q3

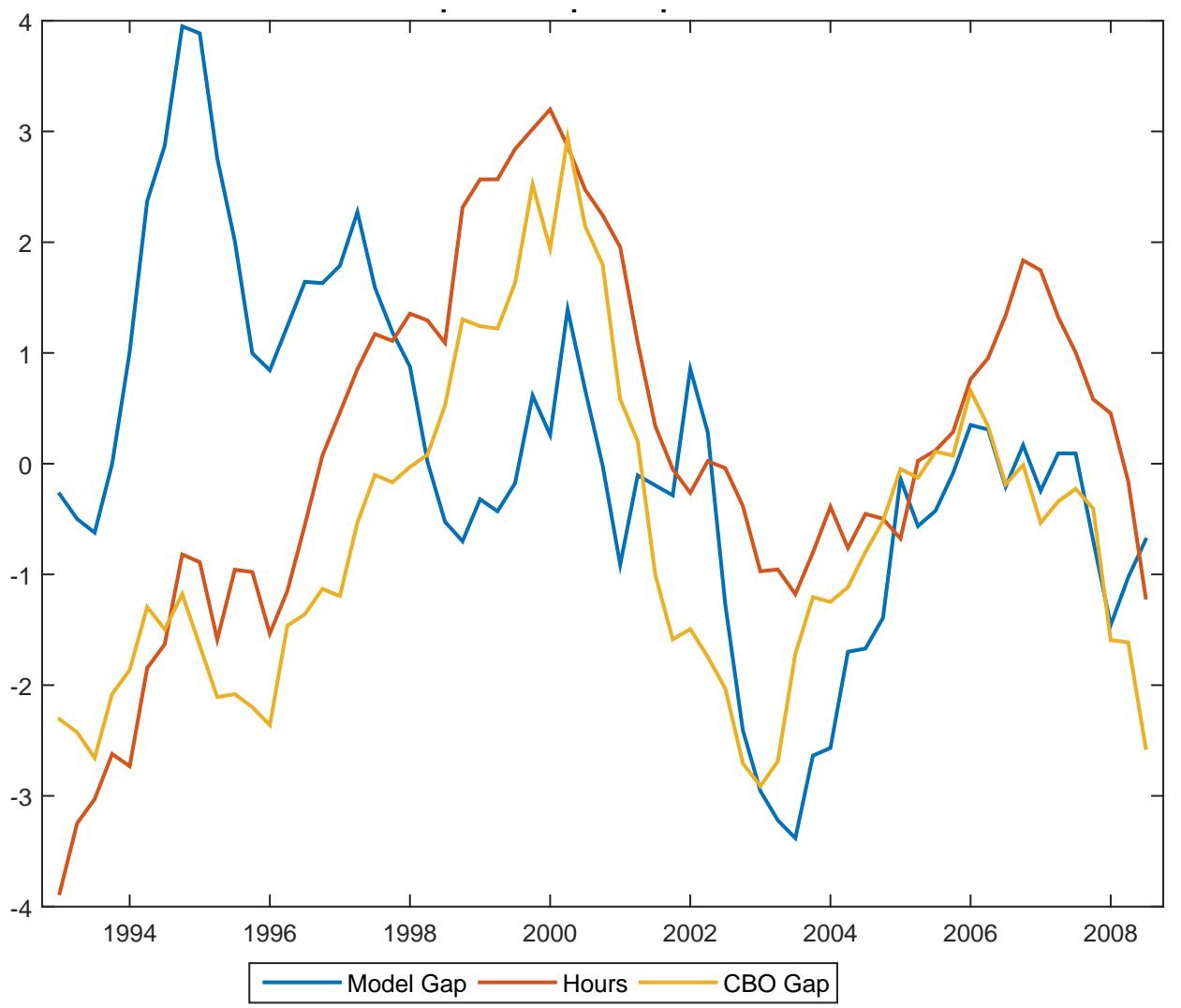

Note: Gaps are in percentage point deviations from stochastic trend and potential. Hours is deviation from steady state.

Figure 8 shows the model's output gap (deviation of output from its stochastic trend) along with the CBO output gap and our measure of hours. Hours and the CBO gap have similar dynamics. The model gap follows the contours of hours and the CBO gap after 1999. Before 1999 the model's gap is substantially larger than both hours and the CBO gap. The large positive model gap in 1994 is consistent with the FOMCs concerns about inflation during that time. Notice that after the 2001 recession the CBO and model gap follow each other quite closely. In both cases the expansion in the 2000s is not interpreted to have brought the economy much above its potential. The plausibility of the dynamics of the model gap in our view lend credibility to our estimated model. 
Figure 9: Shocks' contributions to 2001 recession
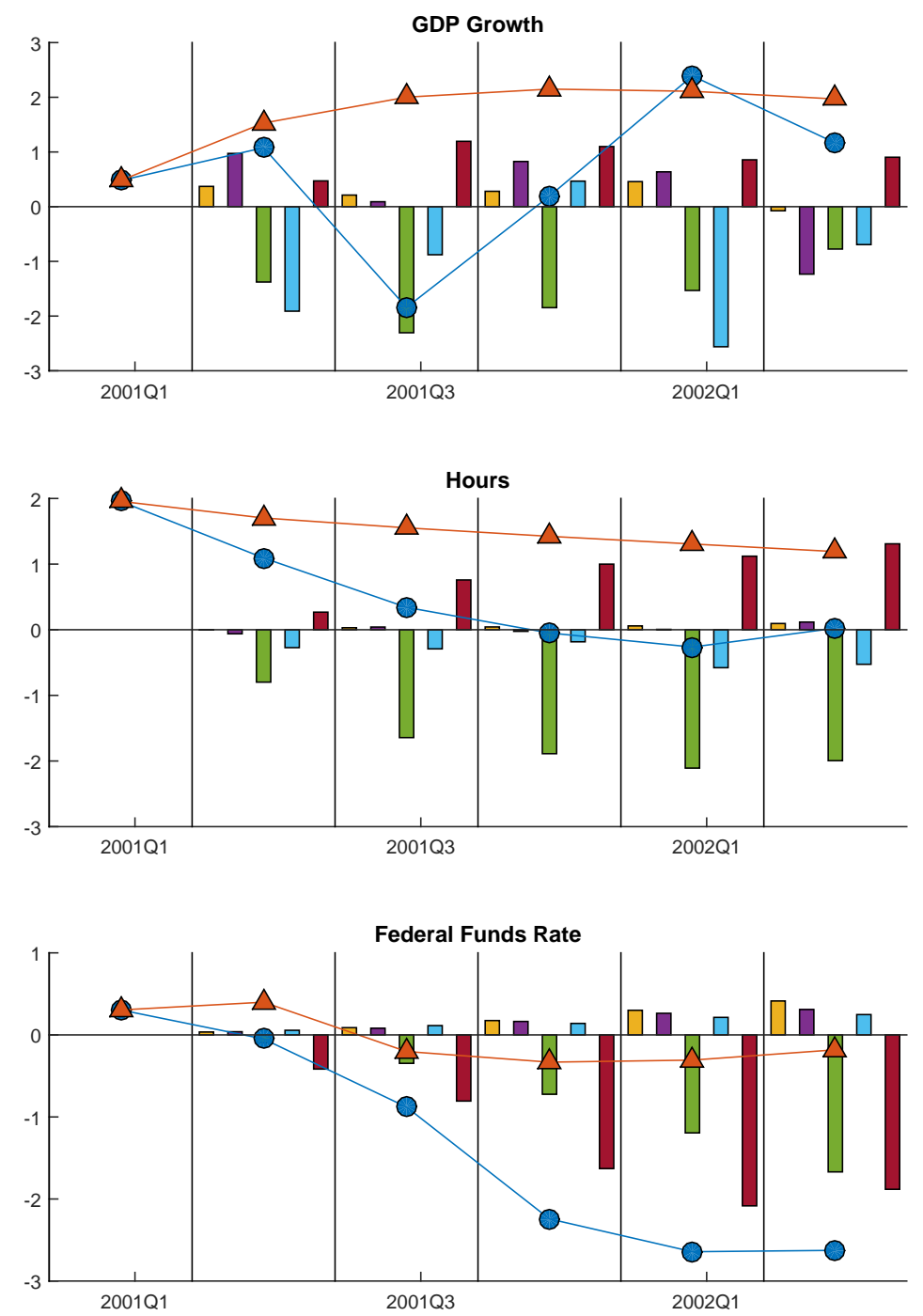

$\square$ Discount Factor $\square$ Investment Shock $\square$ Liquidity Preference $\square$ Permanent Neutral $\square$ Policy - Data $\triangle$ Forecast

Note: GDP growth is quarterly deviation from steady state at an annual percentage rate; hours is percentage point deviation from steady state; and the funds rate is displayed as deviation from its steady state at an annual rate.

\subsection{Forecast error decompositions of the last two recessions}

Figure 9 plots forecast error decompositions of GDP growth, hours and the funds rate, conditional on the NBER business cycle peak in 2001q1 running through 
to $2002 \mathrm{q} 1 .^{35}$ The red triangles indicate the conditional forecast; the blue dots correspond to actual outcomes; and the bars indicate the contribution of shocks to the forecast error. The contributions do not add up to the forecast error since we only consider a subset of the model's shocks. At the business cycle peak the model forecasts GDP growth to rise above its steady state, hours to remain high, and hardly any movement in the funds rate. As realized output and hours come in lower than expected the funds rate drops sharply. Negative neutral technology and an increase in the demand for government bonds drove the recession with liquidity preference shocks driving most of the declines in hours.

Figures 10 and 11 plot forecast error decompositions corresponding to the Great Recession. We split this decomposition into two parts because of the sample split in our estimation and the length of the recession. The decomposition in Figure 10 is conditioned on the state of the economy as of the NBER business cycle peak in 2007q3. Interestingly in the early part of the recession output and hours did not come in sharply below the forecast. Later on they do. The unanticipated declines in output and hours are more than explained by sharp increases in the demand for government bonds as well as negative neutral technology shocks. ${ }^{36}$ The contribution of forward guidance is indicated by the "Policy" bar. According to the model, past and present forward guidance boosted output and hours but its effects were much too small to prevent the recession from gaining momentum.

Figure 11 is conditioned on the state of the economy as of 2008q4. Output growth is forecasted to drop sharply in 2009q1 before moving back to steady state. Interestingly this is about as it turned out. Hours is forecast to stay below steady state, but came in much worse. An outward shift in the demand for government bonds is the major factor pulling down output and hours. With output there are offsetting shocks. The forecast decomposition suggests forward guidance is a substantial drag on the economy starting in 2009q2. Essentially the market's expectations of future funds rates is steeper than predicted by the policy rule alone. This finding is reflected in our counterfactual analysis discussed below.

It is instructive to compare this decomposition of the Great Recession to the one

\footnotetext{
${ }^{35}$ We do not include inflation in this figure because it varies little relative to the forecast and most of the forecast errors are due to price markup shocks.

${ }^{36}$ In 2008q3 these two shocks' contributions to the decline in GDP are very large. Had it not been for large positive contributions to GDP from government spending plus net exports and its real price, GDP would have plummeted much faster.
} 
Figure 10: Shocks' contributions to Great Recession, part I
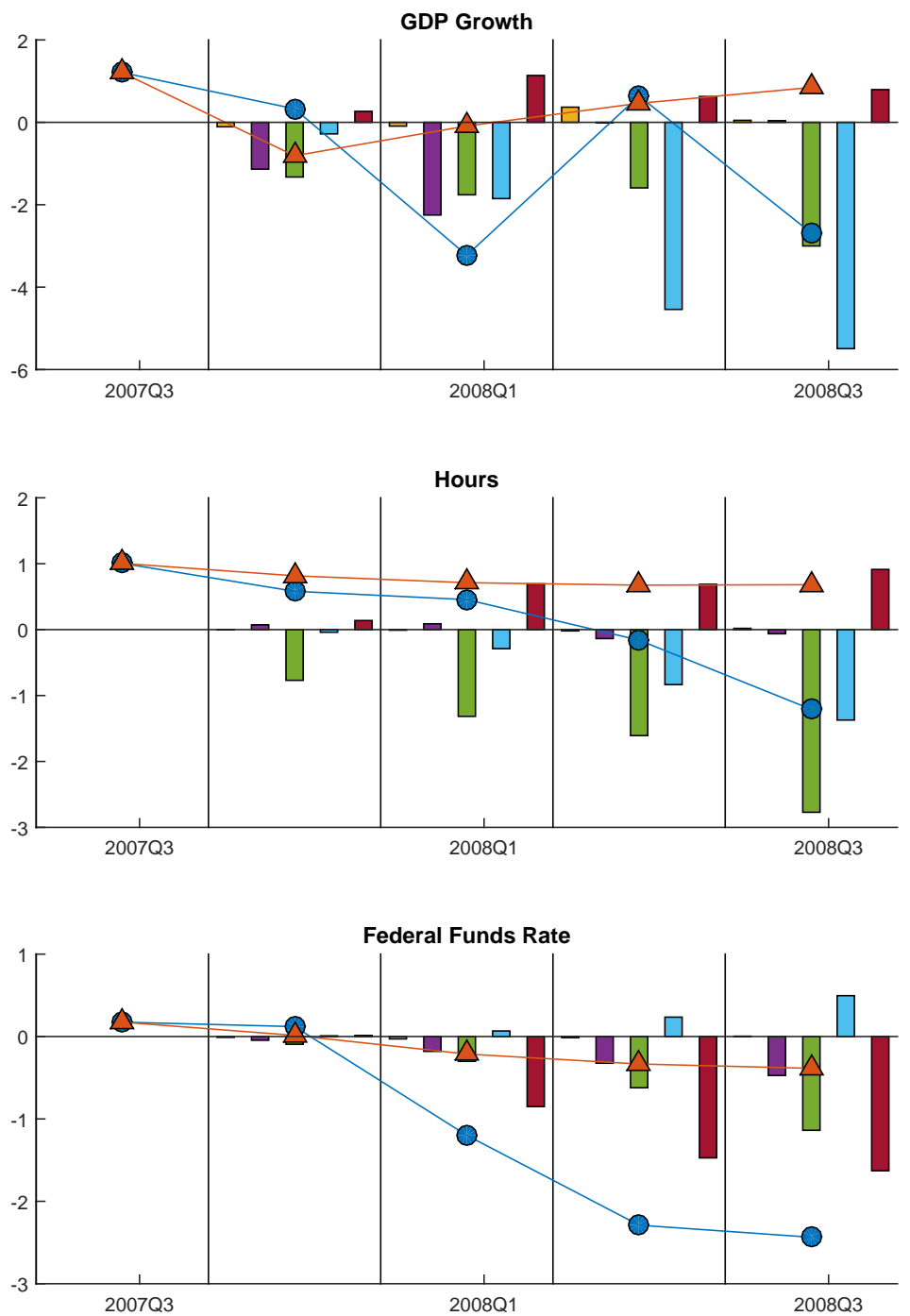

$\square$ Discount Factor $\square$ Investment Shock $\square$ Liquidity Preference $\square$ Permanent Neutral $\square$ Policy - Data $\triangle$ Forecast

Note: GDP growth is quarterly deviation from steady state at an annual percentage rate; hours is percentage point deviation from steady state; and the funds rate is displayed as deviation from its steady state at an annual rate.

calculated in Christiano, Eichenbaum, and Trabandt (2015). Their model attributes a large portion of the Great Recession to a "consumption wedge" and a "financial wedge." The consumption wedge enters their model in the same way as our liquidity 
Figure 11: Shocks' contributions to Great Recession, part II
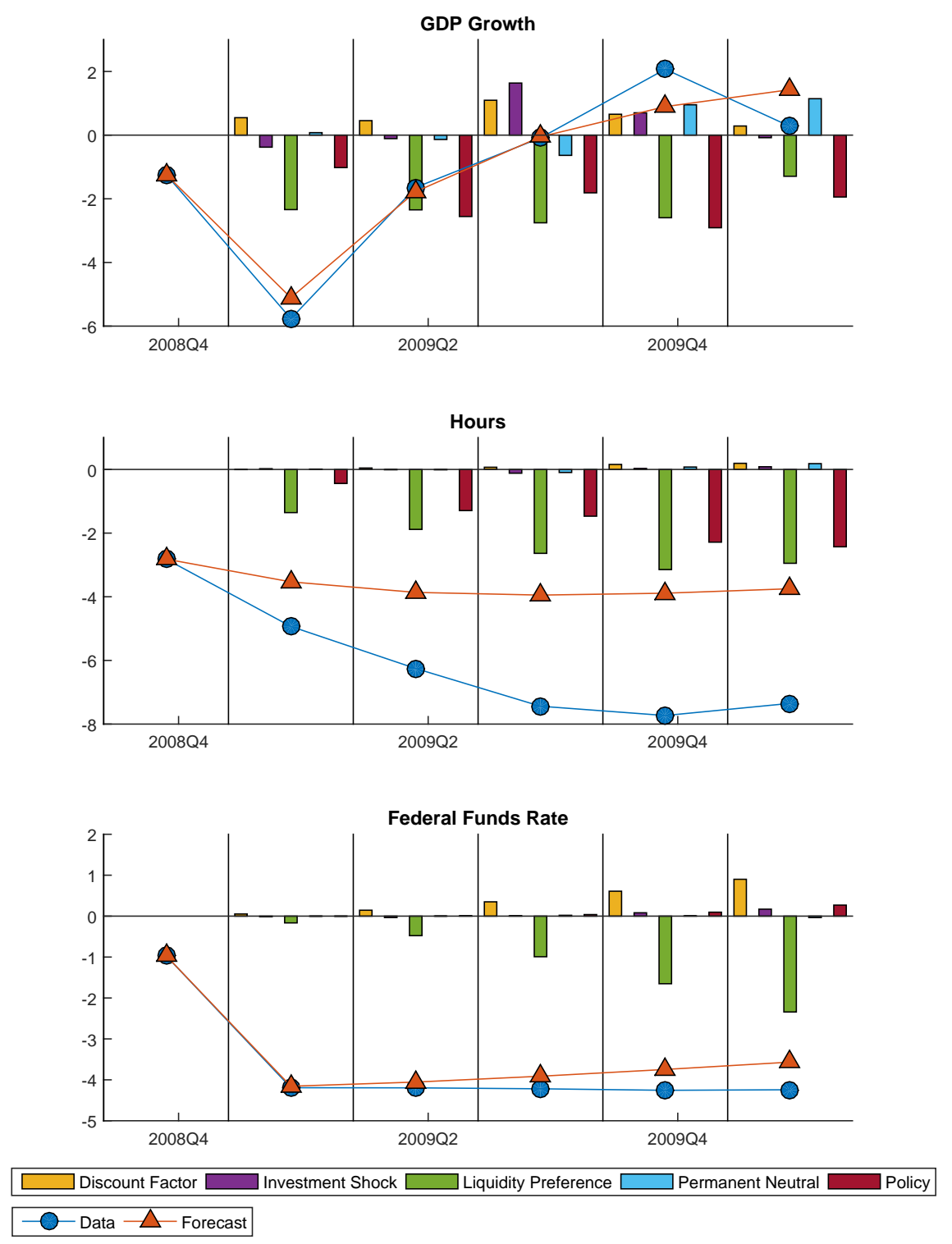

Note: GDP growth is quarterly deviation from steady state at an annual percentage rate; hours is percentage point deviation from steady state; and the funds rate is displayed as deviation from its steady state at an annual rate.

preference shock. The financial wedge enters as the discount factor does in the investment Euler equation in our model. However their financial wedge, unlike our discount factor shock, does not appear in the consumption Euler equation. 
These differences notwithstanding the discount and liquidity preference shocks in our framework span the same space as the two wedges in Christiano et al. (2015). Since the discount rate appears in both the consumption and investment Euler equations our "wedges" are correlated. In the end we attribute the onset of the Great Recession mostly to the liquidity preference shock while Christiano et al. (2015) attribute it mostly to the financial wedge. Their result derives from calibrating the financial wedge to the bond spread estimated by Gilchrist and Zakrajšek (2012). The consumption wedge is essentially a residual. Another difference in our decompositions is that Christiano et al. (2015) do not use data on federal funds rate futures to inform their analysis.

\section{Counter-factual policy analysis}

For the evaluation of recent monetary policy, we compare outcomes from the data with counterfactual outcomes from a version of the model without forward guidance. Our model is linear, and we use shocks to expected future interest rates both to provide forward guidance and to enforce the zero lower bound on expected future interest rates. This presents a technical challenge: How do we remove the guidance while enforcing the effective lower bound? Our solution is to replace the policy signals identified from the data with those chosen by a policy maker who wishes to

minimize deviations from the estimated interest-rate rule subject to never violating the effective lower bound. We begin this section by describing how we do this and then we discuss our findings from implementing the methodology. We conclude this section by demonstrating that our findings do not reflect Del Negro et al. (2015)'s forward guidance puzzle.

\subsection{Methodology}

Our model after being solved can be represented in linear state-space form summarized by equations (16) and (17). Estimated values of the economic model's structural parameters determine the matrices $\Gamma_{0}, \Gamma_{1}, \Gamma_{2}, A, B$ and $C$ in those equations as well as the variance and covariance matrices of the shock processes. With these objects and the observed data in hand, we can apply the Kalman smoother to recover estimates of $s_{t}, \varepsilon_{t}^{1}, \varepsilon_{t}^{2}$, and $u_{t}$. We wish to construct a 
counterfactual series for the observables $y_{t}$ based on the model economy being confronted with the same sequence of non-monetary shocks, $\varepsilon_{t}^{2}$, but in which the monetary authority replaces $\varepsilon_{t}^{1}$ with those chosen to minimize deviations from the estimated interest-rate rule subject to never violating the effective lower bound. We accomplish this as follows.

To begin we normalize the starting date of our calculations to $t=0$. In period 0 the state equations for the current and expected policy rate are

$$
s_{0}^{(0: k)}=\Gamma_{0}^{(0: k)} s_{-1}+\Gamma_{1}^{(0: k)} \varepsilon_{0}^{1}+\Gamma_{2}^{(0: k)} \varepsilon_{0}^{2} .
$$

If the effective lower bound was not a constraint, it would be feasible to replace $\varepsilon_{0}^{1}$ with a vector of zeros. We call this path for interest rates the Taylor Ideal Path (TIP), because the interest rate path would fit the policy rule exactly at all horizons. Consider the problem of choosing $\bar{\varepsilon}_{0}^{1}$ to minimize the distance between the counterfactual path of interest rates and the TIP subject to the feasibility constraint that the interest rate for the current and the $k$ future quarters are no less than the effective lower bound. Since the difference between the counterfactual interest rate path and the TIP equals $\Gamma_{1}^{(0: k)} \varepsilon_{0}^{1}$, the program can be written as

$$
\min _{\varepsilon_{0}^{1}} \varepsilon_{0}^{1 \prime} \Gamma_{1}^{(0: k) \prime} \Gamma_{1}^{(0: k)} \varepsilon_{0}^{1}
$$

subject to the feasibility constraint: $\Gamma_{0}^{(0: k)} s_{-1}+\Gamma_{1}^{(0: k)} \varepsilon_{0}^{1}+\Gamma_{2}^{(0: k)} \varepsilon_{0}^{2} \geq .125 / 4 .{ }^{37}$ Here, $s_{-1}$ and $\varepsilon_{0}^{2}$ come from the application of the Kalman smoother to the estimated model. Since the objective is quadratic and the constraint set is convex, this problem has a connected set of solutions and generically we expect the solution to be unique. We hypothesize that if the submatrix $\Gamma_{1}^{(0: k)}$ is full rank, then the solution is unique. Denote this unique solution with $\bar{\varepsilon}_{0}^{1}$. Given this we obtain $\bar{s}_{0}=\Gamma_{0} s_{-1}+\Gamma_{1} \bar{\varepsilon}_{0}^{1}+\Gamma_{2} \varepsilon_{0}^{2}$ from the state equations.

In period 1 , we choose $\varepsilon_{1}^{1}$ to solve the programming problem analogous to that above in (20) with $\bar{s}_{0}$ replacing $s_{-1}$ and $\varepsilon_{1}^{2}$ replacing $\varepsilon_{0}^{2}$ in the feasibility constraint. We denote this programming problem's solution as $\bar{\varepsilon}_{1}^{1}$, and we use it to obtain $\bar{s}_{1}=\Gamma_{0} \bar{s}_{0}+\Gamma_{1} \bar{\varepsilon}_{1}^{1}+\Gamma_{2} \varepsilon_{1}^{2}$ from the state equations (16). Continuing this recursively until

\footnotetext{
${ }^{37}$ The lower bound is the midpoint of the annualized 0-25 basis point range targeted by the FOMC over the second sample expressed at a quarterly rate.
} 
the end of the sample yields $\bar{\varepsilon}_{t}^{1}$ and $\bar{s}_{t}$ for $t=\{0, \ldots, T\}$. We call the corresponding sequence of interest rates the Taylor Maximum Fidelity Path (TMFP).

We can calculate an alternative path for our observables given the TMFP using the measurement equations (17): $\bar{y}_{t}=A+B \bar{s}_{t}+C u_{t}$. The difference between the actual data $y_{t}$ and the Taylor Maximum Fidelity Outcomes $\bar{y}_{t}$ captures the effects of forward guidance. We study this counterfactual policy using the non-monetary shocks identified using the Kalman smoother over the sample period 2008q4-2014q4 after re-estimating forward guidance and the inflation drift variance over this period as described in Section 4.4.

\subsection{Results}

Since they underly our identification of forward guidance in the second sample, and therefore the non-monetary shocks during that period as well, we begin by considering the empirical future funds rate term structures over the period 20092014. ${ }^{38}$ Figure 12 shows the empirical futures paths quarterly and by year. Through 2009 market participants saw liftoff around the corner. Starting in 2010 the expected duration of being at the lower bound extended a bit but liftoff was still seen as a few quarters hence at most. By the end of 2011, as the economy appeared to deteriorate, the futures path changed dramatically: the funds rate was expected to stay near zero through most of 2013. This change in expectations occurred around the time calendar-based guidance was introduced into the FOMC's postmeeting statement in August 2011. The statement language changed from the June meeting's "The Committee continues to anticipate ... exceptionally low levels for the federal funds rate for an extended period" (emphasis added) to "The Committee currently anticipates ... exceptionally low levels for the federal funds rate at least through mid-2013" (emphasis added).

Figure 13 shows the empirical values of the current and federal funds futures rates from 1q to $10 \mathrm{q}$ ahead along with their TMFP counterparts over the second

\footnotetext{
${ }^{38}$ As emphasized in footnote 1, page I-2 of the January 22, 2009 Greenbook, the ELB complicates inference about market expectations of the federal funds rate path. With the nominal federal funds rate at its effective lower bound, the probability distribution for future short-term interest rates is skewed to the upside. Thus, even though the market's modal forecast may be that the federal funds rate will remain close to zero for some time, its mean forecast is likely to be increasingly above zero as the forecast horizon increases, because the odds of "lifting off" from the zero lower bound increase with time.
} 
Figure 12: Empirical fed funds futures term structure quarterly, 2009-2014
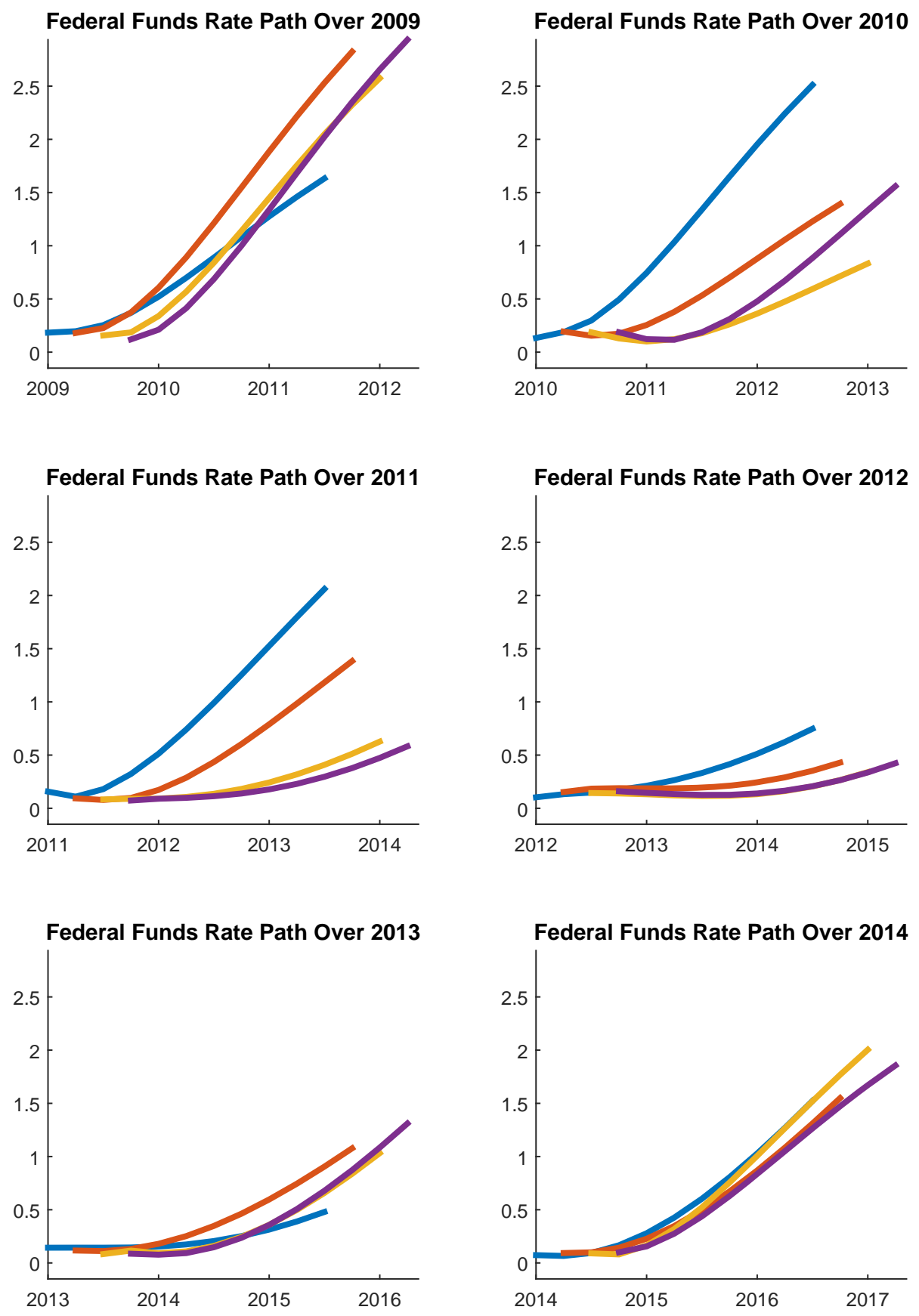

sample. Notice that except for a small deviation in 2009 the current funds rates are almost identical under the two scenarios. Any differences in policy are reflected in 
Figure 13: Actual and TMFP federal funds rates
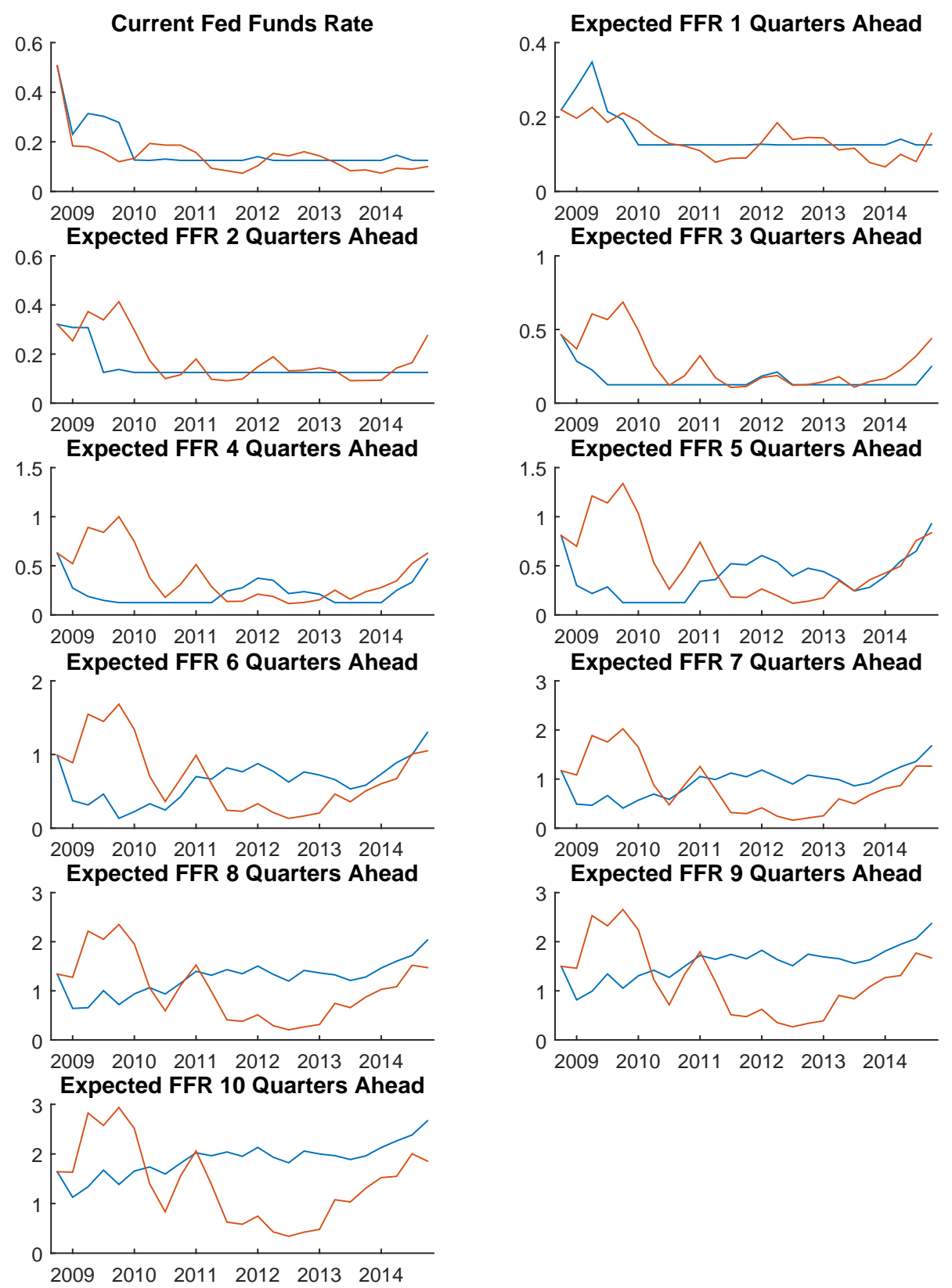

Taylor Maximum Fidelity Path $\longrightarrow$ Observed

the forward guidance. Before 2011 the TMFP is more accommodative than markets expected. For example in 2010q4 the TMFP is at or very near the effective lower 
bound 6 quarters ahead. Only starting in mid 2011 does the market path fall below the TMFP. Substantial differences begin appearing 5 quarters out with the largest differences at the longer horizons.

At a conceptual level the forward guidance path in the data differs from the TMFP for two reasons. First, the FOMC might have wished to differ from the TMFP. In this case, the FOMC and public were in sync. Second, the FOMC might have miss-communicated its intentions to the public. Since we only examine market data, we cannot distinguish between these two hypotheses. However it appears that forward guidance as "heard" by market participants was tighter than that which would have arisen from a perfectly credible policy rule estimated with data from before the financial crisis subject to the ELB constraint. Interestingly while the TMFPs are more accommodative than expected by market participants in 2009-2010 they are less accommodative than assumed by the Board staff in the projections submitted to the FOMC during that period. ${ }^{39}$ At this stage it is an open question whether the FOMC intended to communicate the market path or something in between the Board staff's projection and the market path such as the TMFP path. ${ }^{40}$

Figure 14 shows how the differences in the two expected paths for the funds rate translate into differences in macroeconomic outcomes. By these measures the forward guidance interpreted by markets from FOMC communications lead to worse outcomes than under the TMFP. This is consistent with the more accommodative guidance early on in the TMFP case (and our forecast decomposition of the Great Recession discussed above). From this perspective it would have been more effective for the Fed to communicate that it would be adhering quite closely to its historical policy rule and lifting off when that rule dictated doing so.

Toward the end of 2011 the Fed seems to have found its communications legs. By communicating that its policy would be looser than dictated by the rule alone it achieved more favorable outcomes than would have been the case otherwise.

\footnotetext{
${ }^{39}$ This conclusion is based on an examination of publicly available Greenbooks and Tealbooks. See for example page II-2 of Greenbook Part 1, December 9, 2009 and page 2 of 100 in Tealbook A, December 8, 2010. Documents produced by the Board staff for later FOMC meetings are unavailable to us as we write due to their 5 year publication lag. We thank Narayana Kocherlakota for highlighting the value of comparing Board staff forecasts to the market path in his discussion of the conference draft of this paper in which we did not make such a comparison.

${ }^{40}$ This paragraph is motivated by Narayana Kocherlakota's discussion of the conference draft of this paper. In that discussion he emphasized the distinction between the market path of interest rates and what the FOMC intended to communicate. The conference draft was silent on this issue.
} 
Figure 14: Actual and Taylor Maximum Fidelity Outcomes
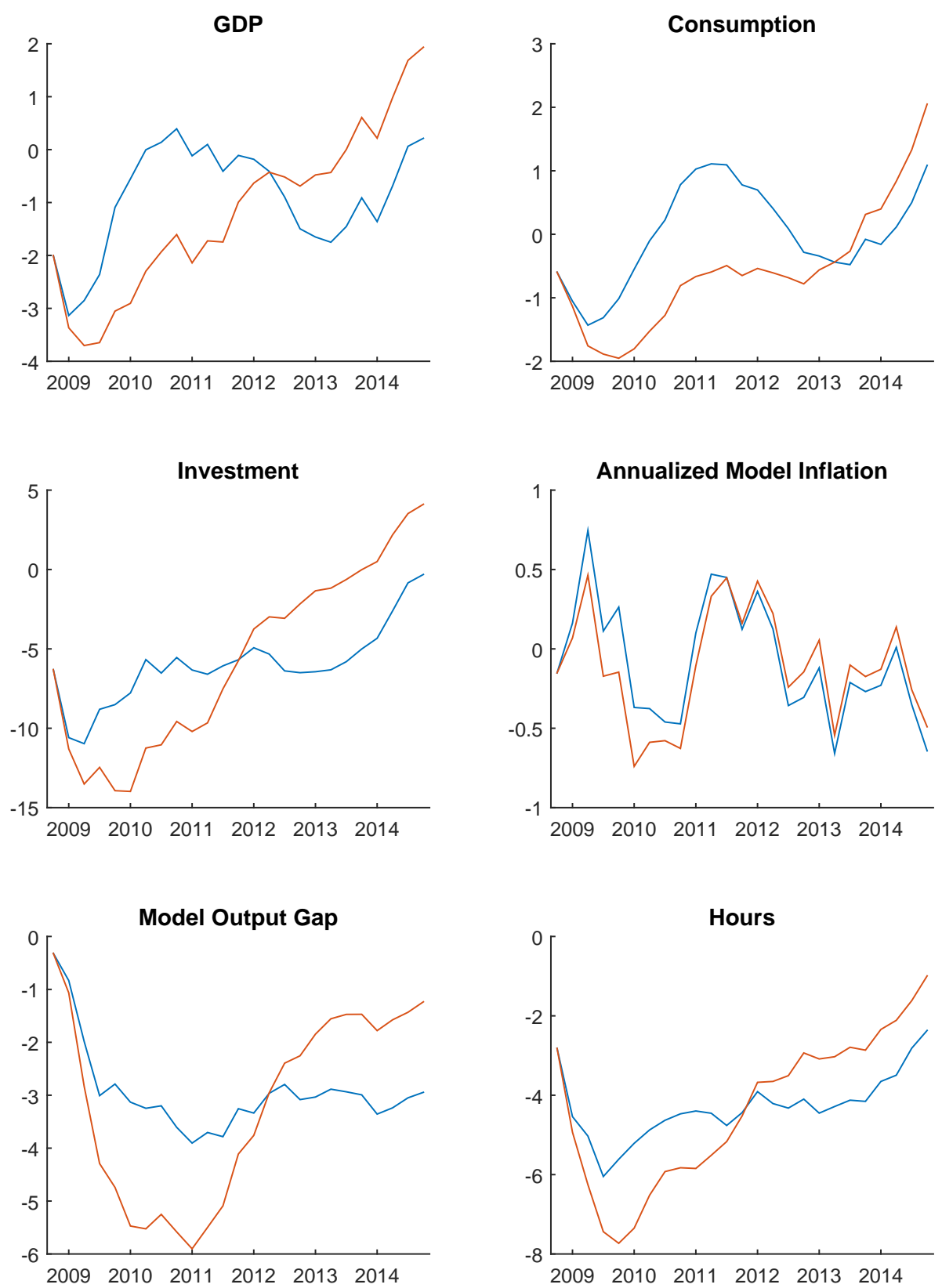

Taylor Maximum Fidelity Path — Observed

Note: Output, consumption and investment are displayed as percentage point deviations from their values in $2008 \mathrm{q} 3$. Inflation is depicted relative to the $2 \%$ steady state. 
Interestingly the divergence in the outcomes occurs around the time the FOMC began using calendar-based forward guidance in August 2011.

\subsection{The forward guidance puzzle}

In our model extending a near zero interest rate peg for additional periods leads to initial responses of output and inflation that grow with the length of the extension and eventually become explosive. This is endemic to all NK models that follow in the tradition of Christiano et al. (2005) and Smets and Wouters (2007). Del Negro et al. (2015) show that in their estimated medium-scale NK model that an extension of a ten quarter zero interest rate peg for just one additional quarter generates extremely large and implausible initial responses of output and inflation. They call this phenomenon the "forward guidance puzzle." Their results suggest than the exploding responses to an extended interest rate peg are actually empirically relevant. In contrast, we find relatively modest effects of forward guidance based on our counterfactual experiment. As such our estimated model seems not to exhibit an empirical forward guidance puzzle, by which we mean at least for experiments founded on observed interest rate expectations.

To show that this is indeed the case we reproduce the interest rate peg experiment Del Negro et al. (2015) use to define the forward guidance puzzle. Figure 15 matches Figure 4 from Del Negro et al. (2015) except that it is constructed using our estimated model. The experiment involves extending the ELB by just one quarter from the path expected as of $2012 \mathrm{q} 2$. The baseline forecasts are the solid blue lines and are conditioned on fed funds futures rates for the next two years and a half, as observed at that point in time. The paths derived from extending the peg by an additional quarter are the red dashed lines.

Del Negro et al. (2015) find that the response of output growth when the peg is extended a single quarter peaks at a large value in the first period (2012q3) and declines gradually thereafter. In particular, the predicted four quarter growth rate of GDP for 2012 jumps from 1.9 in their baseline to 3.5 under the peg (see Table 3 in their paper). In stark contrast the effects of extending the peg in our estimated model are very small, closely following the baseline forecast. Indeed, our comparable numbers for the four quarter growth rate of GDP in 2012 are 1.6 under the baseline and 1.8 under the extended peg. 
Figure 15: The Del Negro et al. (2015) ELB experiment
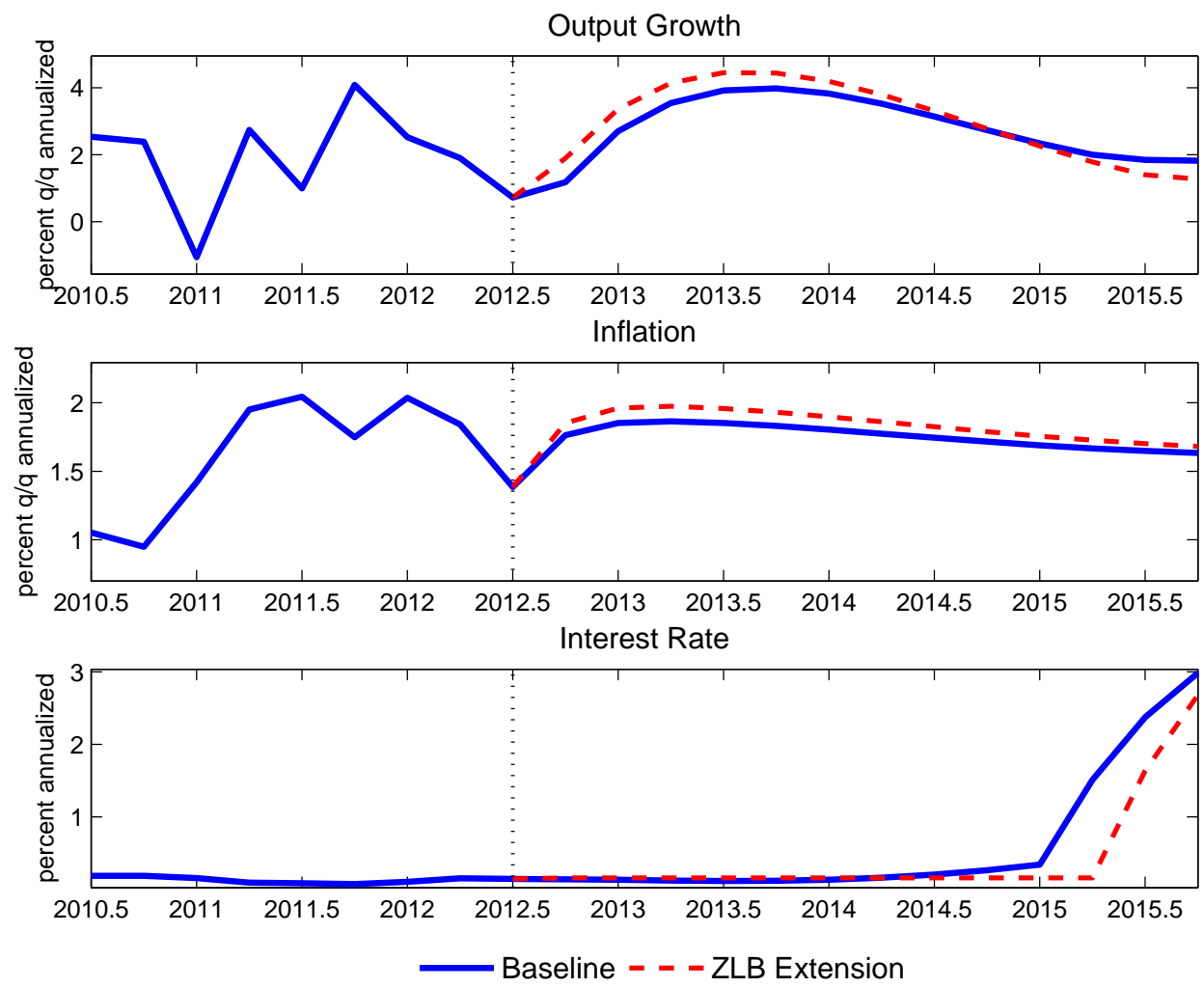

Figure 15 demonstrates that the forward guidance puzzle is not a generic feature of medium-scale NK models estimated with US data. Eventually the responses of key variables will become implausibly large as an interest peg is extended, increasing the appeal of mechanisms that may counter the quantitative bite of these effects. Nonetheless, our results indicate that some medium-scale NK models estimated with US data deliver plausible responses for empirically founded pegs.

A natural question is what features of our model and estimation explain the discrepancy between our results and those of Del Negro et al. (2015). We highlight three key differences that might explain the absence of a forward guidance puzzle in our setting: the inclusion of a spread between the interest rate controlled by the central bank and the rate of return on physical capital; JR preferences; and the data used to estimate the model.

Recall from the discussion in section 3.5 that the spread introduces discounting into the linearized consumption Euler equation that is otherwise not present. Just as shown by Del Negro et al. (2015) and Nakamura and Steinsson (2015) this 
discounting reduces the quantitative effects of forward guidance. So the spread may be one reason why our estimated model does not display a forward guidance puzzle. To gauge this, we eliminate the effects of the spread, while holding fixed the other parameters and the state conditioning the forecast, and redo the experiment plotted in Figure 15. When we eliminate the spread the predicted yearly growth rate of GDP in the first two years is roughly 0.1 and 0.2 percentage points higher than shown in Figure 15. Otherwise the general contours of the paths are unchanged. So while clearly helping to dampen the effects of forward guidance, this model feature on its own does not explain the absence of very large effects of forward guidance. Of course including the spread could change our parameter estimates and the conditioning state and this may be important.

Now consider JR preferences. These preferences with $\mu=1$ represent the specification often employed in empirical NK studies. While we cannot isolate the effects of having estimated $\mu=.1<1$ we have reproduced our TMFP counterfactual using estimates obtained by calibrating $\mu=.99$. When we do this we obtain somewhat larger effects of forward guidance as measured by the TMFP counterfactual experiment. When we redo the peg experiment we find the impact of eliminating the spread is similar to the model with $\mu$ estimated. So including JR preferences also reduces the effects of forward guidance, but this model feature on its own does not explain the absence of the puzzle either and nor does the combination of JR preferences and the spread.

The third key difference is the data that we use for inference. Del Negro et al. (2015) use just 5 observables to estimate their model. Our estimation is based on a much richer set of data that includes 18 observables for the first sample and 10 futures rates and survey expectations of inflation in the second sample. Of particular interest is that we estimate our model with data on expected federal funds rates. These data help to identify the monetary policy rule in the first sample and the forward guidance signals in both samples. Their inclusion might have delivered a configuration of parameters, states and shocks, that imply much more plausible effects of forward guidance, than had we followed Del Negro et al. (2015) by ignoring these data in estimation and using them only to identify forward guidance after estimating the model. Of course the other differences in the data brought to estimation, such as our measure of hours, lead to differences in inferred parameters, states and shocks which should influence the effects of forward guidance 
as well.

\section{Conclusion}

When viewed through the lens of our full-information rational-expectations framework, FOMC forward guidance had mixed effects. Throughout 2009 and into mid 2010, financial market prices indicated that the FOMC would raise interest rates sooner than its pre crisis interest rate rule would have prescribed, and from mid 2010 through mid 2011 financial market participants essentially believed that the FOMC would deviate little from this rule. Our model indicates these expectations of tighterthan-usual policy cost the US economy a decline in the output gap's trough from -4 percent to -6 percent. At its August 2011 meeting, the FOMC became more specific about its forward guidance, forecasting that the policy rate would remain at its effective lower bound "at least through mid-2013." Thereafter, interest rate futures began to indicate that the FOMC's policy accommodation would last substantially

longer; and we estimate that this contributed to a much more rapid recovery in the output gap than would have occurred otherwise.

The policy analysis underlying these conclusions compares the FOMC's actual performance with that of a hypothetical policy maker who deviates as little from the pre crisis interest rate rule as the effective lower bound will allow. The model allows no misunderstanding between this policy maker and the public. All actors understand the policy maker's goals and means of achieving them perfectly. The real world is not so generous to the FOMC. To achieve such perfect communications, the FOMC and public must share a language rich enough to describe policy contingencies and actions, the FOMC must state its policy choices clearly in that language, and private agents must correctly decode the FOMC's statements. Communications obstacles could have prevented any one of these three necessary conditions from being fulfilled. First the situation in which the FOMC found itself in December 2008 was truly unprecedented, so the language needed to describe it to the public was necessarily a work in progress. Second, the FOMC speaks as a committee and not as an individual; and the diplomatic process by which any such committee makes decisions sometimes sacrifices clarity for the sake of consensus. Finally, financial market participants' primary goal is profit, and they only concern themselves with decoding the FOMC's "true" intentions to the extent that is serves that goal. 
Given these practical communications difficulties, we should acknowledge that there are really two reasons that the FOMC's forward guidance, as represented by futures' market prices, could differ from the Taylor Maximum Fidelity Path of our model. First, the FOMC might have actually chosen a different policy. This seems particularly likely after August 2011. Second, the FOMC might have chosen the TMFP path but communication difficulties interfered with its implementation. Possibly, this occurred at some time between December 2008 and August 2011. Indeed, Andrade, Gaballo, Mengus, and Mojon (2015) find that forward guidance during this time greatly reduced dispersion of professionals' forecasts for interest rates without changing their disagreement about output growth or interest rates. They interpret this as disagreement among professional forecasters about whether the FOMC's forward guidance was Delphic or Odyssean. The contributions of disagreement and other such communications difficulties to the policy outcomes we document remain ripe for future study.

Recent advancements in developing and estimating dynamic general equilibrium models in which agents have private information can improve our understanding about the relevance of these communication obstacles. Melosi (2016) shows that, in a model in which agents have private information about the economy's fundamentals and policy actions are publicly observable, changes in the current policy rate have Delphic effects. This result suggests that Delphic effects are sizable and substantially affect the macroeconomic propagation of policy and non-policy shocks. We view these models as promising laboratories for further examination of monetary policy and forward guidance with communications obstacles. 


\section{References}

Aaronson, D., E. Rissman, and D. Sullivan (2004). Assessing the jobless recovery. Federal Reserve Bank of Chicago Economic Perspectives 28, 2-20. 41

Aaronson, S., T. Cajner, B. Fallick, F. Galbis-Reig, C. Smith, and W. Wascher (2014). Labor force participation: Recent developments and future prospects. Brookings Papers on Economic Activity Fall, 197-275. 42

Andrade, P., G. Gaballo, E. Mengus, and B. Mojon (2015). Forward guidance and heterogeneous beliefs. Banque de France Working Paper 573. 76

Barakchian, S. M. and C. Crowe (2013). Monetary policy matters: Evidence from new shocks data. Journal of Monetary Economics 60, 950-966. 19

Barsky, R., A. Justiniano, and L. Melosi (2014). The natural rate of interest and its usefulness for monetary policy. American Economic Review Papers 8 Proceedings 104(5), 37-43. 47

Barsky, R. and E. Sims (2011). News shocks and business cycles. Journal of Monetary Economics 58(3), 273-289. 28

Bassetto, M. (2016). Forward guidance: communication, committment, or both? Chicago Fed manuscript. 8

Ben Zeev, N., C. Gunn, and H. Khan (2015). Monetary news shocks. Carleton University manuscript. 28, 36, 53

Bernanke, B. S. and A. S. Blinder (1992). The federal funds rate and the channels of monetary transmission. American Economic Review 82(4), 901-921. 27

Boivin, J. and M. Giannoni (2006). DSGE models in a data-rich environment. Working Paper 12772, National Bureau of Economic Research. 46

Bundick, B. and A. L. Smith (2015). The dynamic effects of forward guidance shocks. Federal Reserve Bank of Kansas City manuscript. 28

Campbell, J., J. Fisher, A. Justiniano, and L. Melosi (2016). The Forward Guidance Puzzle, the Taylor Principle, and Liquidity Traps: Three sides of the same coin. manuscript. 5 
Campbell, J. R., C. L. Evans, J. D. Fisher, and A. Justiniano (2012). Macroeconomic effects of Federal Reserve forward guidance. Brookings Papers on Economic Activity Spring, 1-54. 2, 3, 4, 9, 10, 11, 14, 21, 27, 29, 35, 53

Carlstrom, C., T. Fuerst, and M. Paustian (2015). Inflation and output in New Keynesian models with a transient interest rate peg. Journal of Monetary Economics 76(C), 230-243. 5

Chari, V. V., P. J. Kehoe, and E. R. McGrattan (2009). New Keynesian models: Not yet useful for policy analysis. American Economic Journal: Macroeconomics 1(1), 242-266. 47

Christiano, L., M. Eichenbaum, and C. Evans (1999). Monetary policy shocks: What have we learned and to what end? In J. B. Taylor and M. Woodford (Eds.), Handbook of of Macroeconomics, Volume 1 of Handbooks in Economics, Chapter 2, pp. 65-148. Elsevier Science, North-Holland. 27

Christiano, L., M. Eichenbaum, and C. Evans (2005). Nominal rigidities and the dynamic effects of a shock to monetary policy. Journal of Political Economy 113(1), 1-45. 4, 29, 32, 72

Christiano, L., M. Eichenbaum, and M. Trabandt (2015). Understanding the great recession. American Economic Journal: Macroeconomics 7(1), 110-167. 63, 65

D'Amico, S. and T. King (2016). What does anticipated monetary policy do? Federal Reserve Bank of Chicago manuscript. 28

Del Negro, M., M. P. Giannoni, and C. Patterson (2015). The forward guidance puzzle. New York Fed working paper. 1, 5, 6, 36, 39, 53, 65, 72, 73, 74

Edge, R., M. T. Kiley, and J.-P. Laforte (2010). Natural rate measures in an estimated DSGE model of the US economy. Journal of Economic Dynamics and Control 32(8), 2512-2535. 45

Eggertsson, G. B. and M. Woodford (2003). The zero bound on interest rates and optimal monetary policy. Brookings Papers on Economic Activity 2003(1), 139211. $2,8,31$ 
Engen, E. M., T. T. Laubach, and D. Reifschneider (2015). The macroeconomic effects of the federal reserve's unconventional monetary policy. Finance and Ecnomics Discussion Series 2012-5, Board of Governors of the Federal Reserve System. 6

Evans, C., J. Fisher, F. Gourio, and S. Krane (2015). Risk management for monetary policy near the zero lower bound. Forthcoming, Brookings Papers on Economic Activity. 2

Fisher, J. (2015, March-April). On the structural interpretation of the smets-wouters "risk premium" shock. Journal of Money, Credit and Banking 47(2-3), 511-516. $5,29,32$

Fleischman, C. A. and J. M. Roberts (2011). From many series, one cycle: improved estimates of the business cycle from a multivariate unobserved components model. FEDS Working Paper 2011-46. 42

Francis, N. and V. Ramey (2009, September). Measures of per capita hours and their implications for the technology-hours debate. Journal of Money, Credit and Banking 41, 1071-1098. 41

Gabaix, X. (2016). A behavioral New Keynesian model. NYU-Stern manuscript. 5, 39

Galí, J. (2005, July/August). Trends, hours, balanced growth and the role of technology in the business cycle. Federal Reserve Bank of St. Louis Review, 459-486. 41

Galí, J., F. Smets, and F. Wouters (2012). Unemployment in an estimated New Keynesian model. In D. Acemogulu and M. Woodford (Eds.), NBER Macroeconomics Annual 2011, Volume 26. 46

Gertler, M. and P. Karadi (2015). Monetary policy surprises, credit costs, and economic activity. American Economic Journal: Macroeconomics 7(1), 44-76. 28

Gilchrist, S. and E. Zakrajšsek (2012). Credit spreads and business cycle fluctuations. American Economic Review 102(4), 1692-1720. 65 
Greenwood, J., Z. Hercowitz, and G. Huffman (1988). Investment, capacity utilization, and the real business cycle. American Economic Review 78, 402-417. 30

Gürkanynak, R. S., B. Sack, and J. H. Wright (2006). The US Treasury yield curve: 1961 to the present. Finance and Ecnomics Discussion Series 2006-28, Board of Governors of the Federal Reserve System. 10, 24

Gürkanynak, R. S., B. Sack, and J. H. Wright (2008). The TIPS yield curve and inflation compensation. Finance and Ecnomics Discussion Series 2008-05, Board of Governors of the Federal Reserve System. 10, 24

Gürkaynak, R., B. Sack, and E. Swanson (2005). Do actions speak louder than words? International Journal of Central Banking 1(1), 55-93. 3, 9

Hanson, S. G. and J. C. Stein (2015, September). Monetary policy and long-term interest rates. Journal of Financial Economics 115, 429-448. 3, 7, 10, 11, 16, 17, 24,26

Jaimovich, N. and S. Rebelo (2009). Can news about the future drive the business cycle? American Economic Review 99(4), 1097-1118. 5, 29

Justiniano, A., G. Primaceri, and A. Tambalotti (2013). Is there a trade-off between inflation and output stabilization? American Economic Journal: Macroeconomics 5(2), 1-31. 46, 47

Justiniano, A., G. E. Primiceri, and A. Tambalotti (2010, March). Investment shocks and business cycles. Journal of Monetary Economics 57(2), 132-145. 31

Kiley, M. T. (2014). Policy paradoxes in the New Keynesian model. FEDS Working Paper 2014-29. 5

King, R. G., C. I. Plosser, and S. T. Rebelo (1988). Production, growth and business cycles I. the basic neoclassical model. Journal of Monetary Economics 21, 195232. 30

Kohn, D. and B. Sack (2004). Central bank talk: Does it matter and why? In Macroeconomics, monetary policy, and financial stability., pp. 175-206. Ottawa, Ontario: Bank of Canada. 8, 9 
Krishnamurthy, A. and A. Vissing-Jorgensen (2011). The effects of quantitative easing on interest rates: Channels and implications for policy. Brookings Papers on Economic Activity Fall, 215-265. 2, 31

Krugman, P. R. (1998). It's baaack: Japan's slump and the return of the liquidity trap. Brookings Papers on Economic Activity Fall, 137-187. 8

Kuttner, K. N. (2001). Monetary policy surprises and interest rates: evidence rom the federal funds futures market. Journal of Monetary Economics 47, 523-544. $8,14,19$

Laséen, S. and L. E. Svensson (2011). Anticipated alternative policy-rate paths in policy simulations. International Journal of Central Banking. 4, 11, 29, 35

McKay, A., E. Nakamura, and J. Steinsson (2015). The power of forward guidance revisited. Columbia University manuscript. 5, 39

Melosi, L. (2016). Signaling Effects of Monetary Policy. Federal reserve bank of chicago mimeo. 76

Nakamura, E. and J. Steinsson (2015). High frequency identification of monetary non-neutrality. Columbia University manuscript. 26, 73

Piazzesi, M. and E. Swanson (2008). Futures prices as risk-adjusted forecasts of monetary policy. Journal of Monetary Economics 55, 677-691. 9, 13, 14, 15

Ramey, V. (2012). The impact of hours measures on the trend and cycle behavior of US labor productivity. UC-San Diego. 41

Ramey, V. A. (2016). Macroeconomic shocks and their propagration. NBER working paper 21978. 27, 28

Rigobon, R. and B. Sack (2004, November). The impact of monetary policy on asset prices. Journal of Monetary Economics 51(8), 1553-1575. 7, 17

Roberts, J. M. (2014). Estimation of latent variables for the FRBUS model. http: // www.federalreserve.gov/econresdata/frbus/files/frbus_package.zip. 42

Schmitt-Grohé, S. and M. Uribe (2012). What's news in business cycles. Econometrica 80(6), 2733-2764. 30 
Smets, F. and R. Wouters (2003). An estimated dynamic stochastic general equilibrium model of the euro area. Journal of the European Economic Association 1(5), 1123-1175. 36

Smets, F. and R. Wouters (2007). Shocks and frictions in US business cycles: A Bayesian DSGE approach. The American Economic Review 97(3), 586-606. 4, $29,32,34,39,72$ 


\section{Working Paper Series}

A series of research studies on regional economic issues relating to the Seventh Federal Reserve District, and on financial and economic topics.

The Urban Density Premium across Establishments

WP-13-01

R. Jason Faberman and Matthew Freedman

Why Do Borrowers Make Mortgage Refinancing Mistakes?

WP-13-02

Sumit Agarwal, Richard J. Rosen, and Vincent Yao

Bank Panics, Government Guarantees, and the Long-Run Size of the Financial Sector:

Evidence from Free-Banking America

WP-13-03

Benjamin Chabot and Charles C. Moul

Fiscal Consequences of Paying Interest on Reserves

WP-13-04

Marco Bassetto and Todd Messer

Properties of the Vacancy Statistic in the Discrete Circle Covering Problem

WP-13-05

Gadi Barlevy and H. N. Nagaraja

Credit Crunches and Credit Allocation in a Model of Entrepreneurship

WP-13-06

Marco Bassetto, Marco Cagetti, and Mariacristina De Nardi

Financial Incentives and Educational Investment:

The Impact of Performance-Based Scholarships on Student Time Use

WP-13-07

Lisa Barrow and Cecilia Elena Rouse

The Global Welfare Impact of China: Trade Integration and Technological Change

WP-13-08

Julian di Giovanni, Andrei A. Levchenko, and Jing Zhang

Structural Change in an Open Economy

WP-13-09

Timothy Uy, Kei-Mu Yi, and Jing Zhang

The Global Labor Market Impact of Emerging Giants: a Quantitative Assessment Andrei A. Levchenko and Jing Zhang

WP-13-10

Size-Dependent Regulations, Firm Size Distribution, and Reallocation

WP-13-11

François Gourio and Nicolas Roys

Modeling the Evolution of Expectations and Uncertainty in General Equilibrium

WP-13-12

Francesco Bianchi and Leonardo Melosi

Rushing into the American Dream? House Prices, the Timing of Homeownership, and the Adjustment of Consumer Credit

WP-13-13

Sumit Agarwal, Luojia Hu, and Xing Huang 


\section{Working Paper Series (continued)}

The Earned Income Tax Credit and Food Consumption Patterns

WP-13-14

Leslie McGranahan and Diane W. Schanzenbach

Agglomeration in the European automobile supplier industry

WP-13-15

Thomas Klier and Dan McMillen

Human Capital and Long-Run Labor Income Risk

WP-13-16

Luca Benzoni and Olena Chyruk

The Effects of the Saving and Banking Glut on the U.S. Economy

WP-13-17

Alejandro Justiniano, Giorgio E. Primiceri, and Andrea Tambalotti

A Portfolio-Balance Approach to the Nominal Term Structure

WP-13-18

Thomas B. King

Gross Migration, Housing and Urban Population Dynamics

WP-13-19

Morris A. Davis, Jonas D.M. Fisher, and Marcelo Veracierto

Very Simple Markov-Perfect Industry Dynamics

WP-13-20

Jaap H. Abbring, Jeffrey R. Campbell, Jan Tilly, and Nan Yang

Bubbles and Leverage: A Simple and Unified Approach

WP-13-21

Robert Barsky and Theodore Bogusz

The scarcity value of Treasury collateral:

Repo market effects of security-specific supply and demand factors

WP-13-22

Stefania D'Amico, Roger Fan, and Yuriy Kitsul

Gambling for Dollars: Strategic Hedge Fund Manager Investment

Dan Bernhardt and Ed Nosal

WP-13-23

Cash-in-the-Market Pricing in a Model with Money and

Over-the-Counter Financial Markets

WP-13-24

Fabrizio Mattesini and Ed Nosal

An Interview with Neil Wallace

WP-13-25

David Altig and Ed Nosal

Firm Dynamics and the Minimum Wage: A Putty-Clay Approach

WP-13-26

Daniel Aaronson, Eric French, and Isaac Sorkin

Policy Intervention in Debt Renegotiation:

Evidence from the Home Affordable Modification Program

WP-13-27

Sumit Agarwal, Gene Amromin, Itzhak Ben-David, Souphala Chomsisengphet,

Tomasz Piskorski, and Amit Seru 


\section{Working Paper Series (continued)}

The Effects of the Massachusetts Health Reform on Financial Distress

WP-14-01

Bhashkar Mazumder and Sarah Miller

Can Intangible Capital Explain Cyclical Movements in the Labor Wedge?

WP-14-02

François Gourio and Leena Rudanko

Early Public Banks

William Roberds and François R. Velde

WP-14-03

Mandatory Disclosure and Financial Contagion

WP-14-04

Fernando Alvarez and Gadi Barlevy

The Stock of External Sovereign Debt: Can We Take the Data at 'Face Value'?

WP-14-05

Daniel A. Dias, Christine Richmond, and Mark L. J. Wright

Interpreting the Pari Passu Clause in Sovereign Bond Contracts:

It's All Hebrew (and Aramaic) to Me

WP-14-06

Mark L. J. Wright

AIG in Hindsight

WP-14-07

Robert McDonald and Anna Paulson

On the Structural Interpretation of the Smets-Wouters "Risk Premium" Shock

WP-14-08

Jonas D.M. Fisher

Human Capital Risk, Contract Enforcement, and the Macroeconomy

WP-14-09

Tom Krebs, Moritz Kuhn, and Mark L. J. Wright

Adverse Selection, Risk Sharing and Business Cycles

WP-14-10

Marcelo Veracierto

Core and 'Crust': Consumer Prices and the Term Structure of Interest Rates

WP-14-11

Andrea Ajello, Luca Benzoni, and Olena Chyruk

The Evolution of Comparative Advantage: Measurement and Implications

WP-14-12

Andrei A. Levchenko and Jing Zhang

Saving Europe?: The Unpleasant Arithmetic of Fiscal Austerity in Integrated Economies

WP-14-13

Enrique G. Mendoza, Linda L. Tesar, and Jing Zhang

Liquidity Traps and Monetary Policy: Managing a Credit Crunch

WP-14-14

Francisco Buera and Juan Pablo Nicolini

Quantitative Easing in Joseph's Egypt with Keynesian Producers

WP-14-15

Jeffrey R. Campbell 


\section{Working Paper Series (continued)}

Constrained Discretion and Central Bank Transparency

WP-14-16

Francesco Bianchi and Leonardo Melosi

Escaping the Great Recession

WP-14-17

Francesco Bianchi and Leonardo Melosi

More on Middlemen: Equilibrium Entry and Efficiency in Intermediated Markets

WP-14-18

Ed Nosal, Yuet-Yee Wong, and Randall Wright

Preventing Bank Runs

WP-14-19

David Andolfatto, Ed Nosal, and Bruno Sultanum

WP-14-20

The Impact of Chicago's Small High School Initiative

Lisa Barrow, Diane Whitmore Schanzenbach, and Amy Claessens

Credit Supply and the Housing Boom

WP-14-21

Alejandro Justiniano, Giorgio E. Primiceri, and Andrea Tambalotti

The Effect of Vehicle Fuel Economy Standards on Technology Adoption

WP-14-22

Thomas Klier and Joshua Linn

What Drives Bank Funding Spreads?

WP-14-23

Thomas B. King and Kurt F. Lewis

Inflation Uncertainty and Disagreement in Bond Risk Premia

WP-14-24

Stefania D'Amico and Athanasios Orphanides

Access to Refinancing and Mortgage Interest Rates:

WP-14-25

HARPing on the Importance of Competition

Gene Amromin and Caitlin Kearns

Private Takings

Alessandro Marchesiani and Ed Nosal

WP-14-26

Momentum Trading, Return Chasing, and Predictable Crashes

WP-14-27

Benjamin Chabot, Eric Ghysels, and Ravi Jagannathan

Early Life Environment and Racial Inequality in Education and Earnings in the United States

WP-14-28

Kenneth Y. Chay, Jonathan Guryan, and Bhashkar Mazumder

Poor (Wo)man's Bootstrap

WP-15-01

Bo E. Honoré and Luojia Hu

Revisiting the Role of Home Production in Life-Cycle Labor Supply

WP-15-02

R. Jason Faberman 


\section{Working Paper Series (continued)}

Risk Management for Monetary Policy Near the Zero Lower Bound

WP-15-03

Charles Evans, Jonas Fisher, François Gourio, and Spencer Krane

Estimating the Intergenerational Elasticity and Rank Association in the US:

Overcoming the Current Limitations of Tax Data

WP-15-04

Bhashkar Mazumder

External and Public Debt Crises

WP-15-05

Cristina Arellano, Andrew Atkeson, and Mark Wright

The Value and Risk of Human Capital

WP-15-06

Luca Benzoni and Olena Chyruk

Simpler Bootstrap Estimation of the Asymptotic Variance of U-statistic Based Estimators

WP-15-07

Bo E. Honoré and Luojia Hu

Bad Investments and Missed Opportunities?

Postwar Capital Flows to Asia and Latin America

Lee E. Ohanian, Paulina Restrepo-Echavarria, and Mark L. J. Wright

WP-15-08

Backtesting Systemic Risk Measures During Historical Bank Runs

Christian Brownlees, Ben Chabot, Eric Ghysels, and Christopher Kurz

WP-15-09

What Does Anticipated Monetary Policy Do?

Stefania D'Amico and Thomas B. King

Firm Entry and Macroeconomic Dynamics: A State-level Analysis

WP-16-01

François Gourio, Todd Messer, and Michael Siemer

Measuring Interest Rate Risk in the Life Insurance Sector: the U.S. and the U.K.

WP-16-02

Daniel Hartley, Anna Paulson, and Richard J. Rosen

Allocating Effort and Talent in Professional Labor Markets

WP-16-03

Gadi Barlevy and Derek Neal

The Life Insurance Industry and Systemic Risk: A Bond Market Perspective

WP-16-04

Anna Paulson and Richard Rosen

Forecasting Economic Activity with Mixed Frequency Bayesian VARs

WP-16-05

Scott A. Brave, R. Andrew Butters, and Alejandro Justiniano

Optimal Monetary Policy in an Open Emerging Market Economy

WP-16-06

Tara Iyer

Forward Guidance and Macroeconomic Outcomes Since the Financial Crisis

Jeffrey R. Campbell, Jonas D. M. Fisher, Alejandro Justiniano, and Leonardo Melosi

WP-16-07 